NBER WORKING PAPER SERIES

\title{
THE LONG-TERM IMPACT OF THE COVID-19 UNEMPLOYMENT SHOCK ON LIFE EXPECTANCY AND MORTALITY RATES
}

\author{
Francesco Bianchi \\ Giada Bianchi \\ Dongho Song \\ Working Paper 28304 \\ http://www.nber.org/papers/w28304 \\ NATIONAL BUREAU OF ECONOMIC RESEARCH \\ 1050 Massachusetts Avenue \\ Cambridge, MA 02138 \\ December 2020, Revised September 2021
}

We thank Michael Boutros for great research assistance. We thank Nancy Berliner, Janet Currie, David Cutler, Cosmin Ilut, Jim Poterba, Emilia Simeonova, Jon Skinner, Ben Sommers, and all seminar participants at the NBER COVID-19 and health outcomes spring 2021 meeting, Duke University, and the U.S. Government Accountability Office for useful comments and suggestions. We thank Arialdi Minimo for helping us to navigate the CDC datasets. The views expressed herein are those of the authors and do not necessarily reflect the views of the National Bureau of Economic Research.

At least one co-author has disclosed additional relationships of potential relevance for this research. Further information is available online at http://www.nber.org/papers/w28304.ack

NBER working papers are circulated for discussion and comment purposes. They have not been peer-reviewed or been subject to the review by the NBER Board of Directors that accompanies official NBER publications.

(C) 2020 by Francesco Bianchi, Giada Bianchi, and Dongho Song. All rights reserved. Short sections of text, not to exceed two paragraphs, may be quoted without explicit permission provided that full credit, including $(\odot$ notice, is given to the source. 
The Long-Term Impact of the COVID-19 Unemployment Shock on Life Expectancy and Mortality Rates

Francesco Bianchi, Giada Bianchi, and Dongho Song

NBER Working Paper No. 28304

December 2020, Revised September 2021

JEL No. C32,E32,I14,J11

\section{ABSTRACT}

We adopt a time series approach to investigate the historical relation between unemployment, life expectancy, and mortality rates. We fit Vector-autoregressions for the overall US population and for groups identified based on gender and race. We use our results to assess the long-run effects of the COVID-19 economic recession on mortality and life expectancy. We estimate the size of the COVID-19-related unemployment shock to be between 2 and 5 times larger than the typical unemployment shock, depending on race and gender, resulting in a significant increase in mortality rates and drop in life expectancy. We also predict that the shock will disproportionately affect African-Americans and women, over a short horizon, while the effects for white men will unfold over longer horizons. These figures translate in more than 0.8 million additional deaths over the next 15 years.

Francesco Bianchi

Social Sciences Building, 201B

Department of Economics

Duke University

Box 90097

Durham, NC 27708-0097

and CEPR

and also NBER

francesco.bianchi@duke.edu

Giada Bianchi

Division of Hematology

Department of Medicine

Brigham and Women's Hospital

Harvard Medical School

4 Blackfan Circle

HIM 742

Boston, MA 02115

GBIANCHI1@BWH.HARVARD.EDU
Dongho Song

Johns Hopkins University

Carey Business School

100 International Drive

Baltimore, MD 21202

dongho.song@jhu.edu 


\section{Introduction}

Severe acute respiratory syndrome coronavirus 2 (SARS-CoV-2) is the pathogenic agent of coronavirus disease 2019 (COVID-19), see Gorbalenya et al. (2020). Initially reported as an outbreak in the province of Wuhan, China at the end of 2019, COVID-19 was recognized as a pandemic by the World Health Organization (WHO) on March 11, 2020, e.g., Guan et al. (2020). Approximately 74 million cases and 1.6 million deaths have been reported worldwide, with over 17 million people infected and approximately 0.3 million deceased in the USA alone (updated December 16, 2020; see WHO (2020) and CDC (2020)).

SARS-CoV-2 is shed by asymptomatic individuals and persists in the environment for days, implying that public health measures to halt virus spreading could be effective at reducing transmission and mortality, see Li et al. (2020) and Pan et al. (2020). Universal masking, social distancing, contact tracing, and quarantine were later identified as effective tools to contain SARS-CoV-2 spreading, see Leung et al. (2020) and Moghadas et al. (2020). Mathematical modeling predicted a catastrophic exhaustion of health care personnel and resources, particularly ventilators, unless strict containment measures to limit SARS-CoV-2 spreading were established, see Anderson et al. (2020) and Davies et al. (2020). Between late March-early April, most U.S. states imposed stay-at-home orders and lockdowns, resulting in widespread shut down of business. Unemployment rate rose from 3.8\% in February 2020 to 14.7\% in April 2020 with 23.1 million unemployed Americans. Despite a decline to 6.7\% in December 2020, the average unemployment rate over the year is comparable with the $10 \%$ unemployment rate at the peak of the 2007-2009 Great Recession and it is near the post-World War II historical maximum reached in the early 1980s (10.8\%). Importantly, COVID-19 related job losses disproportionately affect women, particularly of Hispanic heritage; African Americans; foreign born individuals; less educated adults and individuals age 16-24. In fact, the unemployment rate underestimates the extent of the economic contraction as many potential workers have abandoned the workforce (especially women).

The impact of the loss of income on psychological and physical health has been well documented in white males, see McKee-Ryan et al. (2005), Brenner (2005), and Wilson and Walker (1993). In epidemiological studies, unemployment at the individual level associates with decreased health and higher mortality, regardless of aggregate unemployment rate, see Roelfs et al. (2015). A surge in suicide rates has been clearly observed in unemployed individuals, particularly men. Cardiovascular diseases peak in face of financial stress and preventive ontological care declines, thus contributing to excess mortality.

While the short-run trade-off between containing the COVID-19 pandemic and preserving economic activity has been extensively analyzed, there is currently no analysis regarding the long-term impact of the COVID-19-related economic recession on public health. What is more, 
most of the papers interested in the relation between the COVID-19 pandemic and economic activity argue, correctly, that lockdowns can save lives at the cost of reducing economic activity, ${ }^{1}$ but they do not consider the possibility that severe economic distress might also have important consequences on human well-being (Gordon and Sommers (2016) and Ruhm (2015)). This shortcoming is arguably explained by the fact that current macroeconomic models do not allow for the possibility that economic activity might affect mortality rates of the agents in the economy.

In this paper, we aim at making progress on this gap in the literature by taking a timeseries approach. We use annual data on average life expectancy and age-adjusted mortality rates collected from the Centers for Disease Control and Prevention (CDC) website, which are paired with the unemployment rates from the St. Louis Fred website. We construct the data set not just for the overall US population, but also for subgroups of the population categorized by race (African-American or White) and gender (women or men). We use a vector autoregression (VAR, Sims (1980)) to model the joint dynamics of the growth rates of life expectancy and mortality rates together with the unemployment rates. We acknowledge that life expectancy and mortality rates are likely to present observation errors as the US population is not continuously and perfectly observed. Furthermore, mortality rates in the short run might be affected by factors not directly related to economic conditions or progress in health care. To address these issues, we allow for observation errors that essentially wash out the non-persistent idiosyncratic components in life expectancy and mortality rates.

We rely on Bayesian methods to construct posterior estimates of model unknowns including the VAR coefficients and the smoothed growth rates of life expectancy and mortality rates. Equipped with posterior estimates for the VAR parameters, we use an impulse response analysis based on a Cholesky decomposition method to assess the effects of an increase in unemployment on the life expectancy and mortality rates. The main message arising from our exercise is that the typical unemployment shock results in a significant decline in life expectancy and increase in mortality rates for the overall population. In normal times, the size of unemployment shock is around $0.79 \%$ on an annual basis and it is quite persistent. The effect of the unemployment shock on the growth rate of life expectancy and the death rate reaches its peak in the fourth year and remains elevated for a long time.

We repeat the exercise with data for different population groups identified based on race and gender to highlight substantial heterogeneity. We find that the size of the typical unemployment shock is much larger for African-Americans, with a standard deviation of around 1.05\%, than for the White population (standard deviation around 0.74\%). Specifically, African-American men typically experience the largest unemployment shocks, with a standard deviation of around

\footnotetext{
${ }^{1}$ This literature is constantly growing. A non-exhaustive list includes Eichenbaum et al. (2020a), Coibion et al. (2020), Eichenbaum et al. (2020b), Jones et al. (2020), Hall et al. (2020), among others.
} 
$1.31 \%$, approximately $60 \%$ larger than the typical shock experienced by White men. We find that the typical unemployment shock for White women is the smallest, around $0.63 \%$, which is about $75 \%$ of the unemployment shock experienced by White men. Similarly, the size of a onestandard deviation unemployment shock for African-American women $(0.92 \%)$ is about $70 \%$ of the typical shock experienced by African-American men, but its absolute magnitude is larger than that experienced by White men. In light of this evidence, it is perhaps not surprising that the effects of the typical unemployment shock on life expectancy and the death rate are more severe for the African-American population. However, we emphasize that this is not entirely the consequence of larger shocks, as the pattern largely persists when controlling for the size of the shock, especially for the case of life expectancy. When controlling for the size of the shock, we find that women present a relatively larger increase in death rates. This pattern is especially visible for White women, indicating that even if they generally suffer smaller shocks, they are disproportionately more affected by them.

To understand the channels behind our results, we extend the analysis to study the response of the death rates for the leading causes of death to an unemployment shock. Because of data availability, we focus on the overall population. We find that an unemployment shock leads to increases in death rates due to heart disease (the leading cause of death in the United States), stroke, influenza and pneumonia, and accidents, while we do not find a significant response of the death rate due to cancer. These results suggest that multiple channels might be at work. On the one hand, the effects on heart disease and stroke death rates indicate that access to preventive care and lifestyle might play an important role in explaining why unemployment is followed by an increase in mortality rates. The increase in pneumonia/influenza-related mortality may be also explained based on the lack of access to preventive care and the decline in a healthy life style. On the other hand, the large effect on accidents also indicates that other channels are likely to be at work. Possible explanations are that people engage in more dangerous activities, spend more time driving in a less careful way, and are more subject to domestic accidents during periods of economic distress.

We then move to use our estimats to examine the long-run effect of the COVID-19 unemployment shock on life expectancy and the age adjusted death rates across difference races and gender. Our data for life-expectancy and death rates stop in 2017. However, we have unemployment data until 2020. We thus use observations for the unemployment rate to construct an estimate of the COVID-19 unemployment shock, while treating the corresponding ones for the life expectancy and mortality rates as missing observations. As before, we adopt an identification strategy based on a Cholesky decomposition. By comparing the magnitude of the COVID-19 unemployment shock to those in the normal (non-critical) times, we can infer the severity of the COVID-19 pandemic unemployment shock.

According to our estimates, the COVID-19 unemployment shock is about 3.64 standard 
deviations larger than the typical shock to the unemployment rate for the overall population (about $2.90 \%$ in magnitude). We estimate that this unprecedented unemployment shock will result in a $2.43 \%$ increase in mortality rates and a $0.83 \%$ drop in life expectancy over the next 15 years. Compared to the typical unemployment shock, we find that women (both AfricanAmerican and White) are disproportionately affected relative to men. Particularly for White women, the COVID-19 unemployment shock is about 4.91 standard deviation larger (about $3.10 \%$ in magnitude) than their typical shock to the unemployment rate, by far the largest in relative magnitude with respect to the typical shock. However, African-Americans still suffer the largest shocks in absolute terms (approximately 3.4\% for both African-American men and African-American women). As a result, the impact of the COVID-19 unemployment shock on the death rate is large for all groups, but visibly larger for African-Americans and White women. As explained above, this is in part the result of a larger shock, but also of a larger response conditional on the size of the shock.

The long-term effects of the COVID-19 related unemployment surge on the US aggregate mortality rate have not been characterized in the literature. Thus, as a last step, we compute an estimate of the excess deaths associated with the COVID-19 unemployment shock. This corresponds to the difference between the number of deaths predicted by the model with and without the unemployment shock observed in 2020. For the overall population, the increase in the death rate following the COVID-19 pandemic implies staggering 0.84 and 1.22 million excess deaths over the next 15 and 20 years, respectively. These numbers correspond to $0.23 \%$ and $0.33 \%$ of the projected US population at the 15- and 20-year horizons, respectively. For African-Americans, we estimate 200 thousand and 290 thousand excess deaths over the next 15 and 20 years, respectively. These numbers correspond to $0.38 \%$ and $0.52 \%$ of the projected African-American population at the 15- and 20-year horizons, respectively. For Whites, we estimate 0.76 and 1.09 million excess deaths over the next 15 and 20 years, respectively. These numbers correspond to $0.28 \%$ and $0.40 \%$ of the projected White population at the 15 - and 20-year horizons, respectively.

Overall, our results indicate that, based on the historical evidence, the COVID-19 pandemic might have long-lasting consequences on human health through its impact on economic activity. We interpret these results as a strong indication that policymakers should take into consideration the severe, long-run implications of such a large economic recession on people's lives when deliberating on COVID-19 recovery and containment measures. Without any doubt, lockdowns save lives, but they also contribute to the decline in real activity that can have severe consequences on health. Policy-makers should therefore consider combining lockdowns with policy interventions meant to reduce economic distress, guarantee access to health care, and facilitate effective economic reopening under health care policies to limit SARS-CoV-19 spread.

The idea that economic activity might affect human well-being has been studied before. 
Contrary to what might be expected, there is no widespread agreement on the effect of economic activity on mortality rates. Ruhm (2000, 2003, 2005, 2012) and Mulas-Granados (2005) argue for a procyclical relation between macroeconomic activity and mortality, with death rates increasing during periods of high employment. However, in a more recent contribution, Ruhm (2015) finds that since 1990 the relationship has become weak or non-existent. This seems to be due to a change in the composition of the causes of deaths. Specifically, fatalities due to cardiovascular disease and, to a smaller degree, transport accidents are procyclical, whereas cancer and some external sources of death (particularly accidental poisonings) have emerged as strongly countercyclical. Gordon and Sommers (2016) use county-level data to study the effects of unemployment, poverty rates, and median incomes on mortality rates over the period 1993-2012. They find that higher unemployment has modest negative impacts on mortality, in contrast with previous studies and in line with our findings. Furthermore, they emphasize that county-level poverty rates and lower median incomes are better predictors of mortality rates. In our study, we use unemployment because it is available over a prolonged period of time. In this respect, we should interpret unemployment as a proxy for the overall state of the economy, correlated with other variables of interest such as poverty rates and household income. The effects of unemployment can be heterogeneous across different age groups. For example, Coile et al. (2014) argue that individuals who are approaching retirement when a recession hits may be particularly likely to suffer long-lasting negative consequences, such as reduced longevity. With respect to these studies, our methodological approach is quite different, given that we take a time series approach, as opposed to panel regressions. This allows for a dynamic relation between the variables of interest and for a discussion of the effects of the national business cycle that in these studies is absorbed by the time fixed effect (see Ruhm (2015) for an excellent discussion). We see these two approaches as complementary.

The evidence for a casual link from job loss to poor health is mixed in the literature. Browning et al. (2006) find that there is no impact of job displacement on hospitalization for stress-related diseases for men. Böckerman and Ilmakunnas (2009) find that the crosssectional negative relationship between unemployment and self-assessed health is not found longitudinally. On the other hand, Sullivan and von Wachter (2009) provide evidence that displaced workers experience higher rates of mortality. Noelke and Avendano (2015) find that job loss in the years before retirement is associated with a higher risk of cardiovascular disease and death. Schwandt and von Wachter (2020) show that cohorts coming of age during a deep recession suffer increases in mortality later in their middle age. von Wachter (2020) studies the potential long-run effects of large-scale unemployment during the COVID-19 crisis focusing on vulnerable job losers and labor market entrants. He finds that these losses could be substantially larger than losses in potential life years from deaths directly due to COVID-19. Our results are in line with his findings, despite the different methodological approach taken in 
the paper. With respect to these contributions, our approach based on aggregate data allows for the possibility that unemployment, as a proxy for the overall performance of the economy, might affect mortality rates and health through indirect channels (e.g., income, crime rates, drug abuse,...).

Our benchmark results are based on an identifying assumption that relies on unemployment not having any contemporaneous effect on mortality rates and life-expectancy. Our results on the long-term effects of unemployment on mortality and life-expectancy are qualitatively unchanged when using a different identification strategy in which shocks to unemployment are allowed to have a contemporaneous effect on the other two variables. When using this alternative identification assumption, an interesting result emerges. For some groups, an increase in unemployment leads to a contemporaneous decline in mortality rates and to a contemporaneous increase in life-expectancy. However, error bands for this initial effect tend to be large and the response reverts in two-three years. In the long run, mortality increases and life expectancy declines. The long-term effect dominates and our key results on the long-term cumulative effects of unemployment remain unchanged. At the same time, these results could help reconcile the mixed evidence in the existing literature discussed above. On impact, unemployment can lead to a reduction in mortality as deaths due to work-related causes or motor vehicle accidents decline, but over time economic distress takes a toll on human well-being. We consider this an interesting direction for future research.

Our results add to the body of literature that analyzes the macroeconomic consequences of COVID-19. This literature is growing exponentially and we apologize to our colleagues for being unable to cite all relevant contributions here. A few papers that rely on historical pandemic episodes to provide plausible estimates for outcomes due to COVID-19 include Barro et al. (2020), Ludvigson et al. (2020), and Jorda et al. (2020). Other papers study the interaction between economic decisions (e.g., optimal policy) and epidemics, e.g., Kaplan et al. (2020), Eichenbaum et al. (2020a), Eichenbaum et al. (2020b), Acemoglu et al. (2020), Alvarez et al. (2020), Jones et al. (2020), Krueger et al. (2020), and Glover et al. (2020). Among the existing papers, our work is more closely related to those that examine the medium- to longterm effects of pandemics such as Jorda et al. (2020), who argue that significant macroeconomic after-effects of pandemics can persist for a long time. However, they focus on the long-term economic consequences, while we focus on the long-term health consequences (the two are likely to be related). Overall, the economic literature has extensively analyzed the short-run trade-off between economic activity and the containment of the pandemic. We emphasize that an equally important long-run trade-off exists. It is worth clarifying that with this claim, we do not want to suggest that policymakers should refrain from ordering lockdowns, as necessary lifesaving measures, but rather that, if they decide to do so, they should provide alongside enhanced health and economic support for the most vulnerable portions of the population. 
The rest of the paper is organized as follows. Section 2 presents the data and the methodological approach. Section 3 presents the historical relation between shocks to unemployment and life expectancy and mortality rates. Section 4 studies the implications of the historical results for the COVID-19 unemployment shock. Section 5 concludes.

\section{Empirical Strategy}

In this section, we first describe the data set used in our analysis and then introduce the statistical model employed to study the dynamic relation between real activity, mortality rates, and life expectancy. The statistical model is a VAR in which we allow for the possibility that mortality rates and life expectancy are observed with an error.

\subsection{Data}

We collect data on average life expectancy and age-adjusted mortality rates from the Centers for Disease Control and Prevention (CDC) website. CDC data are available to the public only until 2017. All data are available at annual frequency. The CDC website also provides age-adjusted life expectancy and mortality rates based on gender and limited race breakdown (African-American versus White). Race (African-American, White, Asian, etc) and Hispanic origin (yes/no) are classified independently by the CDC. Thus, Hispanic can be of any race and within each race group there can be descendants of Hispanic origin. No extended data series are available for Hispanic/Latinos heritage, Asians, American Indian/Alaska Natives, Native Hawaiian/Other Pacific Islanders or mixed races. CDC data for the African-American population span a shorter period of time (1972-2017). The series for White population are also shorter (1954-2017) than the series for the overall population (1950-2017). This is important when comparing results across races and with respect to the overall population, because the sample used for the estimation is not homogeneous.

We obtain the Bureau of Labor Statistics unemployment rates for the overall population and for each race and gender groups from FRED, the website of the St. Louis Fed. We pair the CDC series with the corresponding unemployment series to obtain seven groups: Overall population, African-American population, African-American men (20 year old and over), African-American women (20 year old and over), White population, White men (20 year old and over), White women (20 year old and over). Note that the unemployment rates based on gender only include workers 20 year and older. This explains why the unemployment rate based only on race can be larger than both the unemployment rates based on gender and race. This feature is particularly evident for the African-American population, characterized by very high unemployment rates for workers between 16 and 19 . 
Figure 1: Raw data
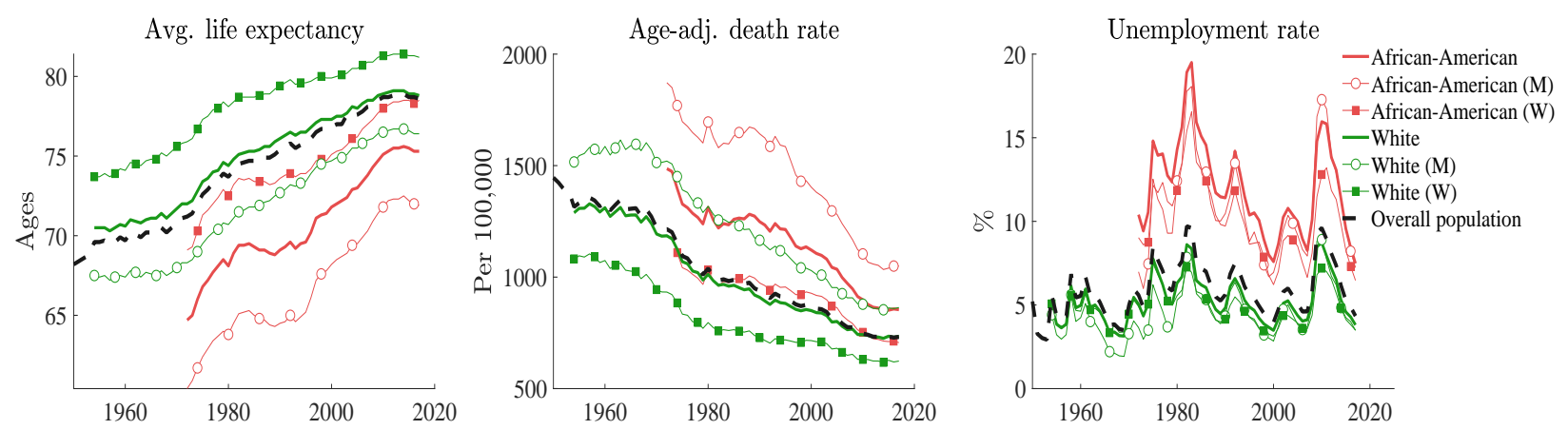

Notes: This figure presents the average life expectancy (first chart), the age-adjusted death rate (second chart), and the unemployment rate (third chart) for the overall US population and for the US population classified according to race and gender. The data span from 1950 to 2017 for the overall population; 1954 to 2017 for White population; and 1972-2017 for African-American population.

Gordon and Sommers (2016), using county level data and panel regressions, find that median income and poverty rates are better predictors of mortality rates than unemployment rates. In our analysis, we use unemployment rates because these series are available over a prolonged period of time. In interpreting our results, unemployment should be regarded as a proxy for the overall state of the economy, correlated with other variables of interest such as poverty rates and household income. In line with this interpretation, an increase in unemployment captures a downturn in real activity that can affect health through multiple channels, direct and indirect, such as income, crime rates, drug abuse, and the life style of the peer group. Furthermore, the panel regression approach used in previous studies assumes that the effects of the national business cycle is absorbed by the time fixed effect (Ruhm (2015)). Thus, our approach is inherently different and complementary to the previous studies interested in the relation between real activity and human health.

Figure 1 provides a first look at the raw data series for the overall population and for the six groups identified based on race and gender. We highlight a series of features in the data that are noteworthy. First, for all groups considered, the average life expectancy has been increasing over time. Second, and consistent with the increase in life-expectancy, the age-adjusted death rates have been falling over time. Third, the African-American population (both men and women) has historically experienced shorter average life expectancy, higher age-adjusted death rates, and higher unemployment rates relative to the White population. Fourth, men have shorter life expectancy and higher death rates, regardless of race. Finally, these differences have been declining over time and the conditions for African-American men have improved the most as they currently experience much longer life expectancy and lower (age adjusted) death rates relative to the 1970s. However, the differences remain large and visible. 
To further elaborate on these points, we compute percentage changes of life expectancy and death rates by taking their log differences and multiplying them by 100. Table 1 provides the summary statistics (i.e., sample average, autocorrelation at first lag, and standard deviation) of these two transformed variables and the unemployment rate. The summary statistics are computed for the overall population and for the six groups identified based on race and gender. In the left part of the table, we report the summary statistics for each group based on the longest sample available for that group. In the right part of the table we report the same statistics over the common subsample (1972-2017) for which we have data for all groups. This approach facilitates the comparison across groups.

In line with what we outlined above, all groups have experienced an improvement in lifeexpectancy and a decline in death rates. However, the table reveals substantial heterogeneity across gender and race. Specifically, we find that proportionally the African-American population has experienced a more significant improvement in these measures of human wellbeing. Given that the White population was starting with lower mortality rates and higher life-expectancy, this difference in growth rates translates into a gap that has been narrowing over time. At the same time, the variables corresponding to the African-American population are much more volatile than those of the White or overall populations. Furthermore, the unemployment rates for the African-American population are also larger and more volatile when compared to those of the White population. This feature of the data already suggests that the impact of the business cycle on human well-being could be more relevant for the AfricanAmerican population.

The data also reveal high frequency movements in the growth rates of life-expectancy and mortality rates. These can be due to measurement error, as the US population is not continuously observable, or other idiosyncratic factors unrelated to the business cycle or the historical improvement in the quality of life. The negative sample autocorrelation of the growth rates speaks to this evidence. Thus, in our empirical analysis we allow for the possibility that life-expectancy and death-rates are measured with error. We discuss the details in the next subsection.

\subsection{The model}

We specify a VAR to describe the joint dynamics of the growth rates of life expectancy, mortality rates, and the level of unemployment rate for each group $i$ that we are interested in (overall population and the six groups organized based on race and gender):

$$
x_{i, t}=\mu_{i}+\Phi_{i} x_{i, t-1}+\eta_{i, t}, \quad \eta_{i, t} \sim N\left(0, \Sigma_{i}\right) .
$$

where $x_{i, t}$ is a three-dimensional vector containing three series for group $i$ : the growth rate of life-expectancy, the growth rate of the age-adjusted death rate, and the unemployment rate; 
Table 1: VAR data summary statistics

\begin{tabular}{|c|c|c|c|c|c|c|}
\hline & \multicolumn{3}{|c|}{ Available sample } & \multicolumn{3}{|c|}{ Common sample } \\
\hline & Mean & Autocorr & Stdev & Mean & Autocorr & Stdev \\
\hline \multicolumn{7}{|c|}{ (A) Percentage change in life expectancy } \\
\hline Overall population & 0.21 & -0.08 & 0.31 & 0.22 & 0.09 & 0.27 \\
\hline African-American & 0.34 & 0.32 & 0.46 & 0.34 & 0.32 & 0.46 \\
\hline African-American (M) & 0.39 & 0.50 & 0.52 & 0.39 & 0.50 & 0.52 \\
\hline African-American (W) & 0.28 & 0.25 & 0.39 & 0.28 & 0.25 & 0.39 \\
\hline White & 0.18 & -0.05 & 0.26 & 0.20 & 0.06 & 0.26 \\
\hline White (M) & 0.20 & 0.07 & 0.28 & 0.25 & 0.28 & 0.24 \\
\hline White (W) & 0.15 & -0.08 & 0.25 & 0.15 & 0.16 & 0.24 \\
\hline \multicolumn{7}{|c|}{ (B) Percentage change in the age-adjusted death rate } \\
\hline Overall population & -1.02 & -0.20 & 1.77 & -1.13 & -0.13 & 1.58 \\
\hline African-American & -1.23 & 0.04 & 2.07 & -1.23 & 0.04 & 2.07 \\
\hline African-American (M) & -1.29 & 0.12 & 2.09 & -1.29 & 0.12 & 2.09 \\
\hline African-American (W) & -1.14 & -0.01 & 2.21 & -1.14 & -0.01 & 2.21 \\
\hline White & -0.89 & -0.16 & 1.68 & -1.06 & -0.14 & 1.57 \\
\hline White (M) & -0.89 & -0.09 & 1.67 & -1.26 & -0.19 & 1.42 \\
\hline White (W) & -0.87 & -0.17 & 1.80 & -0.90 & -0.12 & 1.77 \\
\hline \multicolumn{7}{|c|}{ (C) Unemployment rate } \\
\hline Overall population & 5.82 & 0.77 & 1.62 & 6.36 & 0.75 & 1.56 \\
\hline African-American & 12.08 & 0.81 & 2.91 & 12.08 & 0.81 & 2.91 \\
\hline African-American (M) & 10.94 & 0.76 & 3.06 & 10.94 & 0.76 & 3.06 \\
\hline African-American (W) & 10.23 & 0.83 & 2.41 & 10.23 & 0.83 & 2.41 \\
\hline White & 5.26 & 0.76 & 1.40 & 5.59 & 0.74 & 1.43 \\
\hline White (M) & 4.51 & 0.77 & 1.56 & 4.94 & 0.71 & 1.53 \\
\hline White (W) & 4.79 & 0.77 & 1.14 & 4.96 & 0.79 & 1.23 \\
\hline
\end{tabular}

Notes: We provide the sample moments (mean, autocorrelation at first lag, and standard deviation) of the three series used in the estimation: the growth rate of the average life expectancy (panel A), the growth rate of the age-adjusted death rate (panel B), and the unemployment rate (panel C) for the overall US population and for distinct groups identified based on race and gender. The available data span from 1950 to 2017 for the overall population; from 1954 to 2017 for white workers; and from 1972 to 2017 for African-American workers. The common sample is from 1972 to 2017.

$\mu_{i}$ is a vector of constants, the matrix $\Phi_{i}$ contains the autoregressive coefficients, and $\eta_{i, t}$ is a vector of Gaussian innovations. The VAR above is specified with one lag. This is the number of lags that we use in our empirical analysis and it is chosen based on the Akaike Information 
criterion. However, the methodology that we describe below easily allows for more lags.

In estimating (1), we want to allow for the possibility that life expectancy and death rates are observed with an error or have high frequency swings around a central trend. Thus, we cannot directly run the VAR. To tackle this issue, we specify a state-space model in which the measurement equation allows for measurement errors in the levels of the observables:

$$
y_{i, t}=z_{i, t}+\epsilon_{i, t}, \quad \epsilon_{i, t} \sim N\left(0, \Omega_{i}\right),
$$

where $y_{i, t}$ includes the $\log$ of life expectancy, the $\log$ of death rates, and the unemployment rate for group $i$. Here, $z_{i, t}$ contains the true log-level series for life expectancy and age-adjusted death rates, free from measurement errors. We model the measurement errors as i.i.d. random variables with a diagonal covariance matrix $\Omega_{i}$. We do not allow for measurement errors in the unemployment rate, $\epsilon_{i, 3, t}=0$, as the measurement issue for the unemployment rate is much less of a concern at annual frequency.

As the measurement equation is expressed in log-levels, we express $x_{i, t}$ as linear transformation of the log-level series for consistency:

$$
x_{i, t}=z_{i, t}-M z_{i, t-1}, \quad M=\left[\begin{array}{ccc}
1 & 0 & 0 \\
0 & 1 & 0 \\
0 & 0 & 0
\end{array}\right] .
$$

Combining (1) with (3), the state transition equation (1) can be re-expressed in terms of the true log-level series

$$
z_{i, t}=\mu_{i}+\left(M+\Phi_{i}\right) z_{i, t-1}-\Phi M z_{i, t-2}+\eta_{i, t}, \quad \eta_{i, t} \sim N\left(0, \Sigma_{i}\right) .
$$

In sum, the measurement equation (2) and the state transition equation (4) constitute our state-space representation of the system. Thus, our state-space model enables the estimation of the VAR parameters, $\Phi_{i}$ and $\Sigma_{i}$, which are crucial for the analysis presented below, while at the same time allowing for measurement errors. The fact that observation errors apply to the log-levels of the age-adjusted death rates and life expectancy as opposed to their growth rates implies that the filtered series for life-expectancy and death rates cannot persistently deviate from the observed ones.

Data exploration. We estimate a total of seven VARs: Overall population (our benchmark case), African-American, African-American men, African-American women, White, White men, and White women. All data are available at annual frequency.

Lag order selection. We set the lag order of the VAR in the state transition equation to one. The choice of a one lag in (1) is guided by the Akaike information criterion (AIC) when we directly estimate (1) with bandpass filtered series as a first test. Furthermore, it seems appropriate given the small sample that we have available and the use of data at annual frequency. 
Figure 2: VAR data
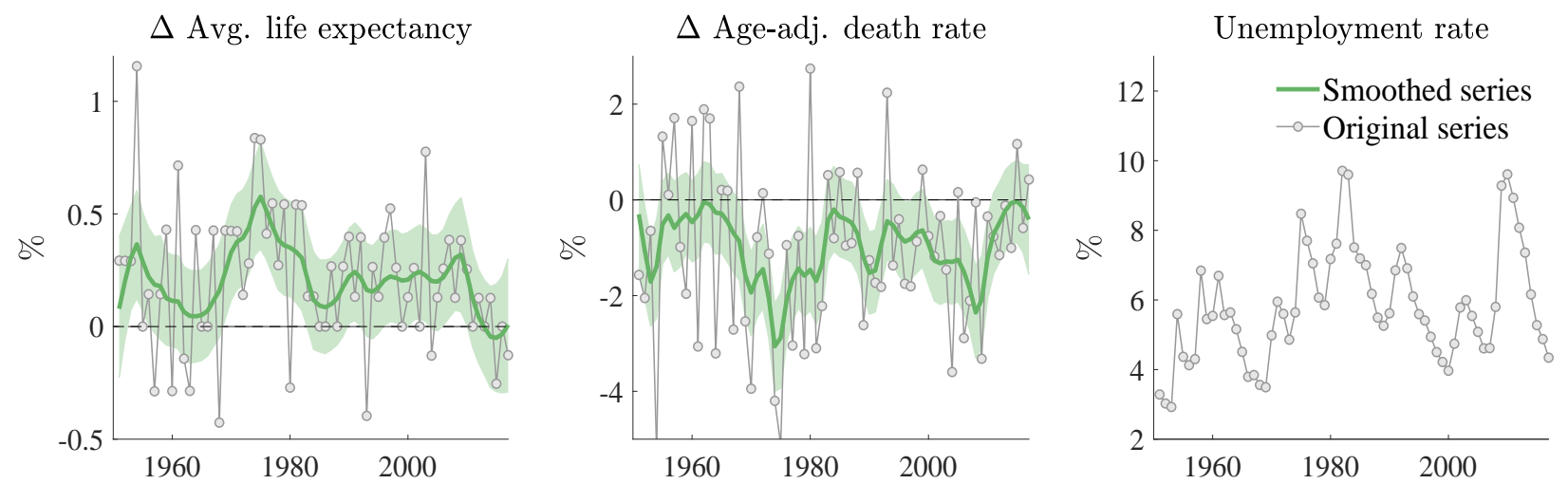

Notes: This figure presents the growth rate of the average life expectancy (first chart), the growth rate of the age-adjusted death rate (second chart), and the unemployment rate (third chart) for the overall US population. The original series are presented in gray circled lines. For the first two series, we compare with the smoothed estimates from our model (green lines). The data span from 1950 to 2017.

Bayesian inference. We conduct Bayesian inference using a Gibbs sampling algorithm. In essence, we draw for the VAR coefficients conditional on the states, and we draw for the state conditional on the VAR coefficients. The priors for the VAR parameters are diffuse and symmetric with respect to the relation between unemployment and the growth rates of life-expectancy and the age-adjusted death rates. In other words, the priors imply that a negative relation is as likely as a positive relation. Furthermore, we use the same priors for the different groups identified based on race and gender. Thus, all the differences between groups documented below are driven by the information contained in the data. The Appendix contains more details about the priors and the Gibbs sampling algorithm.

Cholesky decomposition. To quantify the effects of an increase in unemployment on life expectancy and mortality rates, we need to isolate structural shocks to unemployment, i.e., shocks that are exogenous with respect to the mortality rate and life expectancy. To do this, we orthogonalized the covariance matrix of the VAR residuals using a Cholesky decomposition with unemployment placed last. This assumption implies that the unemployment shock can affect the other two series only with a lag of one year. For robustness, we also consider a specification in which the ordering is reverted and unemployment is allowed to affect the other two variables contemporaneously.

\section{Results}

From the estimation of our state-space model, we obtain posterior estimates of model unknowns including the VAR parameters in (1) and the smoothed estimates of life expectancy and death 
Figure 3: VAR data by race and gender

(1) African-American population: Both gender
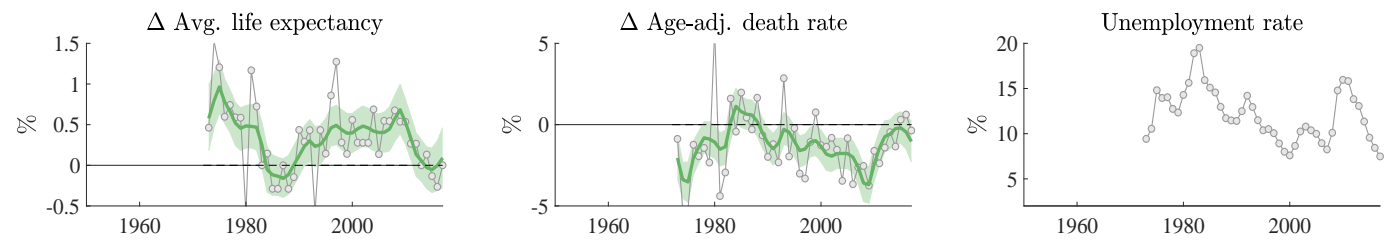

(2) African-American population: Men
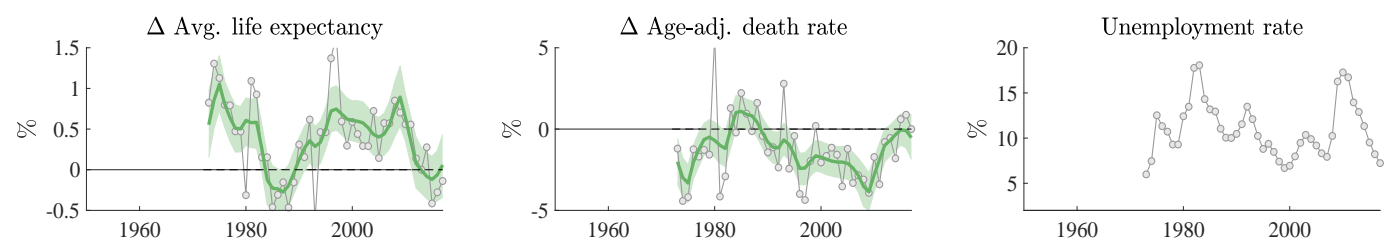

(3) African-American population: Women
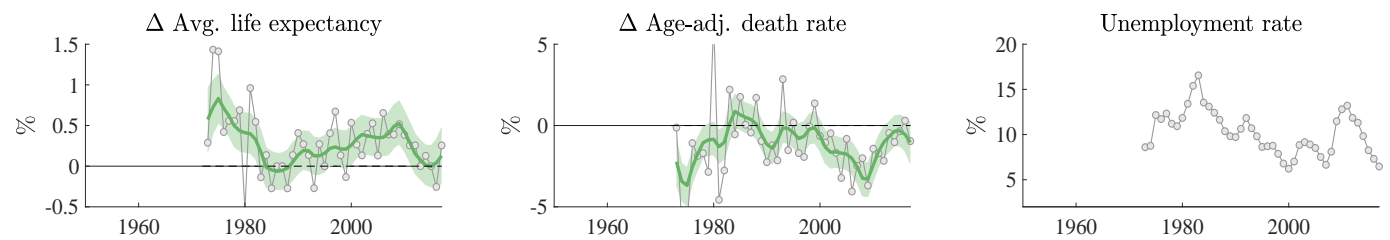

(4) White population: Both gender
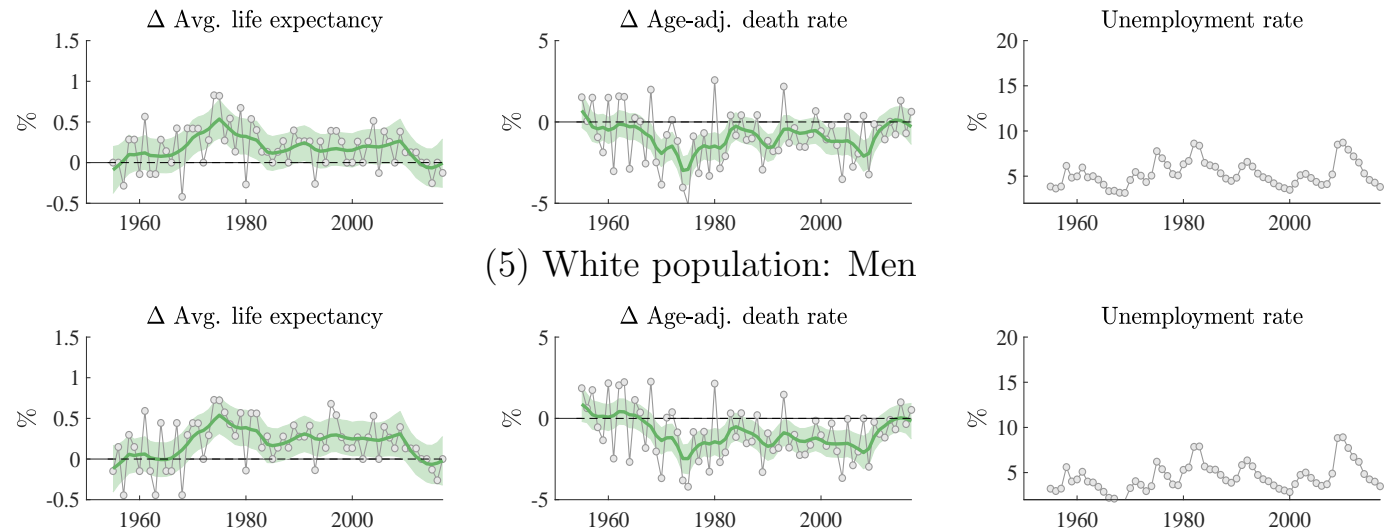

(5) White population: Men
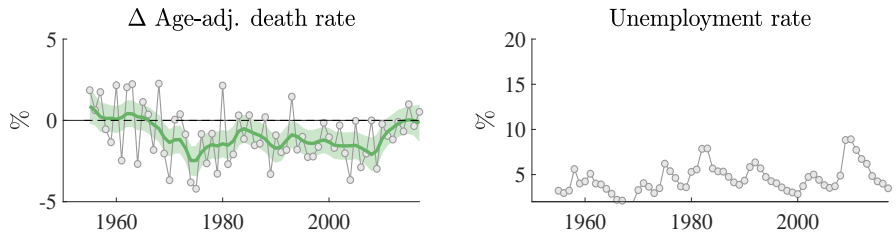

(6) White population: Women
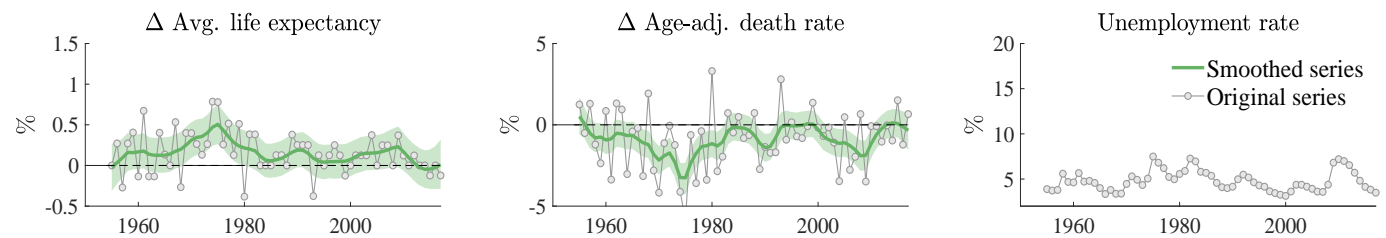

Notes: This figure presents the growth rate of the average life expectancy (first column), the growth rate of the age-adjusted death rate (second column), and the unemployment rate (third column) for distinct groups identified based on race and gender. The original series are presented in gray circled lines. For the first two series, we compare with the smoothed estimates from our model (green lines). The data span from 1954 to 2017 for the White population, and from 1972 to 2017 for the African-American population. 
Table 2: Model summary statistics

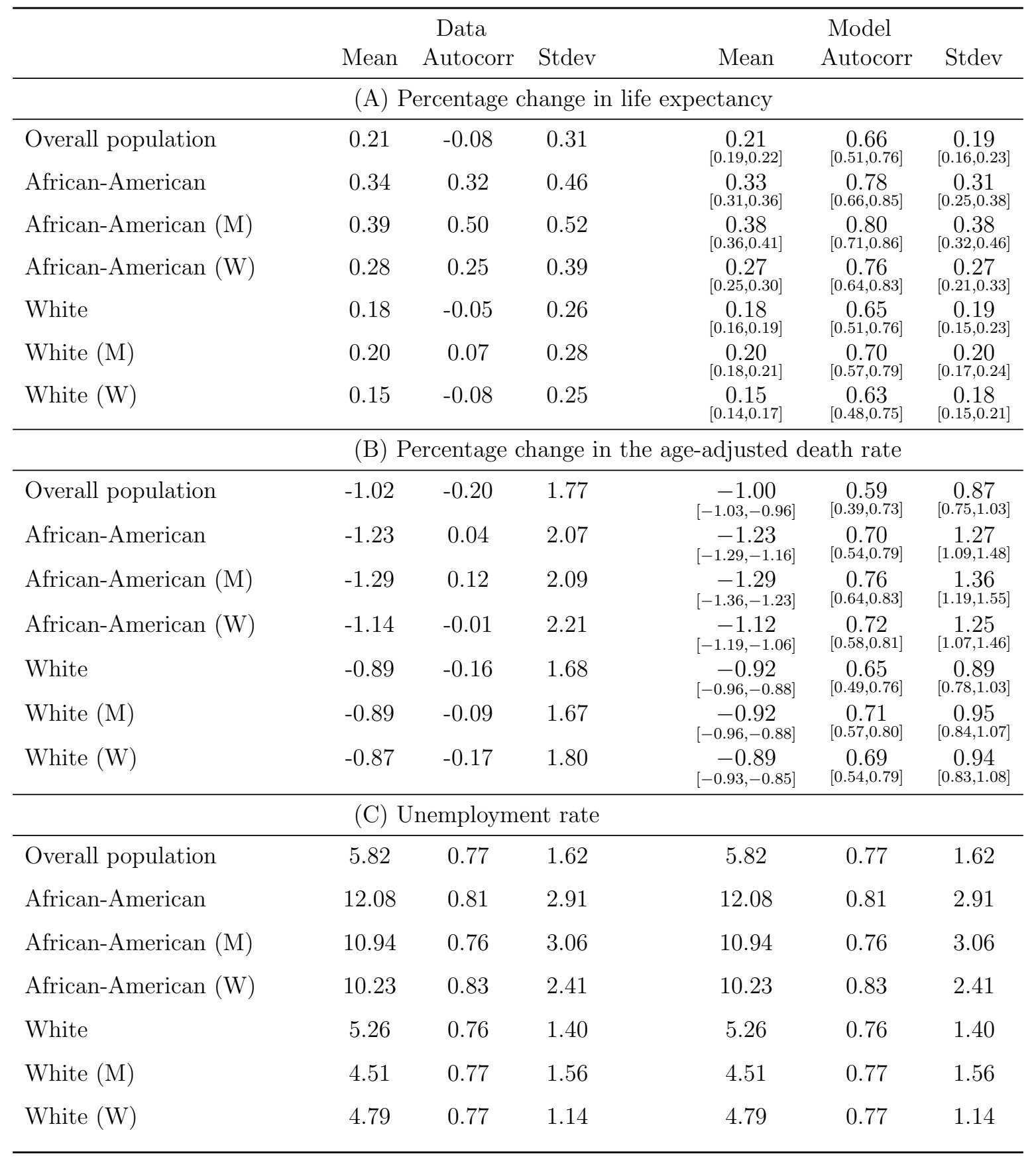

Notes: We provide the sample moments (mean, autocorrelation at first lag, and standard deviation) of the three series used in the estimation: the growth rate of the average life expectancy (panel A), the growth rate of the age-adjusted death rate (panel B), and the unemployment rate (panel C) for the overall US population and for distinct groups identified based on race and gender. We compare with those computed from the smoothed estimates (without measurement errors) of our model. The data span from 1950 to 2017 for the overall population; from 1954 to 2017 for white workers; and from 1972 to 2017 for African-American workers. 
(mortality) rates free from measurement errors. We first discuss the properties of the smoothed growth rates of life expectancy and mortality rates, and subsequently, examine how an increase in unemployment affects the growth rates of life expectancy and mortality rates conditional on the posterior estimates of the VAR coefficients.

\subsection{Model-implied growth rates of life expectancy and mortality}

Figure 2 presents the growth rates of life expectancy and the death rate for the overall population implied by the smoothed estimates and compares them with the corresponding data series. The smoothed and raw series for the sub-groups are reported in Figure 3. We find that the smoothed and raw growth rates move very closely. However, a non-negligible portion of the fluctuations in the raw growth rates is attributable to measurement errors or high frequency changes unrelated to the state of the economy or progress in health care, most notably so for the growth rate of death rates. One way to clearly see this pattern is by analyzing the behavior of the autocorrelation and standard deviations of the raw series and of the smoothed series as reported in the right part of Table 2. For ease of comparison, the left part of Table 1 is reproduced in Table 2. We find that compared to the data moments, the model-implied autocorrelation value is higher and the standard deviation is smaller, as the noise in the original series is removed.

At the same time, observation errors only account for the high frequency movements of the original variables. The Appendix shows that the log level of the two (actual and smoothed) series move very closely, implying that the smoothing algorithm does not alter the core dynamics of the original variables. In sum, our state-space model is able to smooth out fluctuations in the raw growth rates while preserving the core dynamics of the underlying variables. As a result, at lower frequencies (i.e., cycles longer than one year), the smoothed growth rates comove with the raw growth rates. These are arguably the frequencies that we are interested in when studying the relation between unemployment and human health and they are less likely to be contaminated by significant observation errors.

\subsection{Impulse responses to an unemployment shock}

To understand the effects of an increase in unemployment on the mortality rate and life expectancy, we use an impulse response analysis based on a Cholesky decomposition. We order unemployment last, implying that all contemporaneous co-movements between the variables of interest are attributed to structural shocks to the other two variables. In other words, under this identification assumption, shocks to unemployment can affect mortality rates and lifeexpectancy only with a lag. Below, we also discuss results for the case in which unemployment is ordered first. 
Figure 4: Impulse responses to a one-standard-deviation shock to unemployment

$\Delta$ Avg. life expectancy

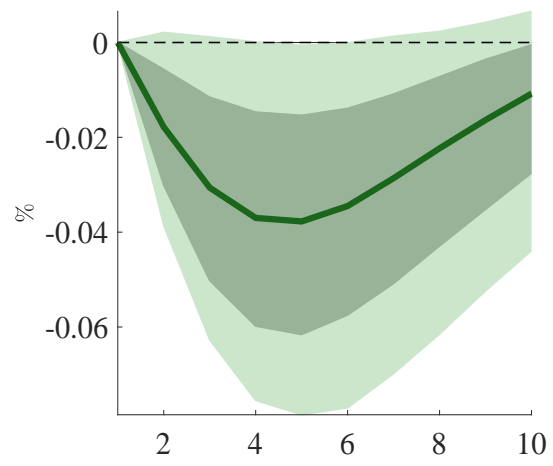

$\Delta$ Age-adj. death rate

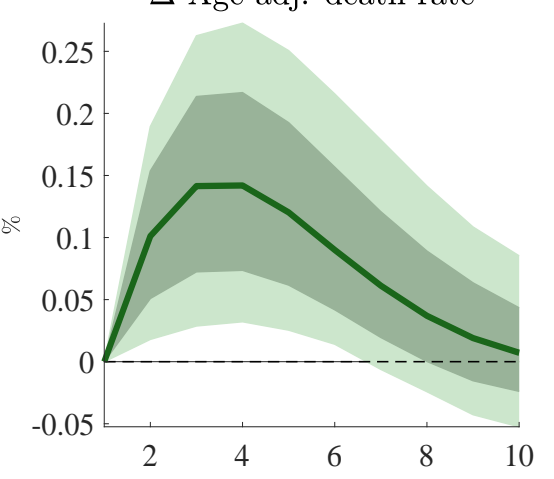

Unemployment rate

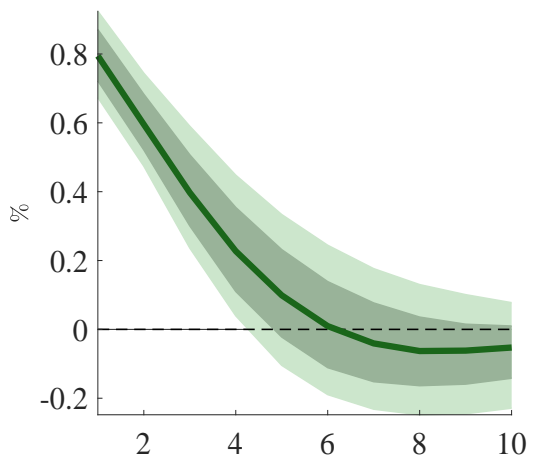

Notes: We provide impulse responses to a one-standard-deviation shock to unemployment for the overall US population. The solid-lines represent the median values and the dark and light-shaded areas indicate $68 \%$ and $90 \%$ bands, respectively.

Figure 4 reports the responses of life expectancy and the age-adjusted death rate to a onestandard deviation shock to the unemployment rate for the overall population. The figure reports the median response and $68 \%$ and $90 \%$ credible sets. The shock to unemployment is quite persistent and is followed by sizable changes in the growth rates of life expectancy and the death rate. These effects are also quite long lasting. Focusing on the median response, we can see that the effect of the unemployment shock on the growth rates of life expectancy and the death rate reaches its peak in the fourth year. The median values for these peaks are around $-0.04 \%$ and $0.15 \%$, respectively.

The impulse responses based on race and gender are presented in Figure 5. To facilitate the comparison across groups, the median impulse responses for each group are reported in Figure 6. The first row of Figure 6 contains the median impulse responses to a one-standard deviation unemployment shock (as in Figure 4 and Figure 5). Given that the size of the typical shock varies across groups, the second row of Figure 6 reports the impulse responses to a normalized (1\%) unemployment shock to keep the size of the shock identical across groups.

Several important observations can be made. The responses of the growth rates of the age-adjusted death rates are sizable for all groups. For the growth rate of life expectancy, $90 \%$ credible sets exclude zero for three out of six groups, while $68 \%$ credible sets exclude zero for all groups. Thus, we find strong statistical evidence of a dynamic relation between unemployment shocks and human well-being for all groups. African-Americans experience larger unemployment shocks and the effects of these shocks on unemployment are more persistent. Conditional on the same race, the shocks for women are smaller. The effects on life expectancy and death rates are more severe for African-Americans, overall. This cannot be entirely explained as a consequence of larger shocks, as the pattern largely persists when controlling for the size of the 
Figure 5: Impulse responses to a one-standard-deviation shock to unemployment

(1) African-American population: Overall
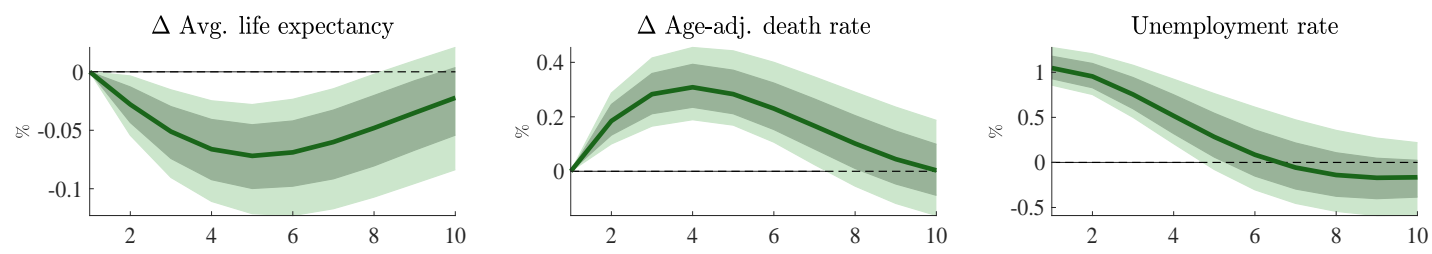

(2) African-American population: Men
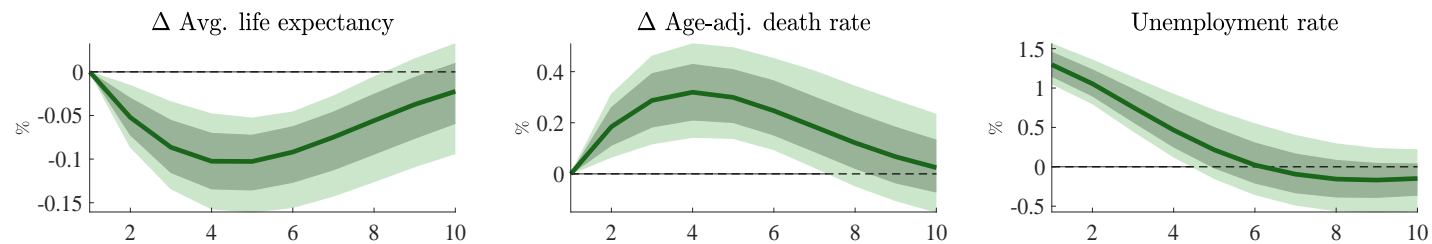

(3) African-American population: Women
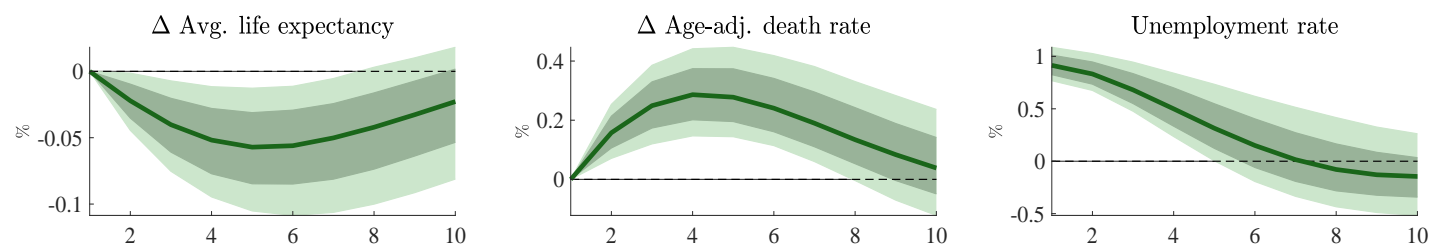

(4) White population: Overall
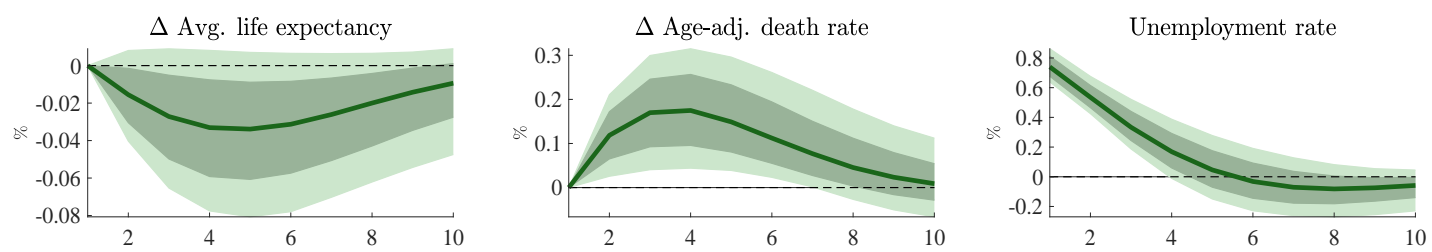

(5) White population: Men
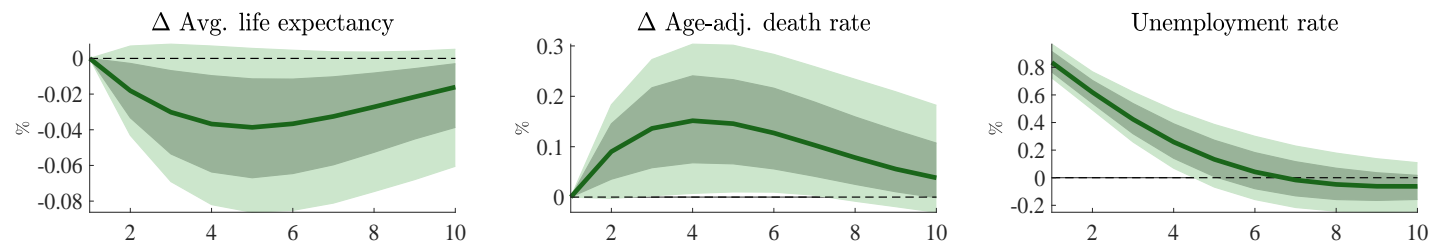

(6) White population: Women
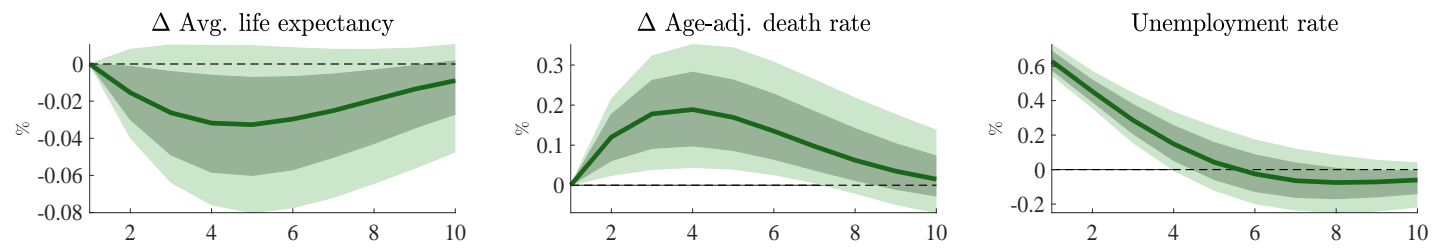

Notes: We provide impulse responses to a one-standard-deviation shock to unemployment for the US population classified according to race and gender. The solid-lines represent the median values and the dark and light-shaded areas indicate $68 \%$ and $90 \%$ bands, respectively. 
Figure 6: Impulse response comparison

(1) A one-standard-deviation shock to unemployment
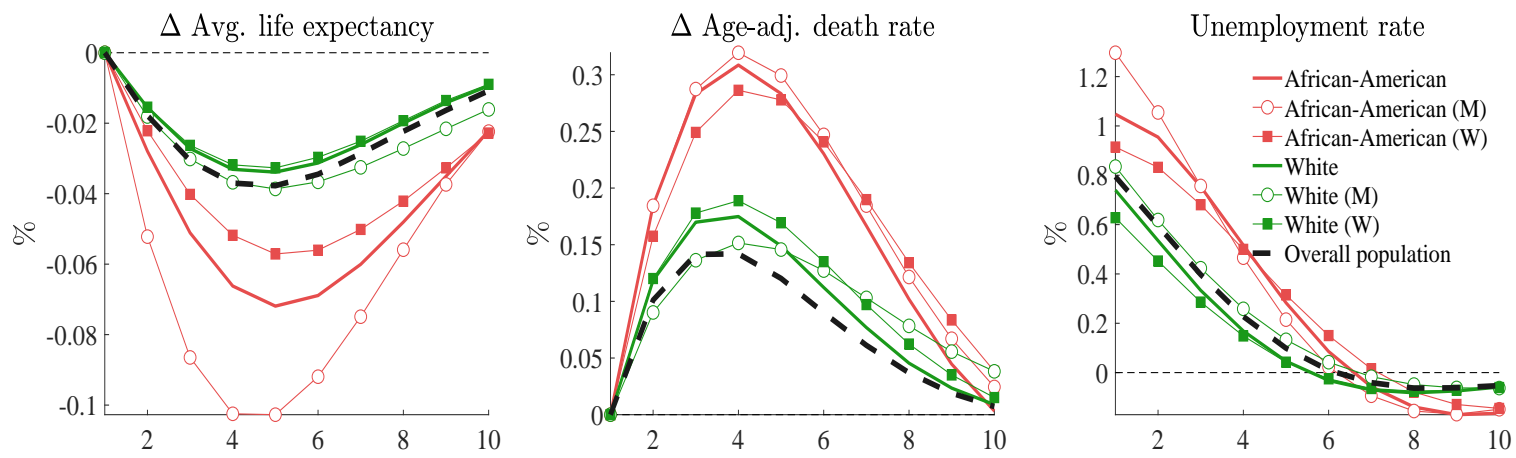

(2) A unit shock to unemployment rate
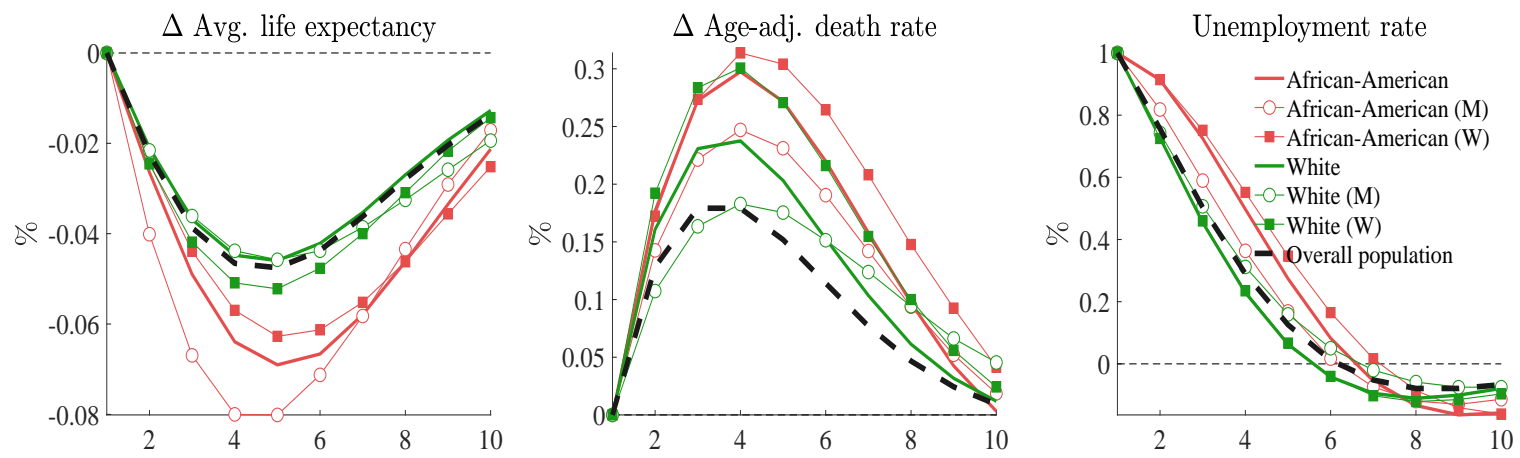

Notes: We compare median impulse responses to a one-standard-deviation (first row panels) or a unit shock (second row panels) to unemployment, which is identified via a Cholesky decomposition, across the overall US population and for the US population classified according to race and gender.

shock. However, it could be the result of the larger persistence of unemployment following the shocks. Conditional on the size of the shock, we find that women (both African-American and White) present a relatively larger increase in death rates. Finally, we notice that the effects for White men unfold over a longer period of time. They experience a mild reaction of death rates in the short-run, but they seem to have the larger response of age-adjusted death rates in the long run (past 10-year horizon).

In comparing these impulse responses, it is important to keep in mind that the sample is not homogeneous across groups. The sample of the African-American population is significantly shorter (1972-2017) than that of the White population (1954-2017). However, most of the results described below are robust to using the common sample 1972-2017 (see Figure A-5 in the appendix). The only pattern that changes when using the common sample is the persistent response of white men death rates at long horizons. When using the shorter sample, this result does not appear. Thus, we infer that it is mostly driven by the dynamics of the three variables 
at the beginning of the sample.

The Appendix also reports results for an identification strategy based on ordering unemployment first in the Cholesky decomposition. In this case, unemployment shocks are allowed to have contemporaneous effects on the other variables in the system. As explained in the introduction, there are several reasons explaining why unemployment could have contemporaneous effects on mortality rates (not commuting to work, no risk of work related deaths, etc.). The finding that an unemployment shock is eventually followed by an increase in mortality and a decline in life-expectancy is robust to using this different identification strategy. However, when using this alternative identification assumption, an interesting result emerges with respect to the short-run dynamics. For some groups, we find evidence that an increase in unemployment can lead to a contemporaneous decline in mortality rates and to a contemporaneous increase in life-expectancy. However, the error bands for this initial response are large and the effect quickly reverts in two-three years. In the long-run, mortality increases and life expectancy declines, in line with our benchmark results. In other words, the long-term effect dominates the short-term dynamics. Thus, the results about the impact of the COVID-19 unemployment shock that we will describe below are not qualitatively affected by the specific identification strategy. At the same time, this different identification strategy could be helpful in understanding why previous studies have often found conflicting results on the effects of unemployment on human health. On impact, unemployment can lead to a decline in mortality as deaths due to motor vehicle or work-related accidents diminish, but over time economic distress might take a toll on human well-being.

\subsection{Historical importance of unemployment shocks}

The previous subsection highlights that unemployment shocks are followed by statistically significant changes in the growth rates of the age adjusted death rate and life expectancy. In this subsection, we are interested in assessing the relative importance of unemployment shocks for these two variables.

To assess the historical importance of unemployment shocks, we compute a variance decomposition by comparing the unconditional variance, as implied by the VAR model, when only the orthogonalized unemployment shock is active, to the overall variance. Specifically, we compute the fraction of forecast error variance of the percentage change in life expectancy and the age-adjusted mortality rate explained by the unemployment shock at 5-, 10-, 15-, and 20-year horizons. Table 3 summarizes our findings. The first row in each panel of Table 3 reports the results for the overall population. At 15 years, the fractions of forecast error variance explained by unemployment shocks are $13.31 \%$ and $10.89 \%$ for life expectancy and the death rate, respectively. Thus, the contribution of unemployment shocks to these measures of human 
Table 3: Fraction of forecast error variance explained by unemployment shock (\%)

\begin{tabular}{|c|c|c|c|c|}
\hline & \multicolumn{4}{|c|}{ (1) Percentage change in life expectancy } \\
\hline & 5 years & 10 years & 15 years & 20 years \\
\hline Overall population & $\begin{array}{c}8.33 \\
{[0.27,28.24]}\end{array}$ & $\begin{array}{c}12.99 \\
{[0.64,38.81]}\end{array}$ & $\begin{array}{c}13.31 \\
{[0.72,38.75]}\end{array}$ & $\begin{array}{c}13.36 \\
{[0.73,39.04]}\end{array}$ \\
\hline African-American & $\begin{array}{c}17.62 \\
{[2.79,39.16]}\end{array}$ & $\begin{array}{c}23.98 \\
{[5.57,46.57]}\end{array}$ & $\begin{array}{c}23.95 \\
{[5.79,45.98]}\end{array}$ & $\begin{array}{c}24.02 \\
{[5.79,46.03]}\end{array}$ \\
\hline African-American (M) & $\begin{array}{c}34.43 \\
{[7.89,58.38]}\end{array}$ & $\begin{array}{c}39.00 \\
{[14.05,62.21]}\end{array}$ & $\begin{array}{c}38.63 \\
{[14.14,61.39]}\end{array}$ & $\begin{array}{c}38.49 \\
{[14.25,61.48]}\end{array}$ \\
\hline African-American (W) & $\begin{array}{c}12.51 \\
{[0.91,34.20]}\end{array}$ & $\begin{array}{c}20.70 \\
{[2.49,46.04]}\end{array}$ & $\begin{array}{c}20.84 \\
{[2.96,44.81]}\end{array}$ & $\begin{array}{c}21.12 \\
{[3.03,45.23]}\end{array}$ \\
\hline White & $\begin{array}{c}7.04 \\
{[0.19,30.31]}\end{array}$ & $\begin{array}{c}11.04 \\
{[0.44,40.22]}\end{array}$ & $\begin{array}{c}11.37 \\
{[0.49,40.24]}\end{array}$ & $\begin{array}{c}11.44 \\
{[0.50,40.69]}\end{array}$ \\
\hline White (M) & $\begin{array}{c}8.15 \\
{[0.17,31.83]}\end{array}$ & $\begin{array}{c}14.03 \\
{[0.43,45.19]}\end{array}$ & $\begin{array}{c}14.89 \\
{[0.52,46.27]}\end{array}$ & $\begin{array}{c}15.02 \\
{[0.53,46.58]}\end{array}$ \\
\hline \multirow[t]{3}{*}{ White (W) } & $\begin{array}{c}6.65 \\
{[0.17,28.76]}\end{array}$ & $\begin{array}{c}10.85 \\
{[0.42,39.07]}\end{array}$ & $\begin{array}{c}11.19 \\
{[0.47,39.71]}\end{array}$ & $\begin{array}{c}11.22 \\
{[0.49,40.03]}\end{array}$ \\
\hline & \multicolumn{4}{|c|}{ (2) Percentage change in the age-adjusted death rate } \\
\hline & 5 years & 10 years & 15 years & 20 years \\
\hline Overall population & $\begin{array}{c}8.80 \\
{[0.56,24.69]}\end{array}$ & $\begin{array}{l}10.73 \\
{[0.97,28.75]}\end{array}$ & $\begin{array}{c}10.89 \\
{[1.07,28.97]}\end{array}$ & $\begin{array}{c}10.93 \\
{[1.09,29.08]}\end{array}$ \\
\hline African-American & $\begin{array}{c}25.88 \\
{[10.86,44.00]}\end{array}$ & $\begin{array}{c}26.53 \\
{[12.76,44.59]}\end{array}$ & $\begin{array}{c}26.75 \\
{[12.84,44.36]}\end{array}$ & $\begin{array}{c}26.78 \\
{[12.85,44.46]}\end{array}$ \\
\hline African-American (M) & $\begin{array}{c}24.42 \\
{[5.16,46.45]}\end{array}$ & $\begin{array}{c}28.37 \\
{[8.05,49.90]}\end{array}$ & $\begin{array}{c}28.65 \\
{[8.43,49.82]}\end{array}$ & $\begin{array}{c}28.82 \\
{[8.47,50.15]}\end{array}$ \\
\hline African-American (W) & $\begin{array}{c}22.42 \\
{[6.11,42.08]}\end{array}$ & $\begin{array}{c}26.09 \\
{[10.22,45.68]}\end{array}$ & $\begin{array}{c}26.18 \\
{[10.52,44.46]}\end{array}$ & $\begin{array}{c}26.33 \\
{[10.67,44.99]}\end{array}$ \\
\hline White & $\begin{array}{c}12.76 \\
{[1.06,31.58]}\end{array}$ & $\begin{array}{c}15.31 \\
{[1.76,35.92]}\end{array}$ & $\begin{array}{c}15.50 \\
{[1.86,36.06]}\end{array}$ & $\begin{array}{c}15.55 \\
{[1.86,36.22]}\end{array}$ \\
\hline White (M) & $\begin{array}{c}8.90 \\
{[0.28,27.55]}\end{array}$ & $\begin{array}{c}13.34 \\
{[0.70,36.54]}\end{array}$ & $\begin{array}{c}13.83 \\
{[0.82,37.71]}\end{array}$ & $\begin{array}{c}13.92 \\
{[0.86,37.98]}\end{array}$ \\
\hline White (W) & $\begin{array}{c}12.72 \\
{[0.93,32.70]}\end{array}$ & $\begin{array}{c}16.20 \\
{[1.52,38.86]}\end{array}$ & $\begin{array}{c}16.47 \\
{[1.66,39.02]}\end{array}$ & $\begin{array}{c}16.50 \\
{[1.69,39.30]}\end{array}$ \\
\hline
\end{tabular}

Notes: The table provides the fraction of forecast error variance of the percentage change in life expectancy and the age-adjusted mortality rate explained by unemployment shock at 5, 10, 15 and 20 years. We present the median values and provide the values that correspond to the $90 \%$ bands in brackets.

health is by no means negligible.

In line with our previous findings, Table 3 reveals substantial heterogeneity across gender and race. We find that unemployment shocks account for larger fractions of the variations in life expectancy in the case of men relative to women. For example, the fraction of variance for the growth rate of life expectancy is twice as large (38.63\% vs 20.84\%) for African-American men with respect to African-American women, while the difference between White men and White women is smaller (14.89\% vs $11.19 \%$ ). A more similar decomposition emerges for the contribution to the age-adjusted death rate: The fraction of variance is similar $(28.65 \%$ vs $26.18 \%$ ) for African-American men with respect to African-American women and lower for 
Figure 7: Leading causes of deaths

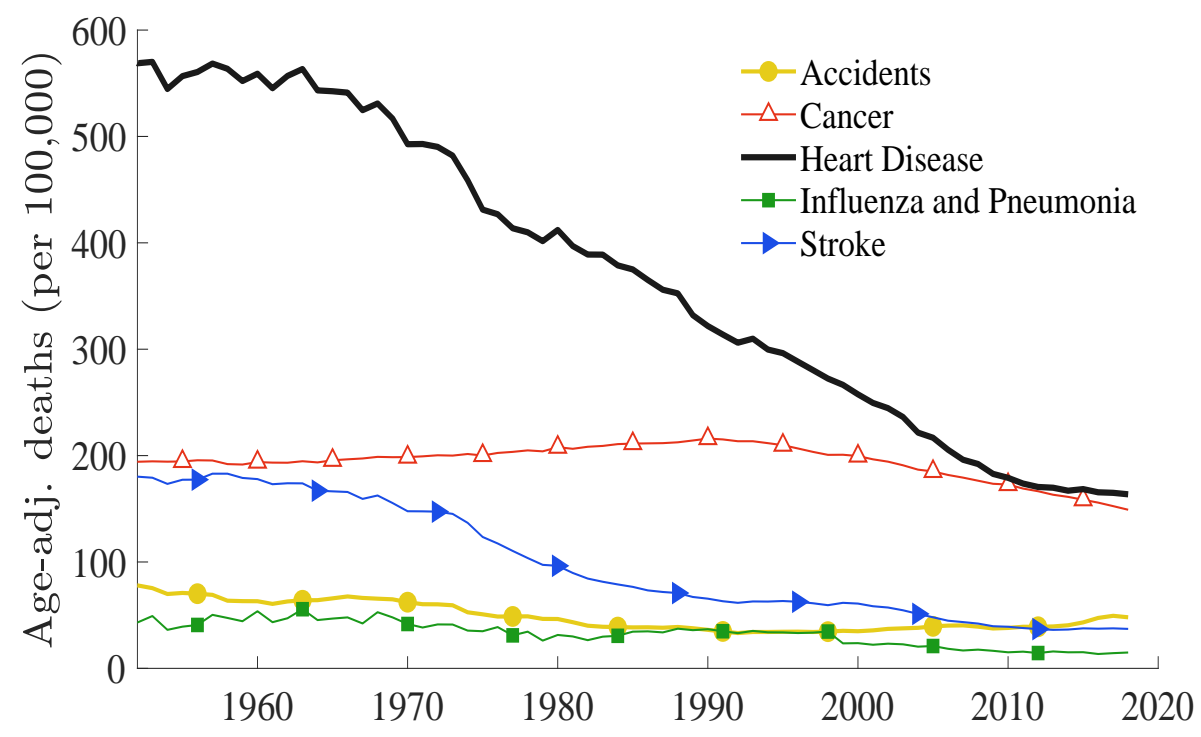

Notes: According to the National Center for Health Statistics (NCHS), National Vital Statistics System, historically, the five leading causes of age-adjusted deaths for the overall population (per 100,000 U.S. standard population) are (1) Heart disease; (2) Cancer; (3) Accidents; (4) Stroke; and (5) Influenza and pneumonia (ordered based on their relative importance).

White men with respect to White women (13.83\% vs $16.47 \%$ at the 15 -year horizon). The gap across races is in this case the most noticeable feature of the results: The contribution of the unemployment shocks to the variance of life expectancy and death rates is around twice as large for the African-American population.

\subsection{Causes of death}

In this section, we explore the effects of economic distress, as captured by the unemployment rate, on the main causes of death. This analysis is helpful in understanding the channels through which economic distress affects the overall mortality rate. Due to data availability, we focus on the overall population. According to the National Center for Health Statistics (NCHS), National Vital Statistics System, historically, the five leading causes of age-adjusted deaths for the overall population (per 100,000 U.S. standard population) are (1) Heart disease; (2) Cancer; (3) Accidents; (4) Stroke; and (5) Influenza and pneumonia (ordered based on their relative importance).

Figure 7 reports the age-adjusted death rates for the five major causes of deaths over the period 1954-2018. These five causes of deaths appear to be consistently important over the years. Since 1950, heart disease and cancer have been identified as the top two leading causes of deaths in the U.S. However, while the death rate due to cancer appears relatively flat over the 
years, the death rate for heart disease shows a significant decline that contributes significantly to the reduction in the overall death rate documented in Figure 1. Interestingly, the two leading causes of death were about to swap their relative importance, but the decline in the death rate due to hearth diseases visibly slowed down around 2010, in the aftermath of the Great Recession. We notice that the late years of the sample also present an increase in the deaths due to accidents, that become the third most important cause of death at the expenses of stroke.

We use our state-space model to relate changes in age-adjusted death rates across the different causes to unemployment shocks. We estimate five separate models, one for each of the five leading causes of death. Due to data availability, we consider a bivariate system by dropping the log change of life expectancy. We then compute the impulse responses of the growth rate of age-adjusted death rates for each of the leading causes of deaths to a unit shock to unemployment rate and report the results in Figure 8. With respect to the exercise reported in Figure 5, we normalize the size of the initial shock to unemployment to $1 \%$ in order to facilitate the comparison across the different impulse responses.

Consistent with our previous findings, an increase in the unemployment rate is associated with significant increases in the growth rates of the leading causes of deaths, with the exception of cancer. The increase is particularly pronounced for accidents and influenza and pneumonia, but at longer horizon it becomes large also for stroke. Of particular interest is the effect on heart disease, the first cause of death. In this case, the increase in the growth rate is smaller, but given the importance of this cause of death, the estimated effect on the growth rate can still translate into an important effect on the overall mortality rate.

Table 4 provides the cumulative effect of the unemployment shock on the age-adjusted death rates for the leading causes of deaths at a 5-, 10-, 15-, and 20-year horizon. Panel (A) of Table 4 summarizes Figure 8. We translate the percentage changes in age-adjusted death rates of the leading causes of deaths into changes in death rates by multiplying the predicted change at 5 , 10, 15, and 20 years provided in Panel (1) of Table 4 with the most recent age-adjusted death rates of the leading causes of deaths in 2018. The age-adjusted death rates (deaths per 100,000 U.S. standard population) for the five leading causes of death in 2018 were: (1) Heart disease, 163.6; (2) Cancer, 149.1; (3) Accidents, 48.0; (4) Stroke, 37.1; and (5) Influenza and pneumonia 14.9. The results are reported in Panel (2) of Table 4. Focusing on the 15 and 20 years horizon, we find that a large increase in the overall death rate can be accounted for by accidents and heart disease, while stroke also plays an important role.

The results presented in this section provide some interesting insights about the channels through which economic activity can affect mortality rates. On the one hand, the effects on mortality due to heart diseases, the leading cause of death in the USA (659,041 deaths in 2019, CDC data), suggest that access to preventive care and lifestyle might play an important role in explaining why unemployment is followed by an increase in mortality rates. Consistently, a 
Figure 8: Impulse responses of the growth rate of age-adjusted death rates for the leading causes of deaths to a unit shock to unemployment rate

(1) Heart disease

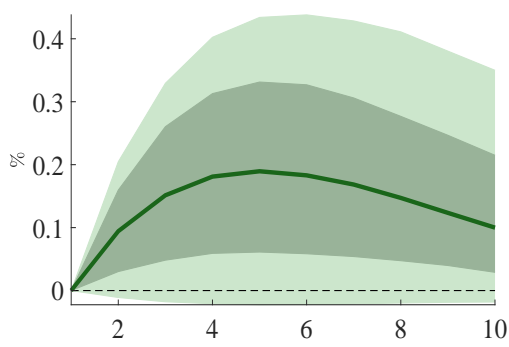

(4) Stroke

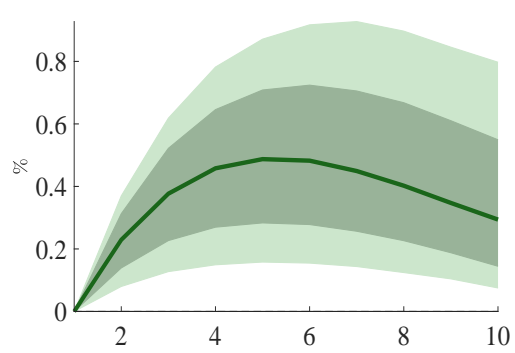

(2) Cancer

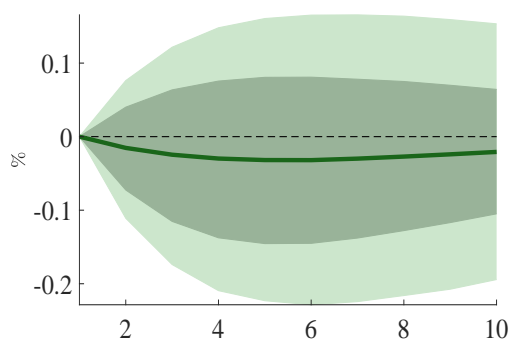

(5) Influenza and pneumonia

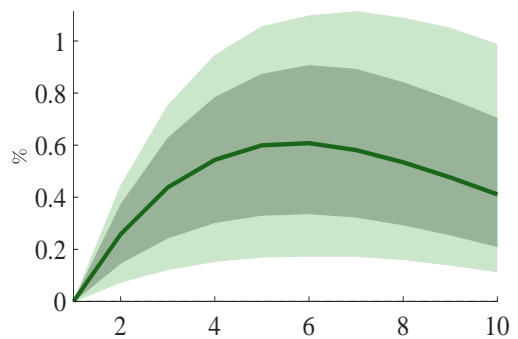

(3) Accidents

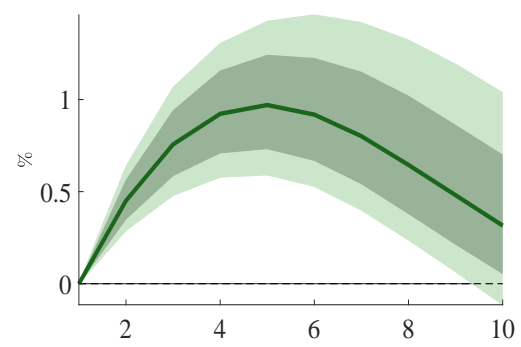

Notes: According to National Center for Health Statistics (NCHS), National Vital Statistics System, the five leading causes of age-adjusted deaths in the U.S. are (1) Heart disease; (2) Cancer; (3) Accidents; (4) Stroke; and (5) Influenza and pneumonia (ordered based on their relative importance). The NCHS Data Visualization Gallery provides the time-series of (1)-(5) as well as the age-adjusted overall death rates from 1900 to 2017.

similar pattern is noted for stroke-related mortality that is largely affected by similar risk and life style factors as heart diseases. A body of literature shows that the use of health services and preventive care are reduced during recessions (Ruhm (2000)). Interestingly, our estimates also indicate an increase in pneumonia/influenza-related mortality. These results may be also explained based on the lack of access to preventive care and the decline in a healthy life style. Vaccination strategies are highly effective in preventing the flu and certain types of pneumonia, but unemployed individuals and their relatives are unlikely to timely seek vaccinations and attend regular doctor visits. Also, an unhealthy lifestyle is likely to increase risks of contracting these infections by weakening the immune system. Importantly, cancer is the second leading cause of death in the USA $(599,601$ deaths in 2019, CDC data) and it is well established that cancer prevention screening is crucial for early identification of the disease, leading to early staging and better outcomes. To our surprise cancer mortality appears to remain stable over time following an increase in unemployment. This result is likely the consequence of the steady progress in cancer care that might avoid the worst outcomes related to a delayed diagnosis.

On the other hand, the large effect of an unemployment shock on accidents indicates that 
Table 4: Cumulative changes of age-adjusted death rates for the leading causes of deaths over different horizons following a $1 \%$ unemployment shock

\begin{tabular}{lcccc}
\hline & \multicolumn{2}{c}{$(1)$ Percentage change } & \\
& 5 years & 10 years & 15 years & 20 years \\
\hline Accidents & 3.10 & 6.24 & 5.93 & 5.06 \\
Cancer & {$[1.96,4.36]$} & {$[3.75,10.19]$} & {$[3.26,12.24]$} & {$[3.12,11.81]$} \\
Heart disease & -0.10 & -0.25 & -0.33 & -0.37 \\
& {$[-0.72,0.51]$} & {$[-1.74,1.29]$} & {$[-2.46,1.95]$} & {$[-2.92,2.51]$} \\
Influenza and pneumonia & 0.62 & 1.38 & 1.66 & 1.71 \\
& {$[-0.07,1.36]$} & {$[-0.17,3.21]$} & {$[-0.23,4.30]$} & {$[-0.27,4.72]$} \\
Stroke & 1.84 & 4.50 & 5.65 & 5.79 \\
& {$[0.52,3.18]$} & {$[1.36,8.19]$} & {$[1.87,11.55]$} & {$[2.13,13.36]$} \\
& 1.56 & 3.56 & 4.28 & 4.36 \\
& {$[0.51,2.63]$} & {$[1.20,6.86]$} & {$[1.52,9.48]$} & {$[1.63,10.99]$} \\
\hline Accidents & $(2)$ Change & & \\
Cancer & 5 years & 10 years & 15 years & 20 years \\
Heart disease & 1.49 & 3.00 & 2.85 & 2.43 \\
Influenza and pneumonia & {$[0.94,2.09]$} & {$[1.80,4.89]$} & {$[1.57,5.87]$} & {$[1.50,5.67]$} \\
Stroke & -0.15 & -0.37 & -0.49 & -0.55 \\
& {$[-1.07,0.76]$} & {$[-2.60,1.93]$} & {$[-3.66,2.91]$} & {$[-4.36,3.74]$} \\
& 1.01 & 2.25 & 2.72 & 2.80 \\
& {$[-0.12,2.23]$} & {$[-0.28,5.25]$} & {$[-0.38,7.03]$} & {$[-0.44,7.73]$} \\
& 0.27 & 0.67 & 0.84 & 0.86 \\
& {$[0.08,0.47]$} & {$[0.20,1.22]$} & {$[0.28,1.72]$} & {$[0.32,1.99]$} \\
& 0.58 & 1.32 & 1.59 & 1.62 \\
& {$[0.19,0.98]$} & {$[0.44,2.55]$} & {$[0.56,3.52]$} & {$[0.60,4.08]$} \\
\hline
\end{tabular}

Notes: We multiply the predicted change at 5, 10, 15, and 20 years provided in Panel (1) of Table 4 with the most recent age-adjusted death rates of the leading causes of deaths in 2018. The age-adjusted death rates (deaths per 100,000 U.S. standard population) for the 10 leading causes of death in the most recent year 2018 are: (1) Heart disease, 163.6; (2) Cancer, 149.1; (3) Accidents, 48.0; (4) Chronic lower respiratory disease, 39.7; (5) Stroke, 37.1; (6) Alzheimer disease, 30.5; (7) Diabetes, 21.4; (8) Kidney disease, 12.9; (9) Influenza and pneumonia 14.9; and (10) Suicide, 14.2.

other channels are likely to be at work. Possible explanations are that people engage in more dangerous activities, spend more time driving in a non-careful way, and are more subject to domestic accidents during periods of economic distress. Notice that unemployment is for us an indicator of the state of the economy. Thus, the less safe behavior and its fatal consequences do not exclusively pertain to unemployed workers, but they might arise as a result of a general equilibrium effect. Finally, an extensive literature provides evidence of an increase in suicides during times of economic distress and data are surfacing regarding worsening opioid crisis during the COVID-19 pandemic. 
Table 5: COVID-19 unemployment shocks

\begin{tabular}{lcc}
\hline & Standard deviation & Magnitude $(\%)$ \\
\hline Overall population & 3.64 & 2.90 \\
& {$[2.37,4.73]$} & {$[1.79,3.80]$} \\
African-American & 2.83 & 2.97 \\
African-American (M) & {$[1.48,4.02]$} & {$[1.48,4.37]$} \\
African-American (W) & 2.59 & 3.39 \\
& {$[1.38,3.58]$} & {$[1.71,4.79]$} \\
White & 3.71 & 3.40 \\
& {$[2.39,4.90]$} & {$[2.13,4.52]$} \\
White $(\mathrm{M})$ & 3.61 & 2.68 \\
White $(\mathrm{W})$ & {$[2.42,4.62]$} & {$[1.70,3.46]$} \\
& 3.34 & 2.79 \\
& {$[2.23,4.21]$} & {$[1.81,3.52]$} \\
& 4.91 & 3.10 \\
& {$[3.62,6.09]$} & {$[2.23,3.82]$} \\
\hline
\end{tabular}

Notes: The table provides the COVID-19 unemployment shock implied by our state-space model for overall US population and for US population classified according to race and gender. To facilitate the interpretation, we provide the scale of standard deviation as well as the actual magnitude (\%) of the shock.

\section{Impact of the COVID-19 unemployment shock}

The COVID-19 pandemic is having immediate, substantial consequences on the death rate in the United States. At the same time, it has led to a severe macroeconomic contraction. Part of this contraction can be explained in light of the shock itself, as several people autonomously decided to scale down their consumption, especially for services such as restaurant and entertainment. On top of this, lockdowns have also contributed to further reduce economic activity. These measures have arguably saved lives, reducing the contagion rate and mitigating the risk of exhaustion of health care personnel and resources. However, the severe economic contraction due to the pandemic itself and the measures used to contain it might have long-term consequences on life-expectancy and death rates. In this section, we are interested in using our VAR to assess the potential impact of the economic contraction in light of the historical relation between unemployment and human health.

\subsection{Effects on life expectancy and death rates}

What is the cumulative effect of the COVID-19 unemployment shock on life expectancy and the age-adjusted death rate at a 5-, 10-, 15-, and 20-year horizon? To answer this question, we rely on our state-space model to produce a measure of the unemployment shock experienced by the US economy. Despite the estimation sample ending in 2017, unemployment data for 2018, 2019, and 2020 are available for the overall population and for each group. Conditional on 
the posterior coefficient estimates and the 2018-2020 values of the unemployment rates, we can filter out the reduced-form shocks $\eta_{i, t}$ in (1) based on the state-space model. We can do so by treating the 2018-2020 values of the life expectancy and the death rate as missing observations.

We then apply a transformation based on the Cholesky decomposition to the inferred reduced-form shocks to back out the structural unemployment shocks. The implied COVID-19 unemployment shock distributions are provided in Table 5. This empirical approach aims at distinguishing and isolating the consequences for human health of the economic distress related to the COVID-19 pandemic as compared to the COVID-19 pandemic itself. Obviously, the original shock that led to the increase in unemployment is a health shock, but our goal here is to only consider the consequences for human health of the COVID-19-related increase in unemployment. In this context, unemployment acts as a readily available proxy for the overall economic distress.

Based on our approach, the COVID-19 unemployment shock is about 3.64 standard deviations larger (about $2.90 \%$ in magnitude) than the typical shock to the unemployment rate. We applied the same method to obtain a measure of the unemployment shock for the groups sorted by gender and race. The scale of these shocks in terms of standard deviations (or percentage points) are: 2.83 (or 2.97\%) for the African-American population, 2.59 (or 3.39\%) for African-American men, 3.71 (or 3.40\%) for African-American women, 3.61 (or 2.68\%) for the White population, 3.34 (or 2.79\%) for White men, and 4.91 (or 3.10\%) for White women. Thus, we find that, with respect to the typical unemployment shock, women (both African-American and White) have been disproportionately affected by the COVID-19 unemployment shock. This effect is particularly visible for White women, who experienced the largest shock with respect to the typical innovation, emphasizing the atypical nature of the current recession. However, when measured in terms of actual changes in the unemployment rate, African-Americans still show the largest increase in unemployment.

Table 6 reports the cumulative effect of the COVID-19 unemployment shock on life expectancy and death rates as predicted by our model at different horizons. The first row in each panel of Table 6 reports the results for the overall population. At the 15 -year horizon, the death rate is $2.43 \%$ higher and life expectancy is $0.83 \%$ lower. These numbers represent the marginal effect of the shock: they indicate the expected change in life expectancy and death rates following the COVID-19 unemployment shock keeping fixed other factors that affect these measures of well-being, like the progress in health care.

Table 6 also reveals substantial heterogeneity across genders and races. The impact on the death rate is large for all groups, but visibly larger for African-Americans. As explained above, this is in part the result of a larger shock, but also of a larger response conditional on the size of the shock. At a 15-year horizon, we expect a decline in life expectancy of $1.16 \%$ for AfricanAmerican citizens, $1.53 \%$ for African-American men, 1.32\% for African-American women, $0.75 \%$ 
Table 6: Cumulative changes of life expectancy and age-adjusted death rates over different horizons following the COVID-19 unemployment shock

\begin{tabular}{|c|c|c|c|c|}
\hline \multicolumn{5}{|c|}{ (1) Percentage change in life expectancy } \\
\hline & 5 years & 10 years & 15 years & 20 years \\
\hline Overall population & $\begin{array}{c}-0.42 \\
{[-0.95,0.01]}\end{array}$ & $\begin{array}{c}-0.80 \\
{[-1.97,0.00]}\end{array}$ & $\begin{array}{c}-0.83 \\
{[-2.27,0.00]}\end{array}$ & $\begin{array}{c}-0.83 \\
{[-2.29,0.00]}\end{array}$ \\
\hline African-American & $\begin{array}{c}-0.58 \\
{[-1.13,-0.16]}\end{array}$ & $\begin{array}{c}-1.20 \\
{[-2.64,-0.32]}\end{array}$ & $\begin{array}{c}-1.16 \\
{[-3.16,-0.25]}\end{array}$ & $\begin{array}{c}-1.09 \\
{[-3.17,-0.28]}\end{array}$ \\
\hline African-American (M) & $\begin{array}{c}-0.84 \\
{[-1.46,-0.33]}\end{array}$ & $\begin{array}{c}-1.57 \\
{[-3.06,-0.58]}\end{array}$ & $\begin{array}{c}-1.53 \\
{[-3.64,-0.52]}\end{array}$ & $\begin{array}{c}-1.47 \\
{[-3.70,-0.54]}\end{array}$ \\
\hline African-American (W) & $\begin{array}{c}-0.62 \\
{[-1.21,-0.14]}\end{array}$ & $\begin{array}{c}-1.34 \\
{[-2.97,-0.27]}\end{array}$ & $\begin{array}{c}-1.32 \\
{[-3.65,-0.16]}\end{array}$ & $\begin{array}{c}-1.21 \\
{[-3.66,-0.15]}\end{array}$ \\
\hline White & $\begin{array}{c}-0.37 \\
{[-0.94,0.10]}\end{array}$ & $\begin{array}{c}-0.72 \\
{[-2.01,0.15]}\end{array}$ & $\begin{array}{c}-0.75 \\
{[-2.34,0.16]}\end{array}$ & $\begin{array}{c}-0.76 \\
{[-2.41,0.17]}\end{array}$ \\
\hline White (M) & $\begin{array}{c}-0.40 \\
{[-0.93,0.07]}\end{array}$ & $\begin{array}{c}-0.85 \\
{[-2.14,0.09]}\end{array}$ & $\begin{array}{c}-0.94 \\
{[-2.66,0.11]}\end{array}$ & $\begin{array}{c}-0.94 \\
{[-2.85,0.12]}\end{array}$ \\
\hline White (W) & $\begin{array}{c}-0.52 \\
{[-1.28,0.16]} \\
\end{array}$ & $\begin{array}{c}-0.99 \\
{[-2.74,0.28]} \\
\end{array}$ & $\begin{array}{c}-1.01 \\
{[-3.16,0.34]}\end{array}$ & $\begin{array}{c}-1.00 \\
{[-3.15,0.35]}\end{array}$ \\
\hline \multicolumn{5}{|c|}{ (2) Percentage change in the age-adjusted death rate } \\
\hline & 5 years & 10 years & 15 years & 20 years \\
\hline Overall population & $\begin{array}{c}1.83 \\
{[0.41,3.55]}\end{array}$ & $\begin{array}{c}2.56 \\
{[0.61,5.67]}\end{array}$ & $\begin{array}{c}2.43 \\
{[0.57,5.70]}\end{array}$ & $\begin{array}{c}2.42 \\
{[0.56,5.52]}\end{array}$ \\
\hline African-American & $\begin{array}{c}2.90 \\
{[1.34,4.81]}\end{array}$ & $\begin{array}{c}4.38 \\
{[1.81,8.88]}\end{array}$ & $\begin{array}{c}3.70 \\
{[1.34,9.22]}\end{array}$ & $\begin{array}{c}3.56 \\
{[1.41,8.76]}\end{array}$ \\
\hline African-American (M) & $\begin{array}{c}2.72 \\
{[1.00,4.83]}\end{array}$ & $\begin{array}{c}4.33 \\
{[1.44,9.15]}\end{array}$ & $\begin{array}{c}3.92 \\
{[1.03,9.92]}\end{array}$ & $\begin{array}{c}3.84 \\
{[1.00,9.95]}\end{array}$ \\
\hline African-American (W) & $\begin{array}{c}3.46 \\
{[1.67,5.70]}\end{array}$ & $\begin{array}{c}5.95 \\
{[2.68,11.86]}\end{array}$ & $\begin{array}{c}5.21 \\
{[1.98,12.55]}\end{array}$ & $\begin{array}{c}4.71 \\
{[1.86,11.71]}\end{array}$ \\
\hline White & $\begin{array}{c}2.16 \\
{[0.62,4.14]}\end{array}$ & $\begin{array}{c}3.09 \\
{[0.89,6.97]}\end{array}$ & $\begin{array}{c}2.91 \\
{[0.87,7.02]}\end{array}$ & $\begin{array}{c}2.93 \\
{[0.87,6.82]}\end{array}$ \\
\hline White (M) & $\begin{array}{c}1.71 \\
{[0.14,3.54]}\end{array}$ & $\begin{array}{c}3.04 \\
{[0.34,7.20]}\end{array}$ & $\begin{array}{c}3.16 \\
{[0.37,8.47]}\end{array}$ & $\begin{array}{c}3.14 \\
{[0.33,8.72]}\end{array}$ \\
\hline White (W) & $\begin{array}{c}3.19 \\
{[0.80,5.98]}\end{array}$ & $\begin{array}{c}4.78 \\
{[1.30,10.73]}\end{array}$ & $\begin{array}{c}4.41 \\
{[1.25,11.04]}\end{array}$ & $\begin{array}{c}4.40 \\
{[1.27,10.41]}\end{array}$ \\
\hline
\end{tabular}

Notes: The table shows the predicted cumulative percentage change in life expectancy and age adjusted mortality rate at 5, 10, 15 and 20 years. We present the median values and provide the values that correspond to the $90 \%$ bands in brackets. Results are presented for the overall US population and subdivided based on race and gender.

for White citizens, $0.94 \%$ for White men, and 1.01\% for White women. At a 15-year horizon, the increases in death rates are 3.70\% for African-Americans, 3.92\% for African-American men, $5.21 \%$ for African-American women, $2.91 \%$ for Whites, $3.16 \%$ for White men, and $4.41 \%$ for White women.

To translate these percentage changes in actual changes of age-adjusted lost lives and years of life expectancy, we multiply the predicted percentage change in life expectancy and the ageadjusted mortality rate at 5, 10, 15 and 20 years provided in Table 6 with the most recent life 
Table 7: Life expectancy and deaths in 2017

\begin{tabular}{lccccc}
\hline & $\begin{array}{c}\text { Life } \\
\text { expectancy }\end{array}$ & $\begin{array}{c}\text { Age-adj. rates } \\
\text { (per million) }\end{array}$ & $\begin{array}{c}\text { Deaths } \\
\text { Crude rates } \\
\text { (per million) }\end{array}$ & Crude numbers & $\begin{array}{c}\text { Implied } \\
\text { population }\end{array}$ \\
\hline Overall population & $(\mathrm{A})$ & $(\mathrm{B})$ & $(\mathrm{C})$ & $(\mathrm{D})$ & $(\mathrm{E})$ \\
African-American & 78.6 & 73.2 & 86.4 & $2,813,503$ & $325,710,000$ \\
African-American (M) & 75.3 & 85.4 & 74.2 & 340,644 & $45,883,808$ \\
African-American (W) & 71.9 & 105.0 & 80.5 & 177,332 & $22,025,436$ \\
White & 78.5 & 70.6 & 68.5 & 163,312 & $23,858,372$ \\
White (M) & 78.8 & 73.5 & 93.7 & $2,378,385$ & $253,935,650$ \\
White (W) & 76.4 & 86.3 & 96.3 & $1,212,488$ & $125,870,081$ \\
\hline
\end{tabular}

Notes: The table summarizes the life expectancy and deaths for the overall US population and for different groups based on race (African-American vs White) and gender (men vs women) in 2017.

expectancy and age-adjusted death rate data provided in Table 7. Table 8 shows the predicted cumulative changes in life expectancy and age-adjusted death rate. Based on these data, a $0.83 \%$ decline in life expectancy translates into a decline of 0.65 life years while a $2.43 \%$ rise in death rate translates in 17.77 age-adjusted excess deaths every 100,000 citizens at a 15year horizon for the overall population. The implied declines in years of life expectancy are 0.87 for African-Americans, 1.10 for African-American men, 1.04 for African-American women, 0.59 for Whites, 0.72 for White men, and 0.82 for White women. The implied increases in age-adjusted deaths every 100,000 citizens are 31.59 for African-Americans, 41.12 for AfricanAmerican men, 36.77 for African-American women, 21.41 for White, 27.31 for White men, 27.47 for White women.

It is interesting to notice that the response of death rates for White men unfolds over a longer period of time. In the short run, White women experience a visibly larger increase in age-adjusted death rates compared to White men. However, at the 15- and 20- year horizon the change is very similar. This is the result of two factors. First, in line with the impulse responses presented above, the percentage change in death rates for white men is initially lower, but it eventually becomes larger past the 10-year horizon. Second, White men start from a less favorable death rate (86.3 for White men vs 62.4 for White women). Thus, White men eventually experience a similar change in death rates at the 15 - and 20- year horizon.

Overall, these results suggest that the COVID-19 economic distress will be followed by significant changes in mortality rates and life expectancy. Our evidence shows that excess deaths 
Table 8: Changes of life expectancy and age-adjusted deaths over different horizons following the COVID-19 unemployment shock

\begin{tabular}{|c|c|c|c|c|}
\hline \multicolumn{5}{|c|}{ (1) Change in life expectancy } \\
\hline & 5 years & 10 years & 15 years & 20 years \\
\hline Overall population & $\begin{array}{c}-0.33 \\
{[-0.75,0.01]}\end{array}$ & $\begin{array}{c}-0.63 \\
{[-1.55,0.00]}\end{array}$ & $\begin{array}{c}-0.65 \\
{[-1.78,0.00]}\end{array}$ & $\begin{array}{c}-0.66 \\
{[-1.80,0.00]}\end{array}$ \\
\hline African-American & $\begin{array}{c}-0.44 \\
{[-0.85,-0.12]}\end{array}$ & $\begin{array}{c}-0.90 \\
{[-1.98,-0.24]}\end{array}$ & $\begin{array}{c}-0.87 \\
{[-2.38,-0.19]}\end{array}$ & $\begin{array}{c}-0.82 \\
{[-2.39,-0.21]}\end{array}$ \\
\hline African-American (M) & $\begin{array}{c}-0.60 \\
{[-1.05,-0.24]}\end{array}$ & $\begin{array}{c}-1.13 \\
{[-2.20,-0.42]}\end{array}$ & $\begin{array}{c}-1.10 \\
{[-2.62,-0.38]}\end{array}$ & $\begin{array}{c}-1.06 \\
{[-2.66,-0.39]}\end{array}$ \\
\hline African-American (W) & $\begin{array}{c}-0.48 \\
{[-0.95,-0.11]}\end{array}$ & $\begin{array}{c}-1.05 \\
{[-2.33,-0.21]}\end{array}$ & $\begin{array}{c}-1.04 \\
{[-2.86,-0.13]}\end{array}$ & $\begin{array}{c}-0.95 \\
{[-2.87,-0.12]}\end{array}$ \\
\hline White & $\begin{array}{c}-0.29 \\
{[-0.74,0.08]}\end{array}$ & $\begin{array}{c}-0.57 \\
{[-1.59,0.12]}\end{array}$ & $\begin{array}{c}-0.59 \\
{[-1.85,0.13]}\end{array}$ & $\begin{array}{c}-0.60 \\
{[-1.90,0.13]}\end{array}$ \\
\hline White (M) & $\begin{array}{c}-0.30 \\
{[-0.71,0.06]}\end{array}$ & $\begin{array}{c}-0.65 \\
{[-1.63,0.07]}\end{array}$ & $\begin{array}{c}-0.72 \\
{[-2.03,0.09]}\end{array}$ & $\begin{array}{c}-0.72 \\
{[-2.18,0.09]}\end{array}$ \\
\hline White (W) & $\begin{array}{c}-0.42 \\
{[-1.04,0.13]}\end{array}$ & $\begin{array}{c}-0.81 \\
{[-2.23,0.23]}\end{array}$ & $\begin{array}{c}-0.82 \\
{[-2.56,0.27]}\end{array}$ & $\begin{array}{c}-0.82 \\
{[-2.56,0.28]}\end{array}$ \\
\hline \multicolumn{5}{|c|}{ (2) Change in the age-adjusted deaths } \\
\hline & 5 years & 10 years & 15 years & 20 years \\
\hline Overall population & $\begin{array}{c}13.39 \\
{[2.97,25.95]}\end{array}$ & $\begin{array}{c}18.73 \\
{[4.45,41.48]}\end{array}$ & $\begin{array}{c}17.77 \\
{[4.16,41.70]}\end{array}$ & $\begin{array}{c}17.71 \\
{[4.10,40.42]}\end{array}$ \\
\hline African-American & $\begin{array}{c}24.78 \\
{[11.47,41.11]}\end{array}$ & $\begin{array}{c}37.39 \\
{[15.49,75.84]}\end{array}$ & $\begin{array}{c}31.59 \\
{[11.44,78.77]}\end{array}$ & $\begin{array}{c}30.41 \\
{[12.06,74.85]}\end{array}$ \\
\hline African-American (M) & $\begin{array}{c}28.49 \\
{[10.53,50.64]}\end{array}$ & $\begin{array}{c}45.44 \\
{[15.14,95.98]}\end{array}$ & $\begin{array}{c}41.12 \\
{[10.83,104.15]}\end{array}$ & $\begin{array}{c}40.25 \\
{[10.45,104.39]}\end{array}$ \\
\hline African-American (W) & $\begin{array}{c}24.43 \\
{[11.78,40.24]}\end{array}$ & $\begin{array}{c}42.04 \\
{[18.94,83.75]}\end{array}$ & $\begin{array}{c}36.77 \\
{[13.97,88.64]}\end{array}$ & $\begin{array}{c}33.26 \\
{[13.13,82.69]}\end{array}$ \\
\hline White & $\begin{array}{c}15.86 \\
{[4.53,30.43]}\end{array}$ & $\begin{array}{c}22.68 \\
{[6.56,51.22]}\end{array}$ & $\begin{array}{l}21.41 \\
{[6.38,51.55]}\end{array}$ & $\begin{array}{c}21.52 \\
{[6.41,50.08]}\end{array}$ \\
\hline White (M) & $\begin{array}{c}14.75 \\
{[1.22,30.57]}\end{array}$ & $\begin{array}{c}26.23 \\
{[2.90,62.18]}\end{array}$ & $\begin{array}{c}27.31 \\
{[3.17,73.10]}\end{array}$ & $\begin{array}{c}27.09 \\
{[2.89,75.25]}\end{array}$ \\
\hline White (W) & $\begin{array}{c}19.87 \\
{[5.02,37.27]}\end{array}$ & $\begin{array}{c}29.82 \\
{[8.13,66.90]}\end{array}$ & $\begin{array}{c}27.47 \\
{[7.80,68.85]}\end{array}$ & $\begin{array}{c}27.44 \\
{[7.91,64.93]}\end{array}$ \\
\hline
\end{tabular}

Notes: The table shows the predicted cumulative change in life expectancy and age adjusted deaths at 5, 10, 15 and 20 years. We multiply the predicted percentage change in life expectancy and age adjusted mortality rate at 5, 10, 15 and 20 years provided in Table 6 with the most recent life expectancy and age-adjusted deaths data provided in Table 7 .

will disproportionately affect African Americans, consistent with previously published work on the impact of race on recovery post disasters and all-cause mortality, see Fothergill et al. (1999), FitzGerald and Hurst (2017), and Schroeder (2020). These figures might be a conservative projection once we recognize that the pandemic has led many workers, especially women, to exit the labor force, with the result that the measured unemployment might underestimate the real dimension of the shock to the labor market. 
Table 9: Excess deaths associated with the COVID-19 unemployment shock (per million)

\begin{tabular}{lcccc}
\hline & 5 years & 10 years & 15 years & 20 years \\
\hline Overall population & 0.13 & 0.47 & 0.84 & 1.22 \\
African-American & {$[0.03,0.24]$} & {$[0.11,0.98]$} & {$[0.19,1.83]$} & {$[0.28,2.69]$} \\
African-American $(\mathrm{M})$ & 0.03 & 0.12 & 0.20 & 0.29 \\
African-American $(\mathrm{W})$ & {$[0.01,0.05]$} & {$[0.05,0.21]$} & {$[0.09,0.42]$} & {$[0.12,0.62]$} \\
& 0.01 & 0.06 & 0.10 & 0.15 \\
White & {$[0.00,0.02]$} & {$[0.02,0.11]$} & {$[0.03,0.22]$} & {$[0.05,0.34]$} \\
& 0.02 & 0.07 & 0.13 & 0.19 \\
White $(\mathrm{M})$ & {$[0.01,0.03]$} & {$[0.03,0.13]$} & {$[0.06,0.27]$} & {$[0.08,0.41]$} \\
& 0.11 & 0.43 & 0.76 & 1.09 \\
White $(\mathrm{W})$ & {$[0.03,0.21]$} & {$[0.12,0.88]$} & {$[0.22,1.67]$} & {$[0.32,2.44]$} \\
& 0.04 & 0.19 & 0.37 & 0.56 \\
& {$[0.00,0.09]$} & {$[0.02,0.42]$} & {$[0.04,0.88]$} & {$[0.06,1.38]$} \\
& 0.08 & 0.32 & 0.56 & 0.81 \\
& {$[0.02,0.15]$} & {$[0.08,0.64]$} & {$[0.15,1.25]$} & {$[0.22,1.83]$} \\
\hline
\end{tabular}

Notes: The table provides an estimate of the excess deaths associated with the COVID-19 unemployment shock based on the CENSUS projections of the US population adjusted to account for the additional deaths resulting from the unemployment shock.

\subsection{Excess deaths}

The long-term effects of the COVID-19 related unemployment surge on the aggregate US mortality rate have not been characterized in the literature. Thus, as a last step, we compute an estimate of the excess deaths associated with the COVID-19 unemployment shock. This corresponds to the difference between the number of deaths predicted by the model with and without the unemployment shock observed in 2020 and provides a measure of the death toll due to the economic distress associated with the COVID19 pandemic.

Here, we briefly explain how we compute the excess deaths and refer the reader to Appendix D for details. In essence, our state-space model provides an estimate for the change in the age-adjusted death rate following the COVID-19 unemployment shock. Using the latest death rate as an initial value, we can construct projections for the age adjusted death rates with, $R_{t}^{u}$, and without, $R_{t}$, the unemployment shock observed in 2020. We can do this for any horizon $t>2020$. Here, we omit the group identifier $i$ for ease of exposition. Note that we use a superscript $u$ to indicate that the variable is computed taking into account the effect of the COVID-19 unemployment shock. We then need to convert $R_{t}^{u}$ and $R_{t}$ into a prediction for the crude death rates with and without the unemployment shock, $R_{c, t}^{u}$ and $R_{c, t}$, respectively. For this step, we model the historical relations between the crude and age adjusted death rates and use this historical relation to convert projections of the age-adjusted death rate into projections for the crude death rate. Specifically, we run an OLS regression of the crude death rate on an intercept and the age-adjusted death rates. Through linear transformation via the OLS coef- 
ficients, we obtain $R_{c, t}^{u}$ and $R_{c, t}$, respectively. Our results are robust to alternative approaches to convert age-djusted death rates into crude death rates.

Finally, we require long-run projection of the US population. We treat the Census Bureau projection as the projection consistent with the model absent the unemployment shock. We then reconstruct the alternative projection based on the change in the death rate as predicted by the model. In sum, we compute the excess deaths $E D_{t}^{u}$ as:

$$
E D_{t}^{u}=R_{c, t}^{u} P_{t}^{u}-R_{c, t} P_{t}
$$

where $R_{c, t}^{u}$ is the predicted crude death rate with the unemployment shock, $R_{c, t}$ is the predicted crude death rate without the unemployment shock, $P_{t}^{u}$ is the population projection with the unemployment shock, $P_{t}$ is the population projection without the unemployment shock (available from the Census Bureau).

Table 9 provides the respective numbers for the overall population and the different groups identified based on race and gender. For the overall population, the increase in the death rate following the COVID-19 pandemic implies a staggering 0.84 and 1.22 million excess deaths over the next 15 and 20 years, respectively. For African-Americans, we estimate 200 thousand and 290 thousand excess deaths over the next 15 and 20 years, respectively. For White, we estimate 0.76 and 1.09 million excess deaths over the next 15 and 20 years, respectively. These numbers are roughly equally split ( $40 \%$ to $60 \%$ ) between men and women. These numbers indicate that the consequences of the pandemic might go well beyond the deaths directly caused by the disease. In fact, the order of magnitudes are such that the long-term effects of economic distress might end up being larger than the direct impact of the pandemic.

As explained above, African-Americans tend to experience larger unemployment shocks and a larger response for a given size of the shocks. The COVID-19 recession has been atypical so far to the extent that it affected white women more than the typical shock to unemployment. However, in absolute terms African-Americans still experienced a larger shock. This implies that in relative terms, they might suffer larger consequences as a result of economic distress. To see this, it is useful to rescale the expected excess deaths based on the projected population of the different groups. The numbers of excess deaths presented above correspond to $0.38 \%$ and $0.52 \%$ of the projected African-American population at the 15- and 20-year horizons, and $0.28 \%$ and $0.40 \%$ of the projected White population at the 15- and 20-year horizons, respectively. Due to data limitations, we cannot further refine our analysis to distinguish between Hispanics and non-Hispanics (a distinction based on heritage instead of race).

While the extent of the long-term excess mortality related to coronavirus crisis is staggering, several considerations are in order. First, the additional number of lives that would have been lost secondary to COVID-19 acute illness and health care resources exhaustion if lockdowns had not been implemented is estimated to be over 100,000 in the US alone, Fothergill et al. 
(1999), Stone (2020), and Emanuel et al. (2020). Second, our analysis makes a number of implicit assumptions based on historical data regarding the time and severity of the recession. It is important to keep in mind the significant amount of uncertainty around this variable. It is possible that the economy will recover faster than in the past. Furthermore, a shift in economic and social policies can affect the duration and severity of the recession, and consequently modify our excess mortality estimates, Bianchi and Melosi (2017). Third, based on emerging data, it is likely that the limited access to health care during the lockdown, temporary discontinuation of preventive care interventions, massive loss of employer-provided health insurance coverage, and the lingering concern of the population about seeking medical care out to fear of contracting COVID-19 will impact mortality rates and life expectancy even more severely, Garfield et al. (2020) and Sharpless (2020). Fourth, this is the first recession with the Affordable Care Act (ACA) in place, a critical resource to mitigate the effects of unemployment on citizens wellbeing, see Gruber and Sommers (2020). Thus, there are factors that could make the projections presented here better, but there are also factors that could make them worse.

Despite these caveats, it is important to emphasize that our results are in line with studies that take a completely different methodological approach and focus on specific cohorts or individuals. For example, Schwandt and von Wachter (2020) argue that cohorts coming of age during a deep recession suffer increases in mortality later in their middle age. von Wachter (2020) focuses on the effects of the COVID-19 recession for mortality rates of vulnerable job losers and labor market entrants and also finds that the losses in potential life years due to unemployment could be substantially larger than those from deaths directly due to COVID-19. With respect to these studies, our time-series approach allows for the possibility that the state of the economy, as captured by the unemployment rate, might affect the general population through indirect channels such as income, poverty rates, crime rates. It is nevertheless reinsuring that the two different methodological approaches lead to similar conclusions about the long-term impact of the COVID-19 recession.

Our analysis focuses on the consequences of economic distress on mortality rates. It is entirely possible that the COVID-19 pandemic will become endemic and that those who contracted the disease might suffer from long-term illness due to the collateral effects of COVID-19. It is much harder to capture this second health channel due to the lack of data. Focusing on the consequences of the recession is relatively easier because we can learn from previous recessions. In this respect, it is worth emphasizing that unlike the Spanish flu of 1918, the younger portion of the population has been less affected by an increase in mortality rates as a result of the COVID-19 pandemic. Thus, we should expect that a large portion of the population that sufferred the economic consequences of the recession might also encounter the long-term health consequences of the recession going forward. This consideration can be phrased in terms of the harvesting vs scarring debate: The young population has not been harvested during the 
COVID-19 pandemic, but it might carry the scars associated with the COVID-19 recession.

Our results have three important policy implications for this and future pandemics. First, it would be desirable to study and implement health policy measures to guarantee activities remain open with minimal risks to workers and public, whenever possible. For instance, implementation of universal masking and social distancing policies at a large health care system in the Northeastern US resulted in a decline of SARS-CoV-2 transmission across health care workers, despite the high-risk setting (see Wang et al. (2020)). Second, it is of utmost importance to facilitate routine preventive care and health care access for the whole US population, including the over 20 million Americans who lost employer-provided health care coverage, Garfield et al. (2020) and Gruber and Sommers (2020). Third, policy interventions meant to reduce the economic impact of the recession are likely to also contribute to save lives.

\section{Conclusion}

We examine the historical relation between life-expectancy, death-rates, and unemployment for the overall US population and groups organized based on race and gender. We use a VAR that allows for observation errors and we find that increases in unemployment are followed by statistically significant increases in death rates and declines in life-expectancy. A sizable fraction of the variation of these two variables can be accounted by unemployment shocks.

We then use this historical relation to form predictions about the potential impact of the recession caused by the COVID-19 pandemic on human health. Our results suggest that the toll of lives claimed by the SARS-CoV-2 virus far exceeds those immediately related to the acute COVID-19 critical illness and that the recession caused by the pandemic can jeopardize population health for the next two decades. Based on our findings, African American citizens and women will be suffering more profoundly from the coronavirus-driven recession, compounding their disproportionate adverse outcome in the setting of acute SARS-CoV-2 infection, Garg et al. (2020). In light of our analysis, large, sustained, and swift government maneuvers to support the currently unemployed labor force and to abate unemployment itself will be as important as the massive efforts focused on limiting and eventually eradicating transmission of SARS-CoV-2 with effective vaccination strategies.

\section{References}

Acemoglu, Daron, Victor Chernozhukov, Ivan Werning, and Michael D. Whinston,

"Optimal Targeted Lockdowns in a Multi-Group SIR Model," 2020. NBER Working Paper 27102. 
Alvarez, Fernando E., David Argente, and Francesco Lippi, "A Simple Planning Problem for COVID-19 Lockdown," 2020. NBER Working Paper 26981.

Anderson, Roy M, Hans Heesterbeek, Don Klinkenberg, and T Derdre Hollingsworth, "How will country-based mitigation measures influence the course of the COVID-19 epidemic?," The Lancet, 2020, 395 (10228), 931-934.

Böckerman, Petri and Pekka Ilmakunnas, "Unemployment and self-assessed health: evidence from panel data.," Health economics, Feb 2009, 18, 161-79.

Barro, Robert J., Jose F. Ursua, and Joanna Weng, "The Coronavirus and the Great Influenza Pandemic: Lessons from the "Spanish Flu" for the Coronavirus's Potential Effects on Mortality and Economic Activity," 2020. NBER Working Paper 26866.

Bianchi, Francesco and Leonardo Melosi, "Escaping the Great Recession," American Economic Review, 2017, 107 (4), 1030-1058.

Brenner, M. Harvey, "Commentary: Economic growth is the basis of mortality rate decline in the 20th century-experience of the United States 1901-2000," Int J Epidemiol, May 2005, 34 (6), 1214-1221.

Browning, Martin, Anne Moller Dano, and Eskil Heinesen, "Job Displacement and Stress-related Health Outcomes," Health Econ., 2006, 15, 1061-10754.

Carter, C. K. and R. Kohn, "On Gibbs Sampling for State Space Models," Biometrika, 1994, 81 (3), 541-553.

CDC, "COVID Data Tracker," December 2020. Accessed December 16, 2020.

Coibion, Olivier, Yuriy Gorodnichenko, and Michael Weber, "The Cost of the Covid19 Crisis: Lockdowns, Macroeconomic Expectations, and Consumer Spending," 2020. NBER Working Paper 27141.

Coile, Courtney C., Phillip B. Levine, and Robin McKnight, "Recessions, Older Workers, and Longevity: How Long Are Recessions Good for Your Health?," American Economic Journal: Economic Policy, 2014, 6 (3), 92-119.

Davies, Nicholas G., Adam J. Kucharski, Rosalind M. Eggo, Amy Gimma, W. John Edmunds, and Centre for the Mathematical Modelling of Infectious Diseases COVID-19 working group, "Effects of non-pharmaceutical interventions on COVID-19 cases, deaths, and demand for hospital services in the UK: a modelling study," The Lancet. Public health, July 2020, 5 (32502389), 375-385. 
Durbin, James and Siem Jan Koopman, Time Series Analysis by State Space Methods, second ed., Oxford University Press, 2001.

Eichenbaum, Martin, Sergio Rebelo, and Mathias Trabandt, "The Macroeconomics of Epidemics," 2020. NBER Working Paper 26882.

_ , _, and _, "The Macroeconomics of Testing and Quarantining," 2020. NBER Working Paper 27104.

Emanuel, Ezekiel J., Govind Persad, Ross Upshur, Beatriz Thome, Michael Parker, Aaron Glickman, Cathy Zhang, Connor Boyle, Maxwell Smith, and James P. Phillips, "Fair Allocation of Scarce Medical Resources in the Time of Covid-19," N Engl J Med, November 2020, 382 (21), 2049-2055.

FitzGerald, Chloë and Samia Hurst, "Implicit bias in healthcare professionals: a systematic review," BMC Medical Ethics, March 2017, 18 (1), 19.

Fothergill, A., E. G. Maestas, and J. D. Darlington, "Race, ethnicity and disasters in the United States: a review of the literature.," Disasters, Jun 1999, 23, 156-73.

Garfield, Rachel, Gary Claxton, Anthony Damico, and Larry Levitt, "Eligibility for ACA Health Coverage Following Job Loss," May 2020. https://www.kff.org/coronavirus-covid-19/issue-brief/ eligibility-for-aca-health-coverage-following-job-loss/.

Garg, Shikha, Lindsay Kim, Michael Whitaker, and et al., "Hospitalization Rates and Characteristics of Patients Hospitalized with Laboratory-Confirmed Coronavirus Disease 2019 - COVID-NET, 14 States, March 1-30, 2020.," Morbidity and Mortality Weekly Report, 2020, 69 (15), 458-464.

Giannone, Domenico, Michele Lenza, and Giorgio E. Primiceri, "Prior Selection for Vector Autoregressions," Review of Economics and Statistics, 2015, 97 (2), 436-451.

Glover, Andrew, Jonathan Heathcote, Dirk Krueger, and Jose-Victor Rios-Rull, "Health versus Wealth: On the Distributional Effects of Controlling a Pandemic," 2020. NBER Working Paper 27046.

Gorbalenya, Alexander E., Susan C. Baker, Ralph S. Baric, Raoul J. de Groot, Christian Drosten, Anastasia A. Gulyaeva, Bart L. Haagmans, Chris Lauber, Andrey M. Leontovich, Benjamin W. Neuman, Dmitry Penzar, Stanley Perlman, Leo L. M. Poon, Dmitry V. Samborskiy, Igor A. Sidorov, Isabel Sola, John Ziebuhr, and Coronaviridae Study Group of the International Committee on 
Taxonomy of Viruses, "The species Severe acute respiratory syndrome-related coronavirus: classifying 2019-nCoV and naming it SARS-CoV-2," Nature Microbiology, April 2020, 5 (4), $536-544$.

Gordon, Sarah H. and Benjamin D. Sommers, "Recessions, Poverty, and Mortality in the United States," American Journal of Health Economics, 2016, 2 (4), 489-510.

Gruber, Jonathan and Benjamin D. Sommers, "Paying for Medicaid - State Budgets and the Case for Expansion in the Time of Coronavirus," N Engl J Med, November 2020, $382(24), 2280-2282$.

Guan, Weijie, Zheng yi Ni, Yu Hu, Wen hua Liang, Chun quan Ou, Jian xing He, Lei Liu, Hong Shan, Chun liang Lei, David S. C. Hui, Bin Du, Lan juan Li, Guang Zeng, Kwok-Yung Yuen, Ru chong Chen, Chun li Tang, Tao Wang, Ping yan Chen, Jie Xiang, Shi yue Li, Jin lin Wang, Zi jing Liang, Yi xiang Peng, Li Wei, Yong Liu, Ya hua Hu, Peng Peng, Jian ming Wang, Ji yang Liu, Zhong Chen, Gang Li, Zhi jian Zheng, Shao qin Qiu, Jie Luo, Chang jiang Ye, Shao yong Zhu, and Nan shan Zhong, "Clinical Characteristics of Coronavirus Disease 2019 in China," N Engl J Med, November 2020, 382 (18), 1708-1720.

Hall, Robert E., Charles I. Jones, and Peter J. Klenow, "Trading Off Consumption and COVID-19 Deaths," 2020. NBER Working Paper 27340.

Jones, Callum J., Thomas Philippon, and Venky Venkateswaran, "Optimal Mitigation Policies in a Pandemic: Social Distancing and Working from Home," 2020. NBER Working Paper 26984.

Jorda, Oscar, Sanjay R. Singh, and Alan M. Taylor, "Longer-run Economic Consequences of Pandemics," 2020. NBER Working Paper 26934.

Kaplan, Greg, Benjamin Moll, and Giovanni L. Violante, "The Great Lockdown and the Big Stimulus: Tracing the Pandemic Possibility Frontier for the U.S.," 2020. NBER Working Paper 27794.

Krueger, Dirk, Harald Uhlig, and Taojun Xie, "Macroeconomic Dynamics and Reallocation in an Epidemic: Evaluating the "Swedish Solution"," 2020. NBER Working Paper 27047.

Leung, Nancy H. L., Daniel K. W. Chu, Eunice Y. C. Shiu, Kwok-Hung Chan, James J. McDevitt, Benien J. P. Hau, Hui-Ling Yen, Yuguo Li, Dennis K. M. Ip, J. S. Malik Peiris, Wing-Hong Seto, Gabriel M. Leung, Donald K. Milton, 
and Benjamin J. Cowling, "Respiratory virus shedding in exhaled breath and efficacy of face masks," Nature Medicine, May 2020, 26 (5), 676-680.

Li, Ruiyun, Sen Pei, Bin Chen, Yimeng Song, Tao Zhang, Wan Yang, and Jeffrey Shaman, "Substantial undocumented infection facilitates the rapid dissemination of novel coronavirus (SARS-CoV-2)," Science, 2020, 368 (6490), 489-493.

Ludvigson, Sydney C., Sai Ma, and Serena Ng, "COVID-19 and The Macroeconomic Effects of Costly Disasters," 2020. NBER Working Paper 26987.

McKee-Ryan, F., Z. Song, C. R. Wanberg, and A. J. Kinicki, "Psychological and Physical Well-Being During Unemployment: A Meta-Analytic Study," Journal of Applied Psychology, 2005, 90 (1), 53-76.

Moghadas, Seyed M., Meagan C. Fitzpatrick, Pratha Sah, Abhishek Pandey, Affan Shoukat, Burton H. Singer, and Alison P. Galvani, "The implications of silent transmission for the control of COVID-19 outbreaks," Proceedings of the National Academy of Sciences, 2020, 117 (30), 17513-17515.

Mulas-Granados, Carlos, "Fiscal Adjustments and the Short-Term Trade-Off between Economic Growth and Equality," Hacienda Publica Espanola/ Review of Public Economics, 2005, $172(1), 61-92$.

Noelke, Clemens and Mauricio Avendano, "Who Suffers During Recessions? Economic Downturns, Job Loss, and Cardiovascular Disease in Older Americans," Am J Epidemiol, November 2015, 182 (10), 873-882.

Pan, An, Li Liu, Chaolong Wang, Huan Guo, Xingjie Hao, Qi Wang, Jiao Huang, Na He, Hongjie Yu, Xihong Lin, Sheng Wei, and Tangchun Wu, "Association of Public Health Interventions With the Epidemiology of the COVID-19 Outbreak in Wuhan, China," JAMA, 05 2020, 323 (19), 1915-1923.

Roelfs, David J., Eran Shor, Aharon Blank, and Joseph E. Schwartz, "Misery loves company? A meta-regression examining aggregate unemployment rates and the unemployment-mortality association.," Annals of epidemiology, May 2015, 25, 312-22.

Ruhm, Christopher J., "Are Recessions Good for Your Health," Quarterly Journal of Economics, 2000, 115 (2), 617-650.

_ , "Good Times Make You Sick," Journal of Health Economics, 2003, 22 (4), 637-658.

_ , "Healthy Living in Hard Times," Journal of Health Economics, 2005, 24 (2), 341-363. 
_ , "Understanding the Relationship Between Macroeconomic Conditions and Health," in Andrew M Jones, ed., Elgar Companion to Health Economics, Edward Elgar, 2012, pp. 5-14. 2nd Edition.

_ , "Recessions, Healthy No More?," Journal of Health Economics, 2015, 42, 17-28.

Schroeder, Steven A., "We Can Do Better - Improving the Health of the American People," N Engl J Med, November 2020, 357 (12), 1221-1228.

Schwandt, Hannes and Till von Wachter, "Socioeconomic Decline and Death: Midlife Impacts of Graduating in a Recession," 2020. NBER Working Paper 26638.

Sharpless, Norman E., "COVID-19 and cancer," Science, June 2020, 368 (6497), 1290.

Sims, Christopher A., "Macroeconomics and Reality.," Econometrica, 1980, 48 (1), 1-48.

Stone, John R., "Social Justice, Triage, and COVID-19: Ignore Life-years Saved.," in "Medical care," Vol. 58 Jul 2020, pp. 579-581.

Sullivan, Daniel and Till von Wachter, "Job Displacement and Mortality: An Analysis Using Administrative Data," Quarterly Journal of Economics, 2009, 124 (3), 1265-1306.

von Wachter, Till, "Lost Generations: Long-Term Effects of the COVID-19 Crisis on Job Losers and Labour Market Entrants, and Policy Options," 2020. Fiscal Studies, forthcoming.

Wang, Xiaowen, Enrico G. Ferro, Guohai Zhou, Dean Hashimoto, and Deepak L. Bhatt, "Association Between Universal Masking in a Health Care System and SARS-CoV-2 Positivity Among Health Care Workers," JAMA, 2020, 324 (7), 703-704.

WHO, "WHO Coronavirus Disease (COVID-19) Dashboard.," December 2020. Accessed December 16, 2020.

Wilson, S.H. and G.M. Walker, "Unemployment and Health: A Review," Public Health, 1993, 107, 153-162. 


\section{Appendix:}

\section{The Long-Term Impact of the COVID-19 Unemployment Shock on Life Expectancy and Mortality Rates}

\section{A State-Space Representation}

We denote the "log average life expectancy," "log age-adjusted mortality rate," and the "unemployment rate" as $y_{1, t}, y_{2, t}, y_{3, t}$, respectively. We allow for (potentially serially correlated but mutually uncorrelated) measurement errors $\epsilon_{i, t}$ in the level series. The joint dynamics of the growth rates of $z_{1, t}$ and $z_{2, t}$ and the level of $z_{3, t}$ follow a VAR(1). Put together,

$$
\begin{aligned}
& {\left[\begin{array}{l}
y_{1, t} \\
y_{2, t} \\
y_{3, t}
\end{array}\right]=\left[\begin{array}{l}
z_{1, t} \\
z_{2, t} \\
z_{3, t}
\end{array}\right]+\left[\begin{array}{l}
\epsilon_{1, t} \\
\epsilon_{2, t} \\
\epsilon_{3, t}
\end{array}\right], \quad \epsilon_{i, t}=\rho_{i} \epsilon_{i, t-1}+u_{i, t}, \quad u_{i, t} \sim N\left(0, \sigma_{i}^{2}\right)} \\
& {\left[\begin{array}{c}
\Delta z_{1, t} \\
\Delta z_{2, t} \\
z_{3, t}
\end{array}\right]=\left[\begin{array}{l}
\mu_{1} \\
\mu_{2} \\
\mu_{3}
\end{array}\right]+\left[\begin{array}{lll}
\phi_{11} & \phi_{12} & \phi_{13} \\
\phi_{21} & \phi_{22} & \phi_{23} \\
\phi_{31} & \phi_{32} & \phi_{33}
\end{array}\right]\left[\begin{array}{c}
\Delta z_{1, t-1} \\
\Delta z_{2, t-1} \\
z_{3, t-1}
\end{array}\right]+\left[\begin{array}{c}
\eta_{1, t} \\
\eta_{2, t} \\
\eta_{3, t}
\end{array}\right], \quad \eta_{t} \sim N(0, \Sigma) .}
\end{aligned}
$$

Note that we can re-express (A-1) by

$$
\begin{aligned}
& y_{t}=z_{t}+\epsilon_{t} \\
& z_{t}=\mu+(M+\Phi) z_{t-1}-\Phi M z_{t-2}+\eta_{t}
\end{aligned}
$$

where

$$
\left[\begin{array}{c}
\Delta z_{1, t-1} \\
\Delta z_{2, t-1} \\
z_{3, t-1}
\end{array}\right]=z_{t}-M z_{t-1}, \quad M z_{t}=\left[\begin{array}{lll}
1 & 0 & 0 \\
0 & 1 & 0 \\
0 & 0 & 0
\end{array}\right]\left[\begin{array}{c}
z_{1, t} \\
z_{2, t} \\
z_{3, t}
\end{array}\right]=\left[\begin{array}{c}
z_{1, t} \\
z_{2, t} \\
0
\end{array}\right]
$$

The state space representation is

$$
\begin{aligned}
& y_{t}=\Gamma s_{t} \\
& s_{t}=C+\Lambda s_{t-1}+\varepsilon_{t}, \quad \varepsilon_{t} \sim N(0, \Omega)
\end{aligned}
$$

where

$$
\begin{aligned}
& \Gamma=\left[\begin{array}{lll}
I & I & 0
\end{array}\right], \quad S_{t}=\left[\begin{array}{c}
\epsilon_{t} \\
z_{t} \\
z_{t-1}
\end{array}\right], \quad C=\left[\begin{array}{c}
0 \\
\mu \\
0
\end{array}\right], \quad \Lambda=\left[\begin{array}{ccc}
\rho & 0 & 0 \\
0 & M+\Phi & -\Phi M \\
0 & I & 0
\end{array}\right] \\
& M=\left[\begin{array}{lll}
1 & 0 & 0 \\
0 & 1 & 0 \\
0 & 0 & 0
\end{array}\right], \quad \varepsilon_{t}=\left[\begin{array}{c}
u_{t} \\
\eta_{t} \\
0
\end{array}\right], \quad \Omega=\left[\begin{array}{ccc}
\sigma^{2} & 0 & 0 \\
0 & \Sigma & 0 \\
0 & 0 & 0
\end{array}\right], \quad \sigma^{2}=\left[\begin{array}{ccc}
\sigma_{1}^{2} & 0 & 0 \\
0 & \sigma_{2}^{2} & 0 \\
0 & 0 & \sigma_{3}^{2}
\end{array}\right] \text {. }
\end{aligned}
$$

For ease of exposition, we collect parameters in

$$
\Theta_{\epsilon}=\{\rho, \sigma\}, \quad \Theta_{z}=\{\mu, \Phi, \Sigma\} .
$$




\section{B Gibbs Sampler}

We use the Gibbs sampler to estimate the model unknowns. We rely on the state-space representation of (A-4). For the $j$ th iteration,

- Run Kalman smoother to generate $Z_{0: T}^{j}$ and $\epsilon_{1: T}^{j}$ conditional on $\Theta_{\epsilon}^{j}$, $\Theta_{z}^{j}$ : This is explained in Section B.1.

- Obtain posterior estimates of $\Theta_{\epsilon}^{j+1}, \Theta_{z}^{j+1}$ from the MNIW conditional on $Z_{0: T}^{j}$ and $\epsilon_{1: T}^{j}$ : This is explained in Section B.2.

\section{B.1 Kalman smoother}

We rely on the state-space representation (A-4). Conditional on the $j$ th draw of $\Theta_{\epsilon}^{j}$, $\Theta_{z}^{j}$, we apply the standard Kalman filter as described in Durbin and Koopman (2001). Suppose that the distribution of

$$
s_{t-1} \mid\left\{y_{1: t-1}, \Theta_{\epsilon}^{j}, \Theta_{z}^{j}\right\} \sim N\left(s_{t-1 \mid t-1}, P_{t-1 \mid t-1}\right) .
$$

Then, the Kalman filter forecasting and updating equations take the form

$$
\begin{aligned}
s_{t \mid t-1} & =C+\Lambda s_{t-1 \mid t-1} \\
P_{t \mid t-1} & =\Lambda P_{t-1 \mid t-1} \Lambda^{\prime}+\Omega \\
s_{t \mid t} & =s_{t \mid t-1}+\left(\Gamma P_{t \mid t-1}\right)^{\prime}\left(\Gamma P_{t \mid t-1} \Gamma^{\prime}\right)^{-1}\left(y_{t}-\Gamma s_{t \mid t-1}\right) \\
P_{t \mid t} & =P_{t \mid t-1}-\left(\Gamma P_{t \mid t-1}\right)^{\prime}\left(\Gamma P_{t \mid t-1} \Gamma^{\prime}\right)^{-1}\left(\Gamma P_{t \mid t-1}\right)
\end{aligned}
$$

In turn,

$$
s_{t} \mid\left\{y_{1: t}, \Theta_{\epsilon}^{j}, \Theta_{z}^{j}\right\} \sim N\left(s_{t \mid t}, P_{t \mid t}\right) .
$$

Next, the backward smoothing algorithm developed by Carter and Kohn (1994) is applied to recursively generate draws from the distributions $s_{t} \mid\left(S_{t+1: T}, Y_{1: T}, \Theta_{\epsilon}^{j}, \Theta_{z}^{j}\right)$ for $t=T-1, T-$ $2, \ldots, 1$. The last element of the Kalman filter recursion provides the initialization for the simulation smoother:

$$
\begin{aligned}
s_{t \mid t+1} & =s_{t \mid t}+P_{t \mid t} \Lambda^{\prime} P_{t+1 \mid t}^{-1}\left(s_{t+1}-C-\Lambda s_{t \mid t}\right) \\
P_{t \mid t+1} & =P_{t \mid t}-P_{t \mid t} \Lambda^{\prime} P_{t+1 \mid t}^{-1} \Lambda P_{t \mid t} \\
s_{t}^{j} & \sim N\left(s_{t \mid t+1}, P_{t \mid t+1}\right), \quad t=T-1, T-2, \ldots, 1 .
\end{aligned}
$$

In sum, we obtain smoothed estimates of $Z_{0: T}^{j}$ and $\epsilon_{1: T}^{j}$.

\section{B.2 Posterior draw}

We treat the smoothed estimates of $Z_{0: T}^{j}$ and $\epsilon_{1: T}^{j}$ as data points. The objective is to draw $\Theta_{\epsilon}^{j+1}$ and $\Theta_{z}^{j+1}$. 


\section{B.2.1 VAR coefficients}

For ease of exposition, we omit the superscript $j$ below. Conditional on $Z_{0: T}$, we transform $z_{t}$ into $x_{t}$ via

$$
x_{t}=z_{t}-M z_{t-1}
$$

for $t \in\{1, \ldots, T\}$. We re-express the VAR as

$$
x_{t}^{\prime}=\underbrace{\left[\begin{array}{ll}
1 & x_{t-1}^{\prime}
\end{array}\right]}_{w_{t}^{\prime}} \underbrace{\left[\begin{array}{c}
\mu \\
\Phi^{\prime}
\end{array}\right]}_{\beta}+\eta_{t}^{\prime}, \quad \eta_{t} \sim N(0, \Sigma) .
$$

Define $X=\left[x_{p}, \ldots, x_{T}\right]^{\prime}, W=\left[w_{p}, \ldots, w_{T}\right]^{\prime}$, and $\eta=\left[\eta_{p}, \ldots, \eta_{T}\right]^{\prime}$ conditional on the initial $p=1$ observations. If the prior distributions for $\beta$ and $\Sigma$ are

$$
\beta \mid \Sigma \sim M N\left(\underline{\beta}, \Sigma \otimes\left(\underline{V}_{\beta} \xi\right)\right), \quad \Sigma \sim I W(\underline{\Psi}, \underline{d}),
$$

then because of the conjugacy the posterior distributions can be expressed as

$$
\beta \mid \Sigma \sim M N\left(\bar{\beta}, \Sigma \otimes \bar{V}_{\beta}\right), \quad \Sigma \sim I W(\bar{\Psi}, \bar{d})
$$

where

$$
\begin{aligned}
\bar{\beta} & =\left(W^{\prime} W+\left(\underline{V}_{\beta} \xi\right)^{-1}\right)^{-1}\left(W^{\prime} X+\left(\underline{V}_{\beta} \xi\right)^{-1} \underline{\beta}\right), \\
\bar{V}_{\beta} & =\left(W^{\prime} W+\left(\underline{V}_{\beta} \xi\right)^{-1}\right)^{-1}, \\
\bar{\Psi} & =(X-W \bar{\beta})^{\prime}(X-W \bar{\beta})+(\bar{\beta}-\underline{\beta})^{\prime}\left(\underline{V}_{\beta} \xi\right)^{-1}(\bar{\beta}-\underline{\beta})+\underline{\Psi}, \\
\bar{d} & =T-p+\underline{d} .
\end{aligned}
$$

We follow the exposition in Giannone et al. (2015) in which $\xi$ is a scalar parameter controlling the tightness of the prior information in (A-10). For instance, prior becomes more informative when $\xi \rightarrow 0$. In contrast, when $\xi=\infty$, then it is easy to see that $\bar{\beta}=\hat{\beta}$, i.e., an OLS estimate.

In sum, we draw $\beta^{j+1}$ and $\Sigma^{j+1}$ from (A-11). Hence, we obtain $\Theta_{z}^{j+1}=\left\{\mu^{j+1}, \Phi^{j+1}, \Sigma^{j+1}\right\}$.

\section{B.2.2 Measurement error variances}

Conditional on $\epsilon_{1: T}^{j}=\left\{\epsilon_{1}, \epsilon_{2}, \epsilon_{3}\right\}^{j}$, the objective is to draw $\Theta_{\epsilon}^{j+1}=\left\{\rho_{i}^{j+1}, \sigma_{i}^{2, j+1}\right\}$. For ease of exposition, we omit the superscript $j$ below. Note that

$$
\epsilon_{i, t}=\rho_{i} \epsilon_{i, t-1}+u_{i, t}, \quad u_{i, t} \sim N\left(0, \sigma_{i}^{2}\right) .
$$

In this analysis, we set $\rho_{i}=0$ for $i \in\{1,2,3\}$ and $\sigma_{3}^{2}=0$. Thus, for $i \in\{1,2\}$, we can draw

$$
\sigma_{i}^{2} \sim \operatorname{IG}\left(\bar{T}_{i}, \bar{\nu}_{i}\right)
$$

where

$$
\bar{T}_{i}=\underline{T}_{i}+\frac{T}{2}, \quad \bar{\nu}_{i}=\underline{\nu}_{i}+\frac{\epsilon_{i}^{\prime} \epsilon_{i}}{2} .
$$

In sum, we obtain $\Theta_{\epsilon}^{j+1}$ from (A-14). 
Table A-1: The role of measurement error variances

\begin{tabular}{llll}
\hline & $50 \%$ & {$[5 \%$,} & $95 \%]$ \\
\hline$\Delta$ avg. life expectancy & 0.19 & {$[0.05$,} & 0.85 \\
$\Delta$ age-adj. death rate & 0.19 & {$[0.06$,} & $0.78]$ \\
\hline
\end{tabular}

Notes: We simulate $\left\{\beta^{j}, \Sigma^{j}\right\}_{j=1}^{N}$ based on (A-10) and (A-16) and $\left\{\sigma_{1}^{j}, \sigma_{2}^{j}\right\}_{j=1}^{N}$ based on (A-14) and (A-16). We then compute the unconditional variance of (A-9) and of $y_{t}-M y_{t-1}$ (which includes the measurement errors and the VAR). The table reports the quantiles of the fraction of variance explained by the VAR.

\section{Prior Predictive Check}

\section{C.1 Prior distributions}

We set the priors for the VAR coefficients (A-10) as

$$
\begin{aligned}
& \underline{\beta}=\left[\begin{array}{ccc}
0 & 0 & 0 \\
0.9 & 0 & 0 \\
0 & 0.9 & 0 \\
0 & 0 & 0.9
\end{array}\right], \quad \underline{V}_{\beta}=\left[\begin{array}{cccc}
1 & 0 & 0 & 0 \\
0 & 1 & 0 & 0 \\
0 & 0 & 1 & 0 \\
0 & 0 & 0 & 1
\end{array}\right], \quad \xi=5000 \\
& \underline{\Psi}=(1 \mathrm{e}-4) \times\left[\begin{array}{ccc}
0.5 & 0 & 0 \\
0 & 10 & 0 \\
0 & 0 & 10
\end{array}\right], \quad \underline{d}=25 .
\end{aligned}
$$

The priors for the measurement error variances are

$$
\begin{aligned}
& \underline{T}_{1}=30, \quad \underline{\nu}_{1}=0.002 \\
& \underline{T}_{2}=30, \quad \underline{\nu}_{2}=0.010 .
\end{aligned}
$$

\section{C.2 Impulse response}

We simulate $\left\{\beta^{j}, \Sigma^{j}\right\}_{j=1}^{N}$ based on (A-10) and (A-16) and compute impulse responses to a one-standard-deviation shock to unemployment via Cholesky decomposition. The results are provided in Figure A-1.

\section{C.3 Measurement error variance}

We simulate $\left\{\beta^{j}, \Sigma^{j}\right\}_{j=1}^{N}$ based on (A-10) and (A-16) and $\left\{\sigma_{1}^{j}, \sigma_{2}^{j}\right\}_{j=1}^{N}$ based on (A-14) and (A-16). We then compute the unconditional variance of (A-9) and of $y_{t}-M y_{t-1}$ (which includes the measurement errors and the VAR). Table A-1 reports the quantiles of the fraction of variance explained by the VAR. 
Figure A-1: Impulse responses to a one-standard-deviation shock to unemployment

(1) Cholesky identification in which unemployment rate is placed last

$\Delta$ Avg. life expectancy

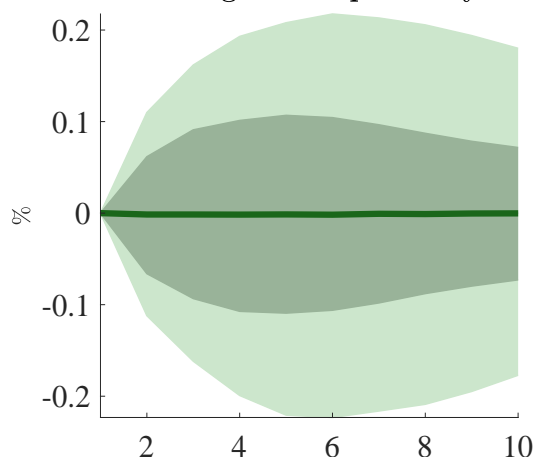

$\Delta$ Age-adj. death rate

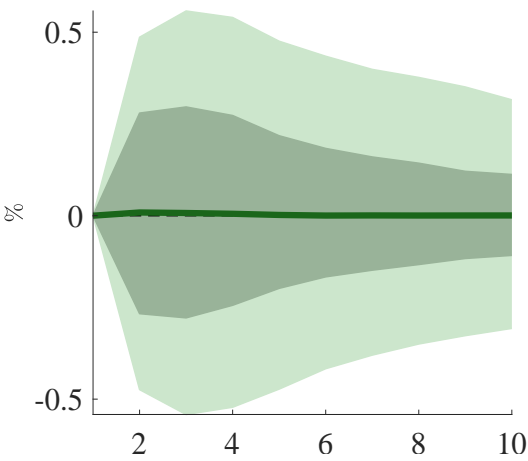

Unemployment rate

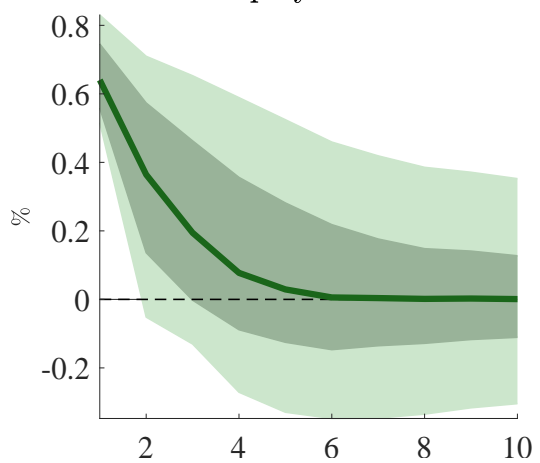

(2) Cholesky identification in which unemployment rate is placed first

$\Delta$ Avg. life expectancy

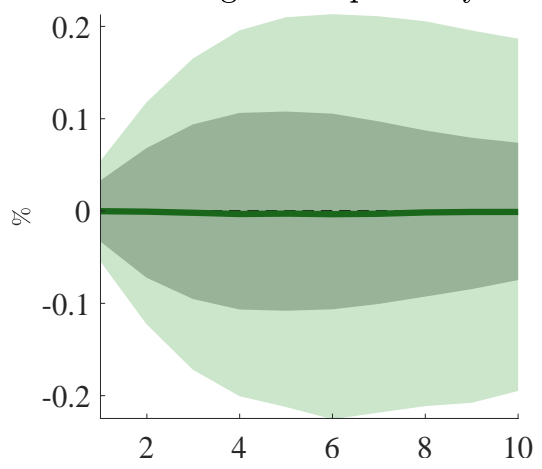

$\Delta$ Age-adj. death rate

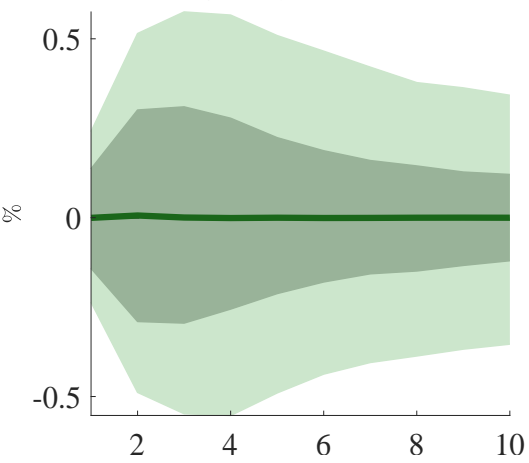

Unemployment rate

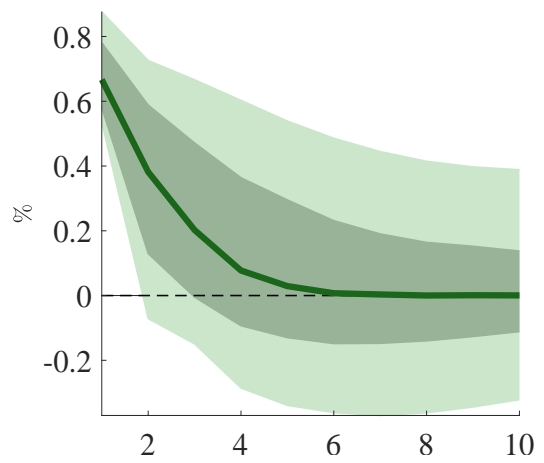

Notes: We provide impulse responses to a one-standard-deviation shock to unemployment. The solid-lines represent the median values and the dark and light-shaded areas indicate $68 \%$ and $90 \%$ bands, respectively.

\section{Computing Excess Deaths}

We omit the group identifier $i$ to ease exposition. The law of motion of the state vector is

$$
X_{t}=\mu+\Phi X_{t-1}+\eta_{t}
$$

We define an indicator vector $e_{\Delta r}$ that selects the mortality growth rate $\Delta r_{t}=e_{\Delta r}^{\prime} X_{t}$ from the state vector. Denote the cumulative sum as

$$
\begin{aligned}
X_{0, t} \equiv \sum_{j=0}^{t} X_{j} & =\sum_{j=1}^{t+1}\left(I-\Phi^{j}\right) \underbrace{(I-\Phi)^{-1} \mu}_{\mathbf{E}\left(X_{t}\right)}+\left(I-\Phi^{t+1}\right)(I-\Phi)^{-1} \eta_{0}, \\
& =\left(I(t+1)-\Phi\left(I-\Phi^{t+1}\right)(I-\Phi)^{-1}\right) \mathbf{E}\left(X_{t}\right)+\left(I-\Phi^{t+1}\right)(I-\Phi)^{-1} \eta_{0} .
\end{aligned}
$$




\section{D.1 Mortality rate}

Let $\eta_{0}^{u}$ be the vector containing the contemporaneous impact of the COVID-19 unemployment shock. Then, the cumulative effect of the shock is then driving the difference between the case with the COVID-19 unemployment shock and the counterfactual scenario

$$
\Delta r_{0, t}^{u}=\underbrace{e_{\Delta r}^{\prime}\left(I(t+1)-\Phi\left(I-\Phi^{t+1}\right)(I-\Phi)^{-1}\right) \mathbf{E}\left(X_{t}\right)}_{\Delta r_{0, t}}+\underbrace{\left.e_{\Delta r}^{\prime t+1}\right)(I-\Phi)^{-1} \eta_{0}^{u}}_{\text {cir } r_{t}^{u}} .
$$

Conditional on $R_{-1}$, we can construct the level of deaths

$$
\begin{aligned}
R_{t}^{u} & =\exp \left(\Delta r_{0, t}^{u}\right) R_{-1} \\
R_{t} & =\exp \left(\Delta r_{0, t}\right) R_{-1}
\end{aligned}
$$

based on the cumulative growth rates of $\Delta r_{0, t}^{u}$ and $\Delta r_{0, t}$ in (A-20), respectively. Note that (A-21) are the age adjusted death rates implied from the VAR estimates.

\section{D.2 Converting from the age adjusted- to crude death rates}

Currently, $R_{t}^{u}$ and $R_{t}$ are defined as the age adjusted death rates. We want to convert to the crude death rates based on Figure A-2, which is to regress the crude death rates on the age adjusted death rates and construct the fitted crude death rates based on the OLS coefficients. Let $\hat{\beta}_{0}$ be the constant OLS coefficient and $\hat{\beta}_{1}$ be the slope coefficient. Then, we construct

$$
\begin{aligned}
& R_{c, t}=\hat{\beta}_{0}+\hat{\beta}_{1} R_{t} \\
& R_{c, t}^{u}=\hat{\beta}_{0}+\hat{\beta}_{1} R_{t}^{u} .
\end{aligned}
$$

For each race and gender group, we use $\hat{\beta}_{0}, \hat{\beta}_{1}$ (based on the overall population) for conversion as we do not have the access to historical crude death rates for different race and gender groups. In sum, the excess death rate caused by the COVID-19 unemployment shock is defined as

$$
E R_{t}^{u}=R_{c, t}^{u}-R_{c, t}
$$

\section{D.3 Population projection}

Denote the Census population projections by

$$
P_{t}=G_{t-1}^{C} P_{t-1}=\prod_{j=0}^{t-1} G_{j}^{C} P_{0} .
$$

For measures of (A-24), we take the population projections for the United States provided by the United States Census Bureau. As we find that the population numbers provided by 
Figure A-2: Age adjusted- and crude death rates for the overall population

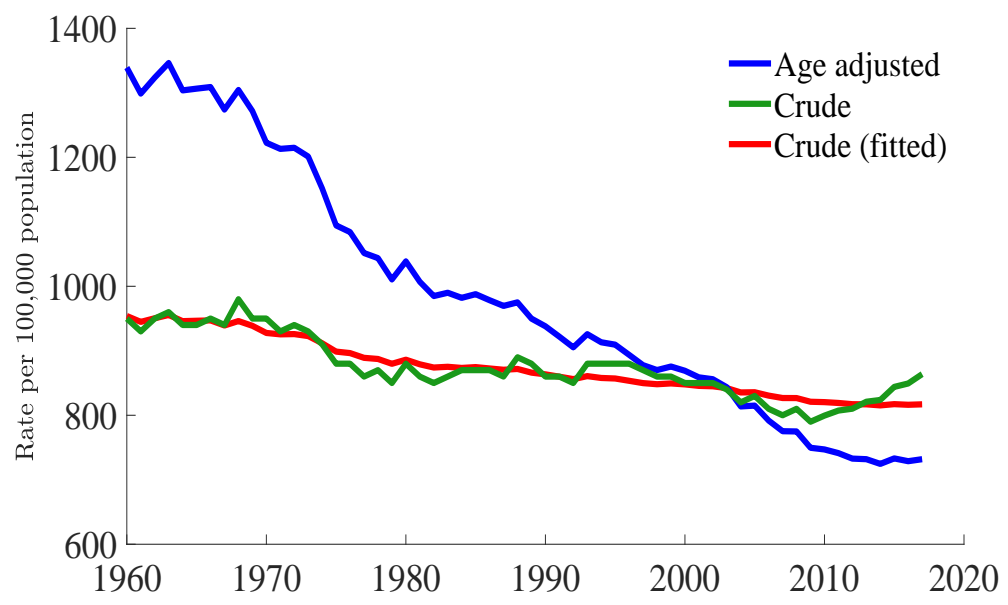

Notes: Data source: The World Bank. We regress the crude death rates on the age adjusted death rates and obtain the following OLS coefficients: the constant coefficient is $\hat{\beta}_{0}=651.9$ and the slope coefficient is $\hat{\beta}_{1}=0.2255$. We plot the fitted crude death rates based on the age adjusted death rates in red line.

the CDC, i.e., (E) of Table 7, and Census Bureau are somewhat different, we adjust the 2017 population numbers in the Census Bureau projections to be consistent with (E) of Table 7.

Because the COVID-19 unemployment shock causes a change in the expected path for the death rate, we adjust the projection as

$$
P_{t}^{u}=\left(G_{t-1}-E R_{t-1}^{u}\right) P_{t-1}^{u}=\prod_{j=0}^{t-1}\left(G_{j}^{C}-E R_{j}^{u}\right) P_{0}^{u} .
$$

Note that we initialize by $P_{0}=P_{0}^{u}$.

\section{D.4 Excess deaths}

The excess deaths caused by the COVID-19 unemployment shock is defined as

$$
E D_{t}^{u}=R_{c, t}^{u} P_{t}^{u}-R_{c, t} P_{t}
$$

which can be computed from (A-21), (A-22), (A-23), (A-24), and (A-25). 


\section{E Additional Figures and Tables}

Figure A-3: Data

Avg. life expectancy

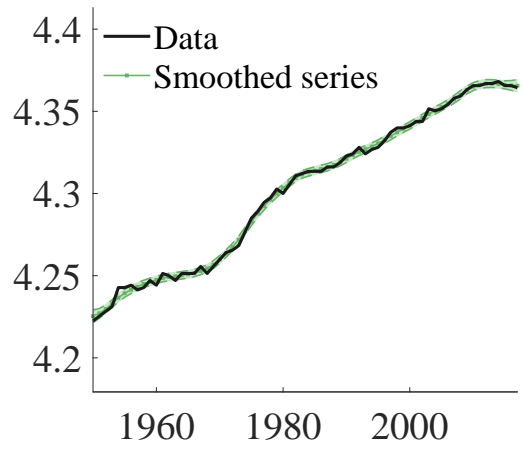

Age-adj. death rate

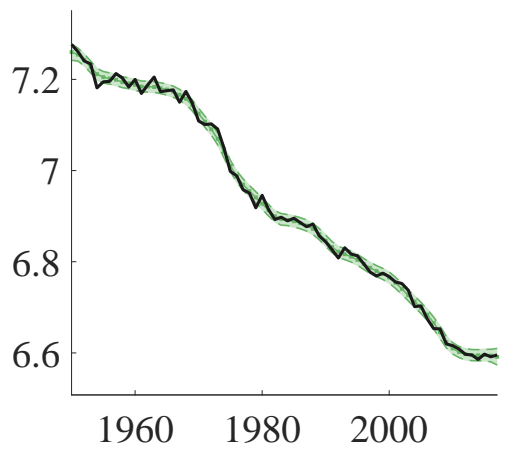

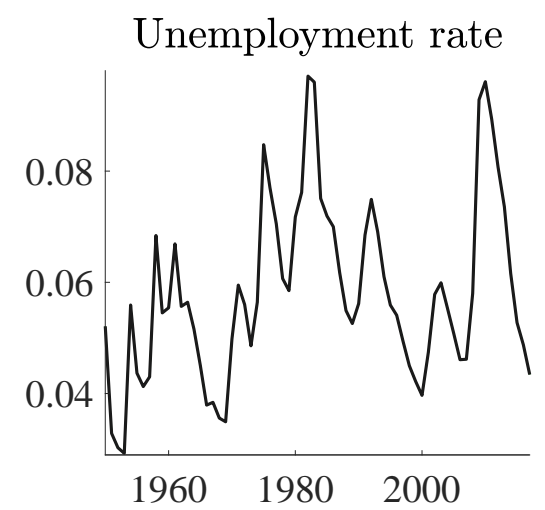

Notes: This figure presents the log average life expectancy (first column), the log age-adjusted death rate (second column), and the unemployment rate (third column) for the overall US population. The original series are presented in black solid lines. For the first two series, we compare with the smoothed estimates from our model (green lines). The data span from 1950 to 2017. 
Figure A-4: Data by race and gender

(1) African-American population: Both gender

Avg. life expectancy

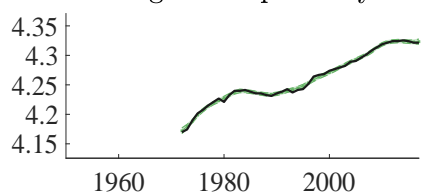

Age-adj. death rate

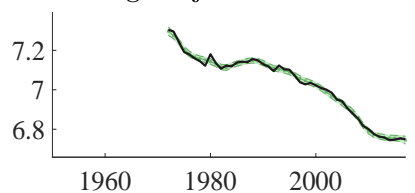

Unemployment rate

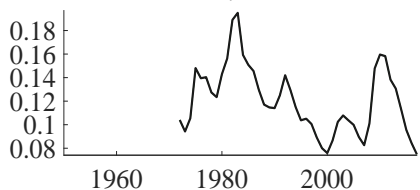

(2) African-American population: Men

Avg. life expectancy

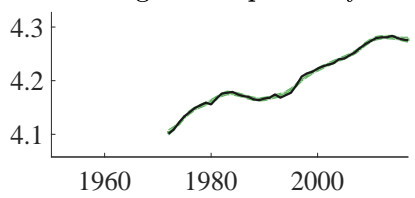

Age-adj. death rate

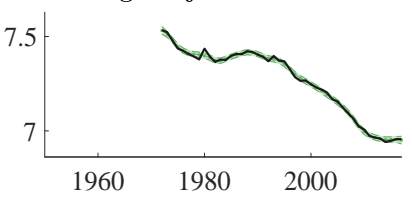

Unemployment rate

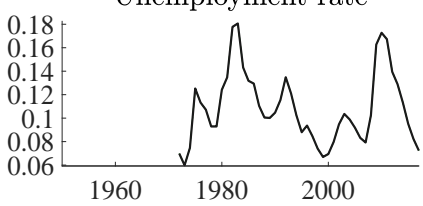

(3) African-American population: Women

Avg. life expectancy

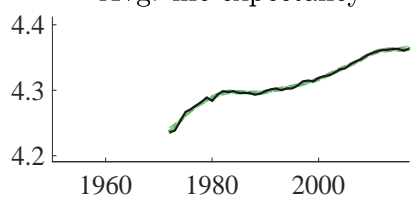

Avg. life expectancy

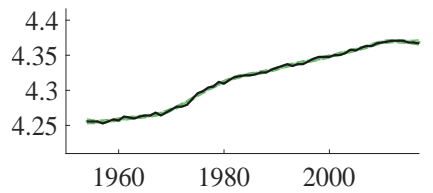

Avg. life expectancy

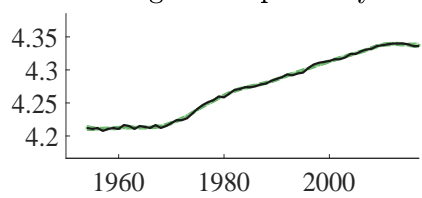

Avg. life expectancy

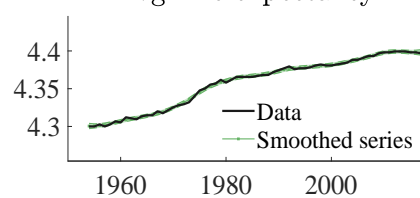

Age-adj. death rate
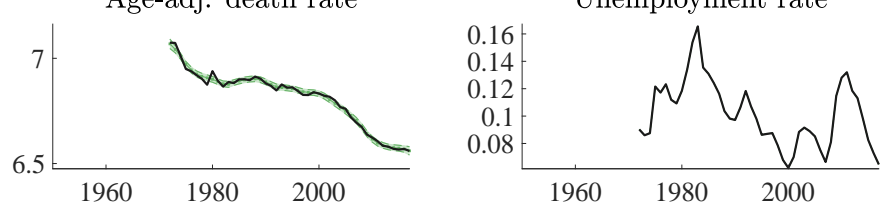

(4) White population: Both gender
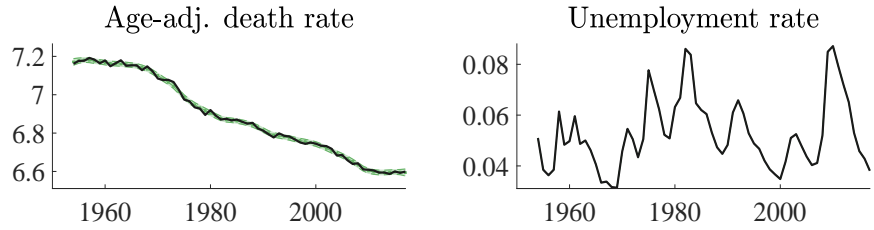

(5) White population: Men

Age-adj. death rate

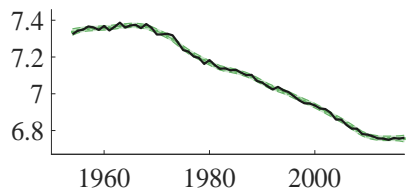

(6) White population: Women

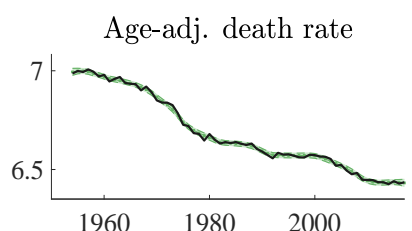

Unemployment rate

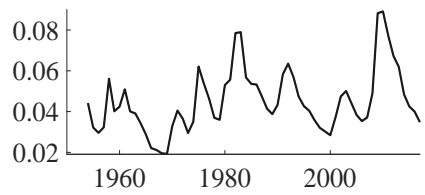

Unemployment rate

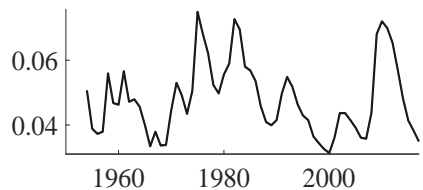

Notes: This figure presents the log average life expectancy (first column), the log age-adjusted death rate (second column), and the unemployment rate (third column) for the overall US population. The original series are presented in black solid lines. For the first two series, we compare with the smoothed estimates from our model (green lines). The data span from 1954 to 2017 for the White population, and from 1972 to 2017 for the African-American population. 
Figure A-5: Impulse response comparison: Common sample

(1) A one-standard-deviation shock to unemployment
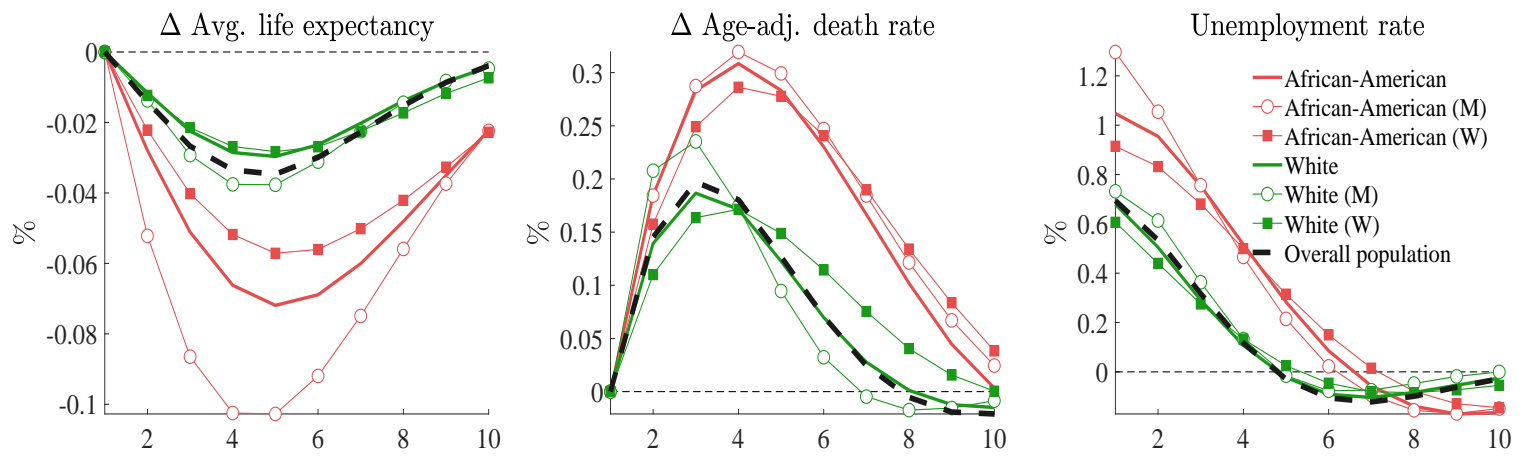

(2) A unit shock to unemployment rate
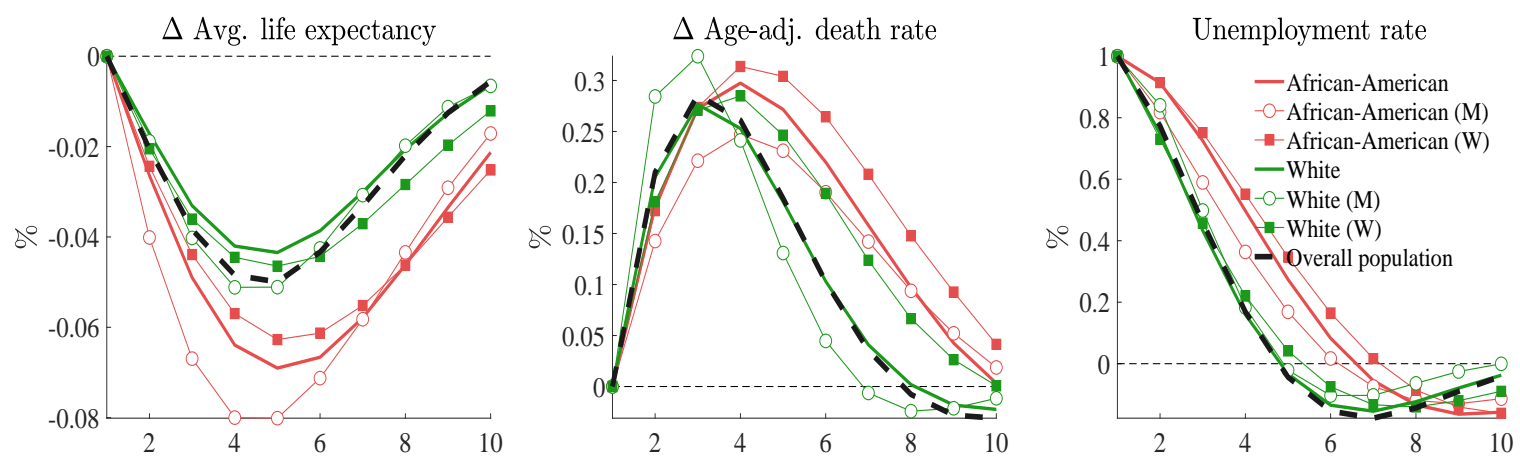

Notes: We compare median impulse responses to a one-standard-deviation (first panel) or a unit shock (second panel) to unemployment, which is identified via a Cholesky decomposition, across the overall US population and for the US population classified according to race and gender. Results are based on an identical estimation sample which spans from 1972 to 2017 for all workers. 


\section{F Results from the Alternative Identification Strategy}

The alternative identification strategy allows for contemporaneous impact of unemployment shock on life expectancy and death rates. With this identification assumption, we replicate the tables and figures in the main text below.

Figure A-6: Impulse responses to a one-standard-deviation shock to unemployment
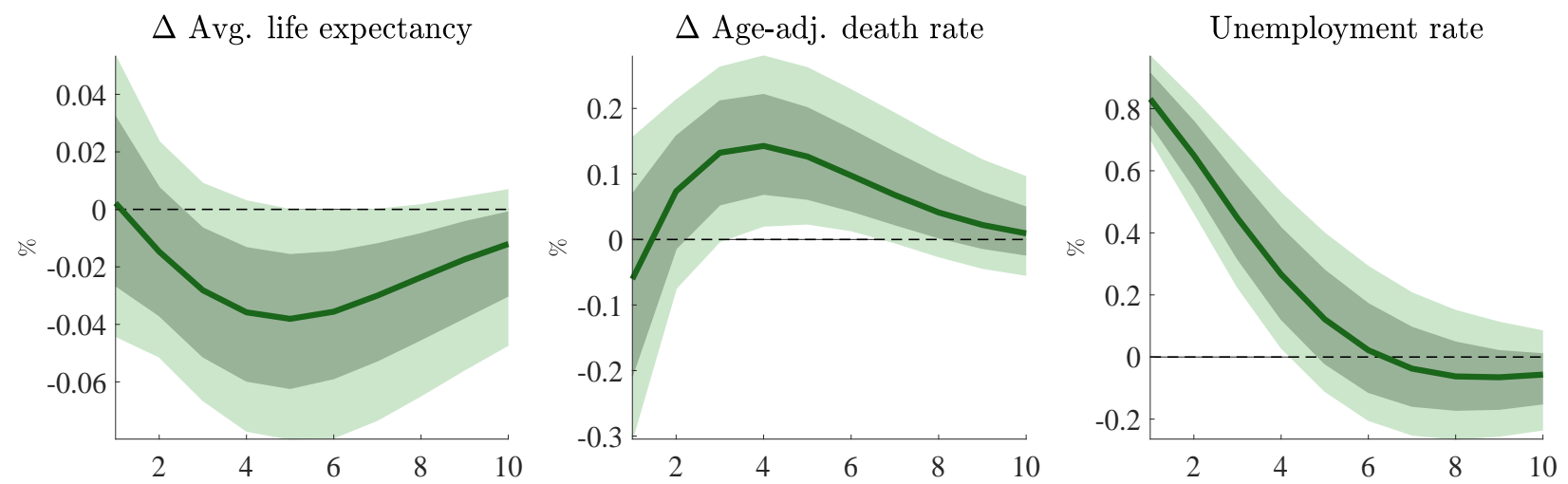

Notes: We provide impulse responses to a one-standard-deviation shock to unemployment for the overall US population. The solid-lines represent the median values and the dark and light-shaded areas indicate $68 \%$ and $90 \%$ bands, respectively. 
Figure A-7: Impulse responses to a one-standard-deviation shock to unemployment

(1) African-American population: Overall
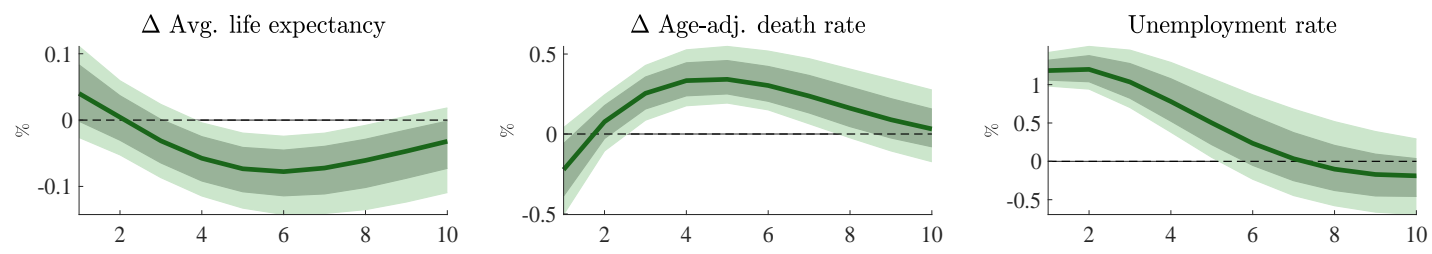

(2) African-American population: Men
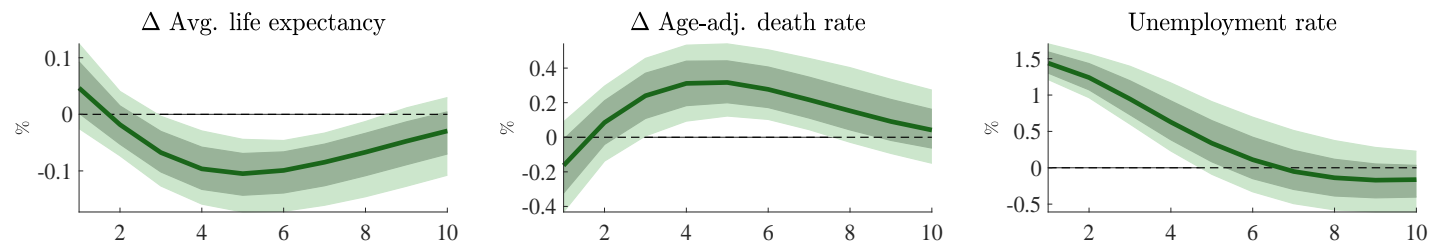

(3) African-American population: Women
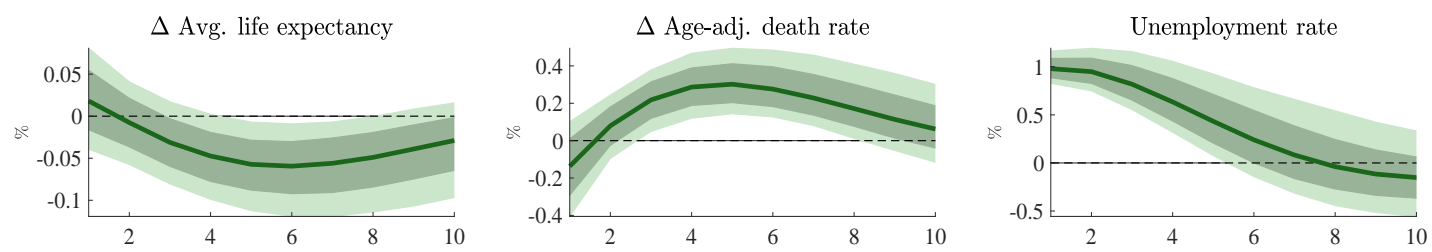

(4) White population: Overall
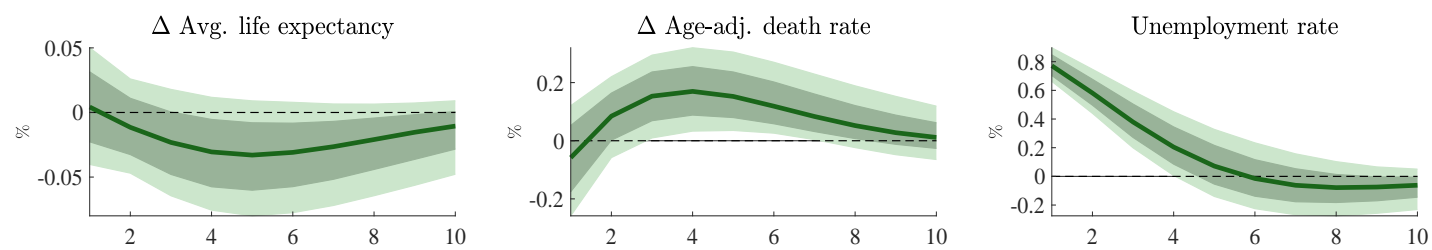

(5) White population: Men
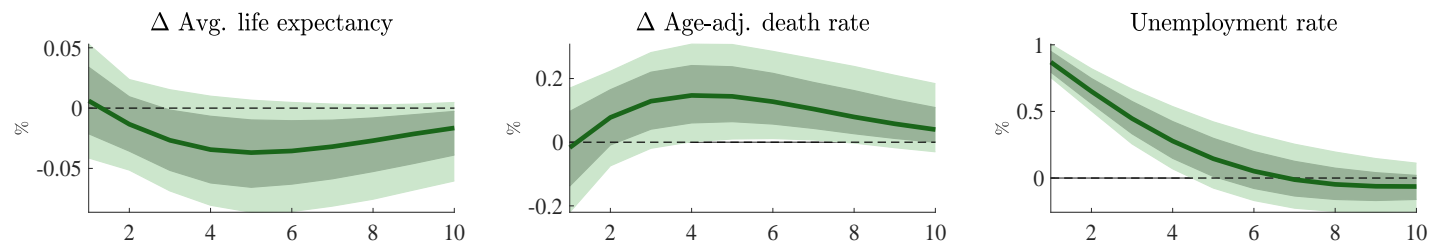

(6) White population: Women
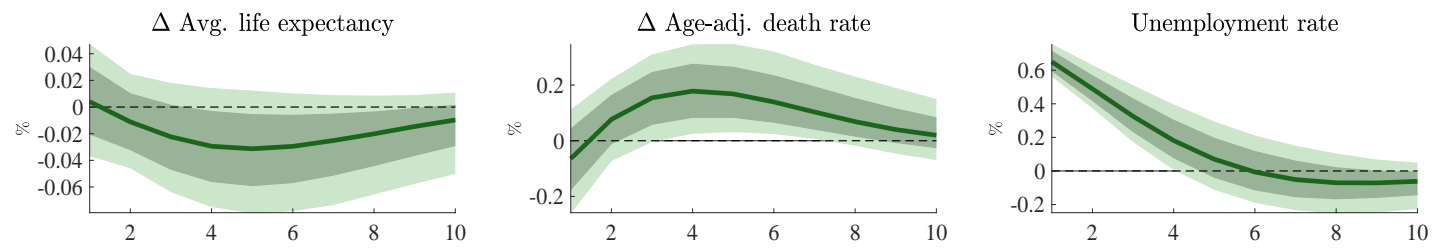

Notes: We provide impulse responses to a one-standard-deviation shock to unemployment for the US population classified according to race and gender. The solid-lines represent the median values and the dark and light-shaded areas indicate $68 \%$ and $90 \%$ bands, respectively. 
Figure A-8: Impulse response comparison

(1) A one-standard-deviation shock to unemployment
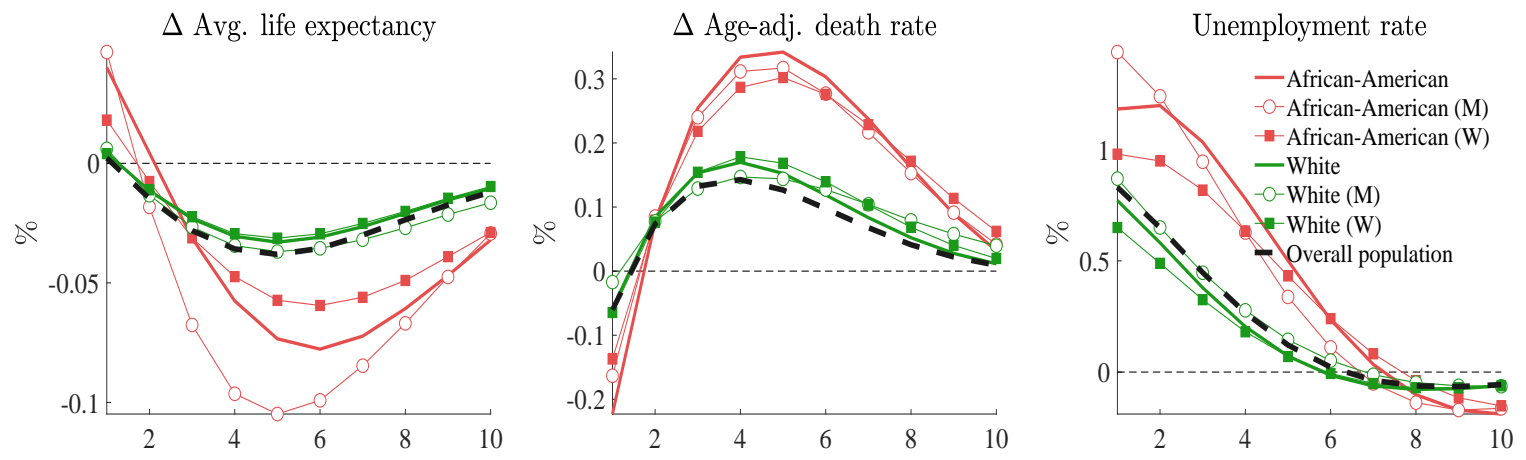

(2) A unit shock to unemployment rate
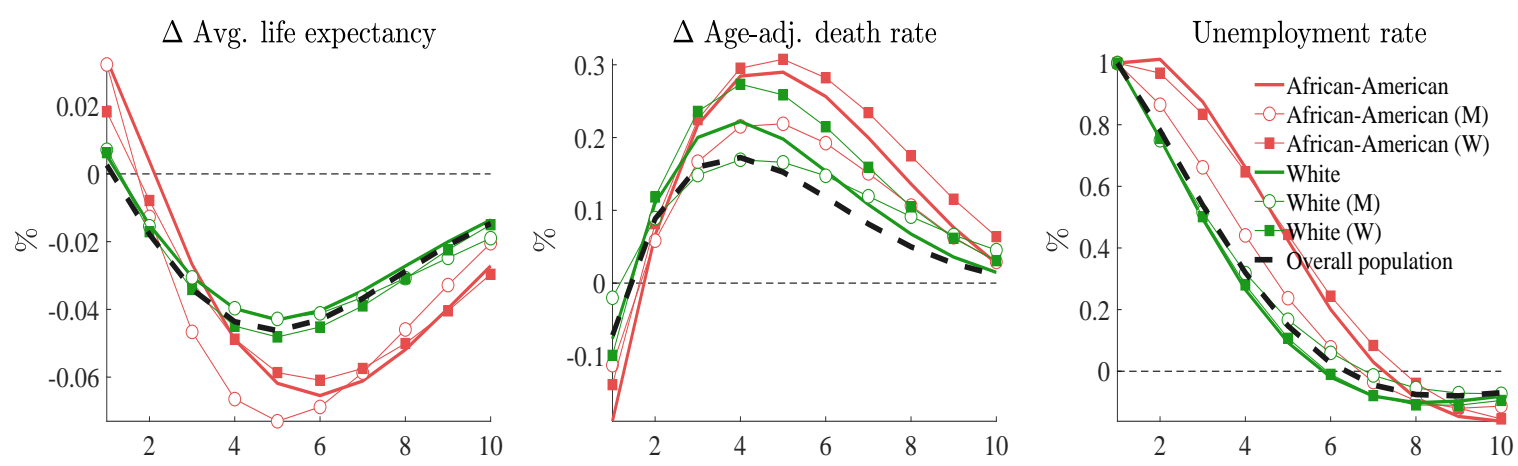

Notes: We compare median impulse responses to a one-standard-deviation (first row panels) or a unit shock (second row panels) to unemployment, which is identified via a Cholesky decomposition, across the overall US population and for the US population classified according to race and gender. 
Table A-2: Fraction of forecast error variance explained by unemployment shock (\%)

\begin{tabular}{|c|c|c|c|c|}
\hline & \multicolumn{4}{|c|}{ (1) Percentage change in life expectancy } \\
\hline & 5 years & 10 years & 15 years & 20 years \\
\hline Overall population & $\begin{array}{c}10.46 \\
{[1.30,31.45]}\end{array}$ & $\begin{array}{c}15.68 \\
{[2.10,40.74]}\end{array}$ & $\begin{array}{c}16.11 \\
{[2.22,40.99]}\end{array}$ & $\begin{array}{c}16.15 \\
{[2.21,41.23]}\end{array}$ \\
\hline African-American & $\begin{array}{c}19.78 \\
{[4.33,43.64]}\end{array}$ & $\begin{array}{c}32.28 \\
{[8.68,58.40]}\end{array}$ & $\begin{array}{c}32.74 \\
{[9.01,58.75]}\end{array}$ & $\begin{array}{c}32.97 \\
{[9.07,59.01]}\end{array}$ \\
\hline African-American (M) & $\begin{array}{c}33.60 \\
{[7.95,59.80]}\end{array}$ & $\begin{array}{c}43.65 \\
{[14.83,68.26]}\end{array}$ & $\begin{array}{c}43.58 \\
{[15.02,68.17]}\end{array}$ & $\begin{array}{c}43.64 \\
{[14.85,68.40]}\end{array}$ \\
\hline African-American (W) & $\begin{array}{c}14.50 \\
{[2.33,37.04]}\end{array}$ & $\begin{array}{c}25.78 \\
{[4.66,52.43]}\end{array}$ & $\begin{array}{c}26.49 \\
{[5.33,52.80]}\end{array}$ & $\begin{array}{c}26.73 \\
{[5.43,53.53]}\end{array}$ \\
\hline White & $\begin{array}{c}8.32 \\
{[0.86,29.70]}\end{array}$ & $\begin{array}{c}12.72 \\
{[1.46,40.13]}\end{array}$ & $\begin{array}{c}13.21 \\
{[1.53,40.85]}\end{array}$ & $\begin{array}{c}13.33 \\
{[1.56,41.30]}\end{array}$ \\
\hline White $(\mathrm{M})$ & $\begin{array}{c}9.60 \\
{[0.86,32.18]}\end{array}$ & $\begin{array}{c}15.09 \\
{[1.39,45.40]}\end{array}$ & $\begin{array}{c}16.02 \\
{[1.46,46.15]}\end{array}$ & $\begin{array}{c}16.18 \\
{[1.47,46.51]}\end{array}$ \\
\hline \multirow[t]{3}{*}{ White (W) } & $\begin{array}{c}7.72 \\
{[0.68,28.96]}\end{array}$ & $\begin{array}{c}12.13 \\
{[1.15,38.92]}\end{array}$ & $\begin{array}{c}12.53 \\
{[1.29,39.66]}\end{array}$ & $\begin{array}{c}12.57 \\
{[1.31,39.96]}\end{array}$ \\
\hline & \multicolumn{4}{|c|}{ (2) Percentage change in the age-adjusted death rate } \\
\hline & 5 years & 10 years & 15 years & 20 years \\
\hline Overall population & $\begin{array}{c}11.67 \\
{[1.85,29.03]}\end{array}$ & $\begin{array}{c}14.00 \\
{[2.55,32.24]}\end{array}$ & $\begin{array}{c}14.15 \\
{[2.67,32.88]}\end{array}$ & $\begin{array}{c}14.20 \\
{[2.70,33.08]}\end{array}$ \\
\hline African-American & $\begin{array}{c}34.39 \\
{[14.19,55.69]}\end{array}$ & $\begin{array}{c}40.11 \\
{[19.48,61.00]}\end{array}$ & $\begin{array}{c}40.38 \\
{[19.52,61.39]}\end{array}$ & $\begin{array}{c}40.67 \\
{[19.66,61.68]}\end{array}$ \\
\hline African-American (M) & $\begin{array}{c}26.25 \\
{[6.55,49.69]}\end{array}$ & $\begin{array}{c}33.31 \\
{[10.04,56.71]}\end{array}$ & $\begin{array}{c}33.56 \\
{[10.74,57.25]}\end{array}$ & $\begin{array}{c}33.75 \\
{[10.74,57.54]}\end{array}$ \\
\hline African-American (W) & $\begin{array}{c}25.62 \\
{[7.43,46.07]}\end{array}$ & $\begin{array}{c}32.70 \\
{[13.18,54.43]}\end{array}$ & $\begin{array}{c}32.80 \\
{[13.42,53.98]}\end{array}$ & $\begin{array}{c}32.91 \\
{[13.64,54.47]}\end{array}$ \\
\hline White & $\begin{array}{c}13.93 \\
{[2.39,32.72]}\end{array}$ & $\begin{array}{c}17.41 \\
{[3.23,37.47]}\end{array}$ & $\begin{array}{c}17.58 \\
{[3.38,37.91]}\end{array}$ & $\begin{array}{c}17.65 \\
{[3.43,38.13]}\end{array}$ \\
\hline White (M) & $\begin{array}{c}10.57 \\
{[1.37,29.99]}\end{array}$ & $\begin{array}{c}15.25 \\
{[2.03,38.28]}\end{array}$ & $\begin{array}{c}15.73 \\
{[2.21,39.15]}\end{array}$ & $\begin{array}{c}15.85 \\
{[2.23,39.40]}\end{array}$ \\
\hline White (W) & $\begin{array}{c}13.02 \\
{[1.90,32.24]}\end{array}$ & $\begin{array}{c}17.19 \\
{[2.80,38.75]}\end{array}$ & $\begin{array}{c}17.52 \\
{[2.87,39.07]}\end{array}$ & $\begin{array}{c}17.61 \\
{[2.91,39.55]}\end{array}$ \\
\hline
\end{tabular}

Notes: The table provides the fraction of forecast error variance of the percentage change in life expectancy and the age-adjusted mortality rate explained by unemployment shock at 5, 10, 15 and 20 years. We present the median values and provide the values that correspond to the $90 \%$ bands in brackets. 
Figure A-9: Impulse responses of the growth rate of age-adjusted death rates for the leading causes of deaths to a unit shock to unemployment rate based on the alternative Choleski ordering.

(1) Heart disease

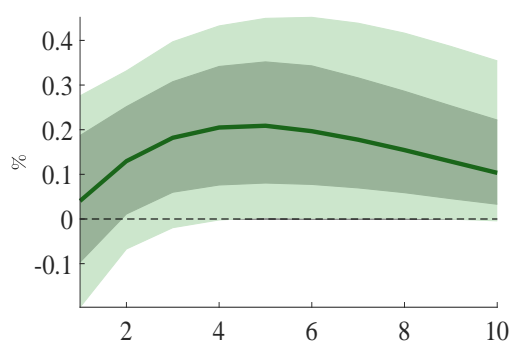

(4) Stroke

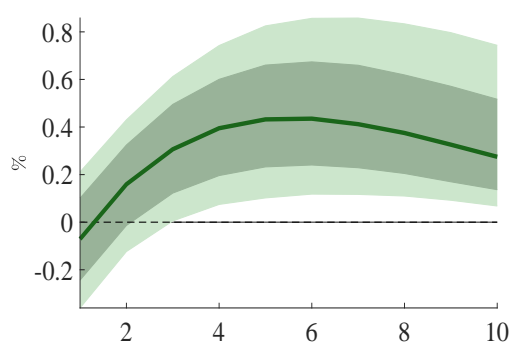

(2) Cancer

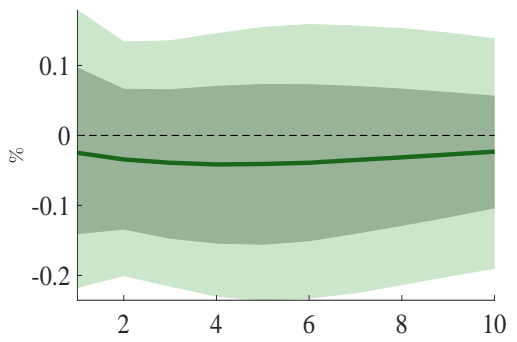

(5) Influenza and pneumonia

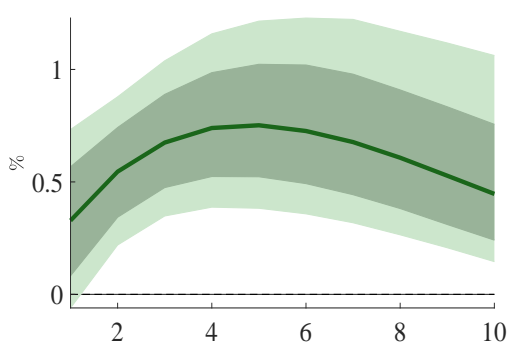

(3) Accidents

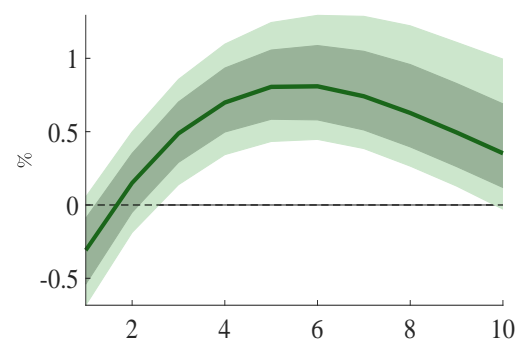

(6) Residual causes

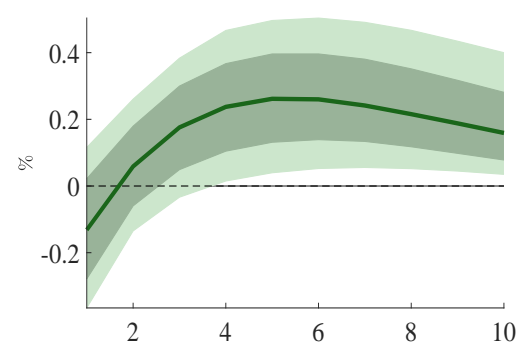

Notes: According to National Center for Health Statistics (NCHS), National Vital Statistics System, the five leading causes of age-adjusted deaths in the U.S. are (1) Accidents; (2) Cancer; (3) Heart disease; (4) Influenza and pneumonia; and (5) Stroke in alphabetical order. The NCHS Data Visualization Gallery provides the time-series of (1)-(5) as well as the age-adjusted overall death rates from 1900 to 2017. We construct (6) The residual causes by subtracting the sum of (1)-(5) from the overall death rates. 
Table A-3: Cumulative changes of age-adjusted death rates for the leading causes of deaths over different horizons following a $1 \%$ unemployment shock

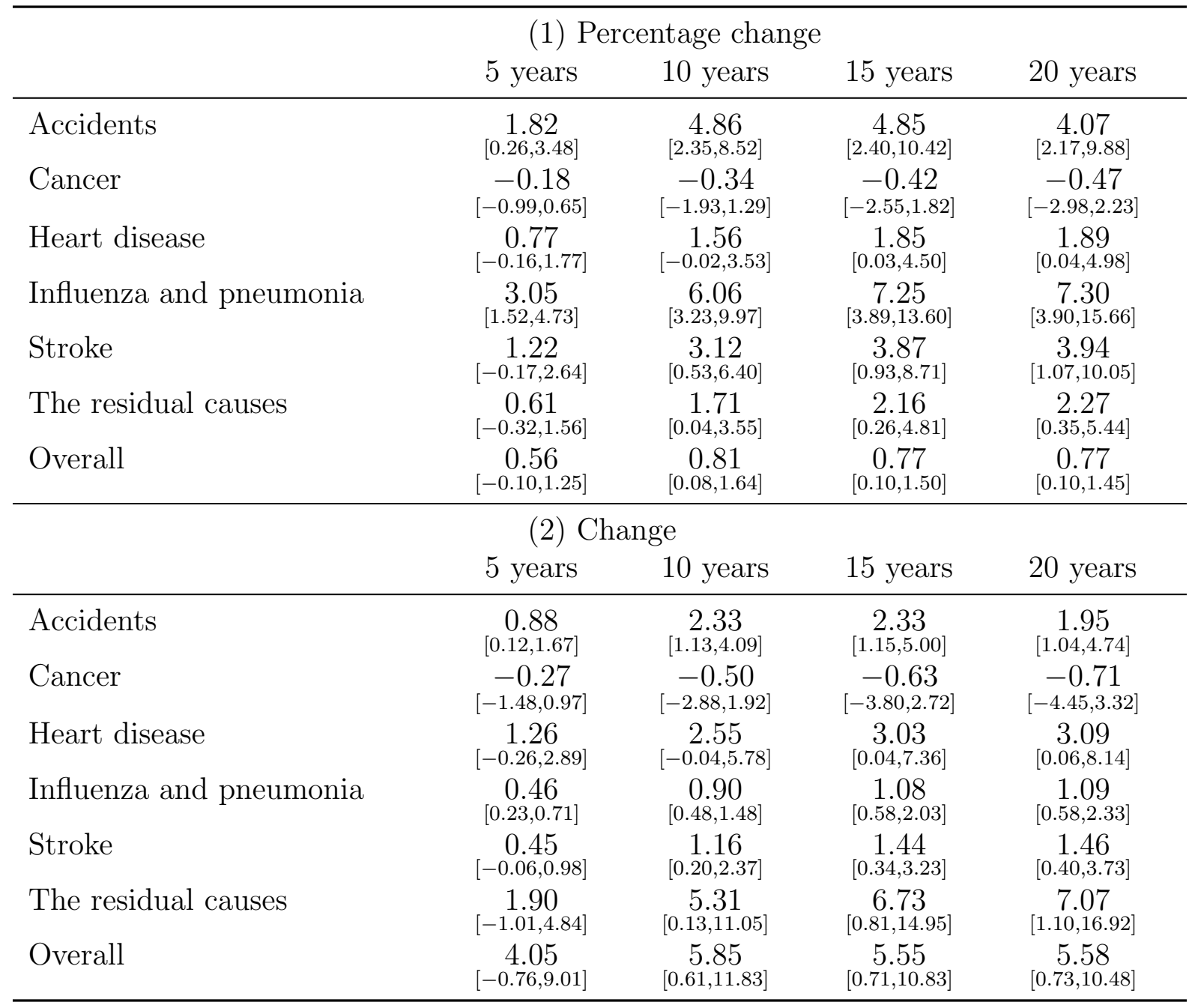

Notes: We multiply the predicted change at 5, 10, 15, and 20 years provided in Panel (1) of Table 4 with the most recent age-adjusted death rates of the leading causes of deaths in 2019. The age-adjusted death rates (deaths per 100,000 U.S. standard population) for the 10 leading causes of death in the most recent year 2019 are: (1) Heart disease, 163.6; (2) Cancer, 149.1; (3) Accidents, 48.0; (4) Chronic lower respiratory disease, 39.7; (5) Stroke, 37.1; (6) Alzheimer disease, 30.5; (7) Diabetes, 21.4; (8) Kidney disease, 12.9; (9) Influenza and pneumonia 14.9; and (10) Suicide, 14.2. The overall death rate was 723.6. 
Table A-4: COVID-19 unemployment shocks

\begin{tabular}{lcc}
\hline & Standard deviation & Magnitude $(\%)$ \\
\hline Overall population & 3.82 & 3.20 \\
African-American & {$[2.61,4.80]$} & {$[2.06,4.02]$} \\
African-American (M) & 3.15 & 3.77 \\
& {$[2.07,4.16]$} & {$[2.37,4.88]$} \\
African-American (W) & 2.85 & 4.14 \\
& {$[1.92,3.67]$} & {$[2.74,5.18]$} \\
White & 3.98 & 3.92 \\
White $(\mathrm{M})$ & {$[2.81,5.04]$} & {$[2.71,4.92]$} \\
& 3.75 & 2.90 \\
White $(\mathrm{W})$ & {$[2.61,4.67]$} & {$[1.93,3.61]$} \\
& 3.46 & 3.04 \\
& {$[2.50,4.25]$} & {$[2.12,3.62]$} \\
& 5.09 & 3.32 \\
& {$[3.86,6.19]$} & {$[2.47,3.98]$} \\
\hline
\end{tabular}

Notes: The table provides the COVID-19 unemployment shock implied by our state-space model for overall US population and for US population classified according to race and gender. To facilitate the interpretation, we provide the scale of standard deviation as well as the actual magnitude (\%) of the shock. 
Table A-5: Cumulative changes of life expectancy and age-adjusted death rates over different horizons following the COVID-19 unemployment shock

\begin{tabular}{|c|c|c|c|c|}
\hline \multicolumn{5}{|c|}{ (1) Percentage change in life expectancy } \\
\hline & 5 years & 10 years & 15 years & 20 years \\
\hline Overall population & $\begin{array}{c}-0.43 \\
{[-1.09 .0 .18]}\end{array}$ & -0.86 & -0.91 & -0.91 \\
\hline African-American & -0.37 & -1.26 & -1.29 & -1.18 \\
\hline African-American (M) & $\begin{array}{l}-0.63 \\
-1.34,0.05]\end{array}$ & $\begin{array}{c}-1.56 \\
-3.12,-0.48\end{array}$ & $\begin{array}{c}-1.53 \\
-3.75,-0.45]\end{array}$ & $\begin{array}{c}-1.45 \\
-3.81,-0.44\end{array}$ \\
\hline African-American (W) & $\begin{array}{c}-0.49 \\
{[-1.37,0.33]}\end{array}$ & $\begin{array}{c}-1.40 \\
{[-3.29,-0.09]}\end{array}$ & $\begin{array}{c}-1.44 \\
{[-4.18,-0.02]}\end{array}$ & $\begin{array}{c}-1.30 \\
{[-4.27,0.04]}\end{array}$ \\
\hline White & $\begin{array}{c}-0.36 \\
{[-1.05 .0 .26]}\end{array}$ & $\begin{array}{c}-0.75 \\
{[-2.14 .0 .26]}\end{array}$ & $\begin{array}{c}-0.79 \\
{[-2.52,0.28]}\end{array}$ & $\begin{array}{c}-0.79 \\
{[-2.56 .0 .29]}\end{array}$ \\
\hline White $(\mathrm{M})$ & -0.37 & -0.83 & -0.94 & -0.94 \\
\hline White (W) & -0.47 & -0.97 & -1.00 & -0.99 \\
\hline & {$[-1.39,0.40]$} & {$[-2.87,0.48]$} & {$[-3.33,0.53]$} & {$[-3.38,0.55]$} \\
\hline \multicolumn{5}{|c|}{ (2) Percentage change in the age-adjusted death rate } \\
\hline & 5 years & 10 years & 15 years & 20 years \\
\hline Overall population & $\begin{array}{c}1.51 \\
{[-0.53,3.68]}\end{array}$ & $\begin{array}{c}2.39 \\
{[0.02,5.74]}\end{array}$ & $\begin{array}{c}2.29 \\
{[0.03,5.73]}\end{array}$ & $\begin{array}{c}2.29 \\
{[0.00,5.61]}\end{array}$ \\
\hline African-American & $\begin{array}{c}2.32 \\
{[0.29,4.34]}\end{array}$ & $\begin{array}{c}4.93 \\
{[2.07,9.87]}\end{array}$ & $\begin{array}{c}4.11 \\
{[1.38,10.67]}\end{array}$ & $\begin{array}{c}3.84 \\
{[1.35,10.19]}\end{array}$ \\
\hline African-American (M) & $\begin{array}{c}2.18 \\
{[-0.374 .56]}\end{array}$ & $\begin{array}{l}4.36 \\
{[0.87944]}\end{array}$ & $\begin{array}{c}3.94 \\
{[0.34 .1042]}\end{array}$ & $\begin{array}{l}3.81 \\
0.16 .10 .21]\end{array}$ \\
\hline African-American (W) & $\begin{array}{c}2.85 \\
{[0.11,5.52]}\end{array}$ & $\begin{array}{c}6.14 \\
{[2.56,12.49]}\end{array}$ & $\begin{array}{c}5.45 \\
{[1.85,13.97]}\end{array}$ & $\begin{array}{c}4.79 \\
{[1.54,13.08]}\end{array}$ \\
\hline White & $\begin{array}{c}1.95 \\
{[-0.24,4.21]}\end{array}$ & $\begin{array}{c}2.99 \\
{[0.36,7.03]}\end{array}$ & $\begin{array}{c}2.82 \\
{[0.38,7.14]}\end{array}$ & $\begin{array}{c}2.84 \\
{[0.39,7.00]}\end{array}$ \\
\hline White (M) & $\begin{array}{c}1.72 \\
{[-0.52,4.06]}\end{array}$ & $\begin{array}{c}3.17 \\
{[0.03,7.51]}\end{array}$ & $\begin{array}{c}3.27 \\
{[0.16,8.78]}\end{array}$ & $\begin{array}{c}3.28 \\
{[0.11,9.13]}\end{array}$ \\
\hline White (W) & $\begin{array}{c}2.67 \\
{[-0.68,6.03]}\end{array}$ & $\begin{array}{c}4.49 \\
{[0.21,10.88]}\end{array}$ & $\begin{array}{c}4.13 \\
{[0.21,11.20]}\end{array}$ & $\begin{array}{c}4.11 \\
{[0.18,10.45]}\end{array}$ \\
\hline
\end{tabular}

Notes: The table shows the predicted cumulative percentage change in life expectancy and age adjusted mortality rate at 5, 10, 15 and 20 years. We present the median values and provide the values that correspond to the $90 \%$ bands in brackets. Results are presented for the overall US population and subdivided based on race and gender. 
Table A-6: Changes of life expectancy and age-adjusted deaths over different horizons following the COVID-19 unemployment shock

\begin{tabular}{|c|c|c|c|c|}
\hline \multicolumn{5}{|c|}{ (1) Change in life expectancy } \\
\hline & 5 years & 10 years & 15 years & 20 years \\
\hline Overall population & $\begin{array}{c}-0.34 \\
{[-0.86,0.14]}\end{array}$ & $\begin{array}{c}-0.68 \\
{[-1.69,0.05]}\end{array}$ & $\begin{array}{c}-0.72 \\
{[-1.96,0.03]}\end{array}$ & $\begin{array}{c}-0.72 \\
{[-2.02,0.03]}\end{array}$ \\
\hline African-American & $\begin{array}{c}-0.28 \\
{[-0.87,0.26]}\end{array}$ & $\begin{array}{c}-0.95 \\
{[-2.23,-0.12]}\end{array}$ & {$\left[\begin{array}{c}-0.97 \\
{[-2.77,-0.06]}\end{array}\right.$} & $\begin{array}{c}-0.89 \\
{[-2.76,-0.07]}\end{array}$ \\
\hline African-American (M) & $\begin{array}{c}-0.45 \\
{[-0.96,0.03]}\end{array}$ & $\begin{array}{c}-1.12 \\
{[-2.24,-0.35]}\end{array}$ & $\begin{array}{c}-1.10 \\
{[-2.70,-0.32]}\end{array}$ & $\begin{array}{c}-1.04 \\
{[-2.74,-0.32]}\end{array}$ \\
\hline African-American (W) & $\begin{array}{c}-0.38 \\
{[-1.07,0.26]}\end{array}$ & $\begin{array}{c}-1.10 \\
{[-2.58,-0.07]}\end{array}$ & $\begin{array}{c}-1.13 \\
{[-3.29,-0.02]}\end{array}$ & $\begin{array}{c}-1.02 \\
{[-3.35,0.03]}\end{array}$ \\
\hline White & $\begin{array}{c}-0.29 \\
{[-0.83,0.21]}\end{array}$ & $\begin{array}{c}-0.59 \\
{[-1.68,0.21]}\end{array}$ & $\begin{array}{c}-0.62 \\
{[-1.99,0.22]}\end{array}$ & $\begin{array}{c}-0.62 \\
{[-2.01,0.23]}\end{array}$ \\
\hline White $(\mathrm{M})$ & $\begin{array}{c}-0.28 \\
{[-0.77,0.17]}\end{array}$ & $\begin{array}{c}-0.64 \\
{[-1.66,0.16]}\end{array}$ & $\begin{array}{c}-0.72 \\
{[-2.07,0.15]}\end{array}$ & $\begin{array}{c}-0.71 \\
{[-2.23,0.15]}\end{array}$ \\
\hline White (W) & $\begin{array}{c}-0.38 \\
{[-1.13,0.32]}\end{array}$ & $\begin{array}{c}-0.79 \\
{[-2.33,0.39]}\end{array}$ & $\begin{array}{c}-0.81 \\
{[-2.70,0.43]}\end{array}$ & $\begin{array}{c}-0.80 \\
{[-2.74,0.45]}\end{array}$ \\
\hline \multicolumn{5}{|c|}{ (2) Change in the age-adjusted deaths } \\
\hline & 5 years & 10 years & 15 years & 20 years \\
\hline Overall population & $\begin{array}{c}11.06 \\
{[-3.87,26.90]}\end{array}$ & $\begin{array}{c}17.46 \\
{[0.15,42.00]}\end{array}$ & $\begin{array}{c}16.78 \\
{[0.22,41.90]}\end{array}$ & $\begin{array}{c}16.76 \\
{[0.01,41.08]}\end{array}$ \\
\hline African-American & $\begin{array}{c}19.83 \\
{[2.44,37.10]}\end{array}$ & $\begin{array}{c}42.08 \\
{[17.66,84.25]}\end{array}$ & $\begin{array}{c}35.07 \\
{[11.80,91.16]}\end{array}$ & $\begin{array}{c}32.80 \\
{[11.55,86.98]}\end{array}$ \\
\hline African-American (M) & $\begin{array}{c}22.89 \\
{[-3.89,47.80]}\end{array}$ & $\begin{array}{c}45.71 \\
{[9.11,99.10]}\end{array}$ & $\begin{array}{c}41.37 \\
{[3.59,109.38]}\end{array}$ & $\begin{array}{c}40.02 \\
{[1.67,107.13]}\end{array}$ \\
\hline African-American (W) & $\begin{array}{c}20.11 \\
{[0.78,38.94]}\end{array}$ & $\begin{array}{c}43.34 \\
{[18.06,88.19]}\end{array}$ & $\begin{array}{c}38.46 \\
{[13.06,98.62]}\end{array}$ & $\begin{array}{c}33.83 \\
{[10.86,92.34]}\end{array}$ \\
\hline White & $\begin{array}{c}14.31 \\
{[-1.75,30.93]}\end{array}$ & $\begin{array}{c}21.95 \\
{[2.66,51.65]}\end{array}$ & $\begin{array}{c}20.69 \\
{[2.79,52.45]}\end{array}$ & $\begin{array}{c}20.83 \\
{[2.84,51.40]}\end{array}$ \\
\hline White (M) & $\begin{array}{c}14.83 \\
{[-4.45,35.02]}\end{array}$ & $\begin{array}{c}27.35 \\
{[0.23,64.80]}\end{array}$ & $\begin{array}{c}28.26 \\
{[1.35,75.81]}\end{array}$ & $\begin{array}{c}28.32 \\
{[0.98,78.85]}\end{array}$ \\
\hline White (W) & $\begin{array}{c}16.63 \\
{[-4.22,37.60]}\end{array}$ & $\begin{array}{c}27.97 \\
{[1.31,67.83]}\end{array}$ & $\begin{array}{c}25.74 \\
{[1.30,69.83]}\end{array}$ & $\begin{array}{c}25.64 \\
{[1.11,65.13]}\end{array}$ \\
\hline
\end{tabular}

Notes: The table shows the predicted cumulative change in life expectancy and age adjusted deaths at 5, 10, 15 and 20 years. We multiply the predicted percentage change in life expectancy and age adjusted mortality rate at 5,10, 15 and 20 years provided in Table 6 with the most recent life expectancy and age-adjusted deaths data provided in Table 7 . 
Table A-7: Excess deaths associated with the COVID-19 unemployment shock (per million)

\begin{tabular}{lcccc}
\hline & 5 years & 10 years & 15 years & 20 years \\
\hline Overall population & 0.08 & 0.40 & 0.74 & 1.09 \\
African-American & {$[-0.14,0.29]$} & {$[-0.16,1.03]$} & {$[-0.15,1.89]$} & {$[-0.15,2.75]$} \\
African-American $(\mathrm{M})$ & 0.01 & 0.10 & 0.20 & 0.29 \\
African-American $(\mathrm{W})$ & {$[-0.02,0.04]$} & {$[0.02,0.21]$} & {$[0.05,0.45]$} & {$[0.08,0.69]$} \\
& 0.01 & 0.05 & 0.10 & 0.14 \\
White & 0.01 & {$[-0.00,0.11]$} & {$[0.00,0.22]$} & {$[0.00,0.34]$} \\
White $(\mathrm{M})$ & {$[-0.01,0.03]$} & {$[0.01,0.13]$} & 0.13 & 0.19 \\
White $(\mathrm{W})$ & 0.09 & 0.39 & 0.71 & {$[0.05,0.44]$} \\
& {$[-0.08,0.24]$} & {$[-0.05,0.91]$} & {$[-0.01,1.71]$} & {$[0.03,2.51]$} \\
& 0.04 & 0.20 & 0.38 & 0.57 \\
& {$[-0.04,0.12]$} & {$[-0.05,0.48]$} & {$[-0.04,0.95]$} & {$[-0.03,1.48]$} \\
& 0.05 & 0.27 & 0.50 & 0.73 \\
& {$[-0.06,0.16]$} & {$[-0.06,0.66]$} & {$[-0.05,1.27]$} & {$[-0.04,1.85]$} \\
\hline
\end{tabular}

Notes: The table provides an estimate of the excess deaths associated with the COVID-19 unemployment shock based on the CENSUS projections of the US population adjusted to account for the additional deaths resulting from the unemployment shock. 